THE SENSORY MEDIATION OF SYMBIOSIS BETWEEN

HYPERIID AMPHIPODS AND SALPS

by

Carol Elizabeth Diebel

B.A., Humboldt State University

(1974)

SUBMITTED IN PARTIAL FULFILLMENT OF THE

REQUIREMENTS FOR THE DEGREE OF

DOCTOR OF PHILOSOPHY

at the

MASSACHUSETTS INSTITUTE OF TECHNOLOGY

and the

WOODS HOLE OCEANOGRAPHIC INSTITUTION

March 1988

() Carol E. Diebel 1988

The author hereby grants to MIT and WHOI permission to reproduce and distribute copies of this thesis document in whole or in part.

Signature of Author

Joint Program in Oceanography,

Massachusetts Institute of Technology/ Woods Hole

Oceanographic Institution

Certified by

Laurence P. Madin

Thesis Supervisor

Accepted by

Sallie W. Chisholm

Chairwoman, Joint Committee for Biological Oceanography, Massachusetts Institute of Technology/ Woods Hole Oceanographic Institution 


\title{
THE SENSORY MEDIATION OF SYMBIOSIS BETWEEN HYPERIID AMPHIPODS AND SALPS
}

by

\section{CAROL ELIZABETH DIEBEL}

Submitted in partial fulfillment of the requirements for the Degree of Doctor of Philosophy, March, 1988.

\begin{abstract}
Hyperiid amphipods are open ocean crustaceans which use gelatinous planktonic animals for food, shelter, and brooding space for their offspring. These associations involve varying degrees of host specificity; and there are few obvious correlations between gross morphology of the amphipods and the types of host they choose. The mechanisms which allow hyperiids to find and select specific hosts in the water column were investigated through the sensory and behavioral basis of these symbioses in three genera of hyperiids, Vibilia , Lycaea, and Phronima, which differ in the nature of their association with a common host - salps. The investigation included the description of the distribution and morphology of sensilla on the dorsal surface of the exoskeleton and antennules of the three genera of hyperiids with speculation on their functions. The ultrastructure of the aesthetasc sensilla of Vibilia sp. was determined for comparison with other crustacean aesthetasc sensilla, making a chemosensory function plausible. Behavioral experiments were conducted at sea which demonstrated a chemosensory basis for the host-specific associations between species of Vibilia and Lycaea and salps. Observations on the internal anatomy and behavior of Phronima are described which underscore the importance of salps to their general ecology.

Thesis Supervisor: $\quad$ Dr. Laurence P. Madin Associate Scientist
\end{abstract}


for

Dad and Mom 


\section{DON'T PANIC!}

There's still time to read this

thesis before everyone else has! 


\section{Biographical Sketch}

How does one decide to become an oceanographer? Lord knows I haven't the faintest idea. It certainly isn't decided by where one is born as I was born in Bakersifield, California surrounded by citrus, grapes, potatoes, cotton, almonds, alfalfa, rice, and fields and fields of other fruits and vegetables (I left before the kiwi boom). All I know is that my first trip to the ocean made me decide that I would do anything to have an excuse to live next to it for the rest of my life. Not that I am a contrary person mind you but the agricultural fields just did not inspire me.

What else is important about me? Well, I am a middle child in a rather large family. This, I believe makes me well-balanced. My mother encouraged me to be my own person, to love reading and to think about every aspect of an issue. My father demanded that I give my best (which was never quite enough at report card time). I can still remember the report card review at the dinner table. "Hmmm, what is this B in history or art or math" or whatever it was at the time. He also taught me that being honest is always the best in the long run.

Since this "CV" is pure endulgence I suppose I will talk about my brothers and sisters, since as a group of siblings we are so different but alike. Stephen "the eldest" spent many a long evening debating issues with me. He has an insatiable curiousity which I admire. Andrea took all my dolls off my hands so I could go outside and play with my brother Paul and the Tonka trucks in the back yard. Paul also taught me how to catch a football which still comes in handy on Sunday mornings, and how to put lizards to sleep which hasn't come in very handy lately but you never know. I wish I had Philip's ease with people and sense of humor. Rita has a personal flair which is enviable and very attractive. Tom has great artistic and manual skills 
which I hope he gets a chance to develop more. So that's a little bit about them all. Its just my first thoughts on them, they are a terrific if somewhat noisy group of people to be around.

After Bakersfield Junior College I went on up to northern California and Humboldt State University. What a great place; at last I felt inspired by the surrounding environment. So what did I do as soon as I graduated? Went off to the San Joaquin Valley again (Fresno), then to South Korea as a Peace Corps Volunteer. But I came back to Arcata and struggled for years trying to make a living and trying to decide just what direction I should go. These jack-of-all-trade and master-of-none years make me exhausted just thinking about them. I did learn a lot during this time and that always makes me happy. But, it was time to move on. I had decided that living on the east coast for a while would be a good idea and my survey trip of that coast made me focus on Woods Hole.

So began my endurance run. As many of my friends know, MIT was not exactly my most favorite place on earth (typical understatement). But there is ying and yang to every situation. Working and living down in Woods Hole saved what little sanity I possessed. I also made an excellent choice in thesis advisors: Larry Madin. There is so much that he taught me by osmosis. He taught me how to cope with the vagueries of cruise life - work like hell when necessary and relax like hell when you can't work. The Calanus cruises are a special memory.

I learned a lot during my stint at WHOI - about myself, science, politics, the Celtics, softball and scientists. I got to do a lot of travelling but very little sleeping. I have a lot of ambivalence about the place but that's okay.

So now its on to the next stretch of road. 
Title Page ............................................................................... $\frac{\text { Page }}{1}$

Biographical Sketch............................................................. 4

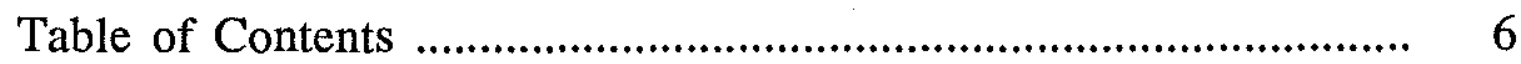

List of Figures andTables ...........................................................

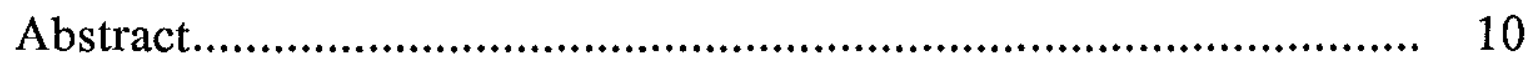

Acknowledgements.................................................................... 11

Chapter 1 General Introduction ....................................................... 14

Literature Cited........................................................................ 24

Chapter 2 The distribution and morphology of sensory hairs (sensilla) on three genera of hyperiid amphipods (Phronima , Lycaea , and Vibilia )........................................................... 30

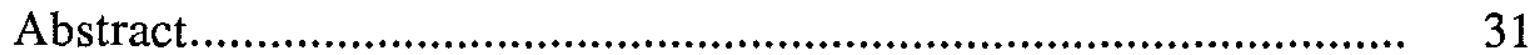

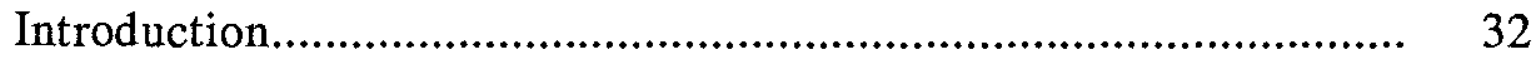

Materials and Methods ...................................................................... 37

Results............................................................................. 39

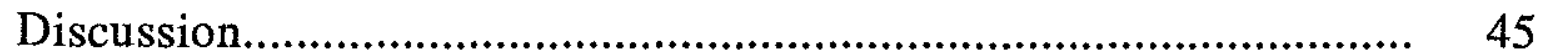

Literature Cited....................................................................... 49

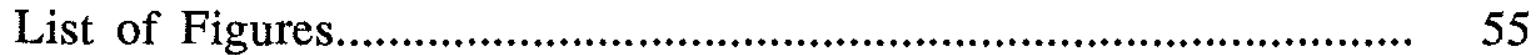


Chapter 3 Ultrastructure of the aesthetasc (olfactory) sensilla of the hyperiid amphipod, Vibilia ............................................ 76

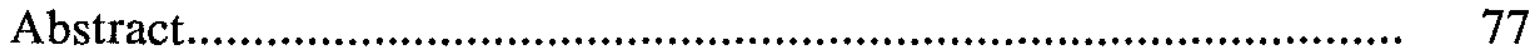

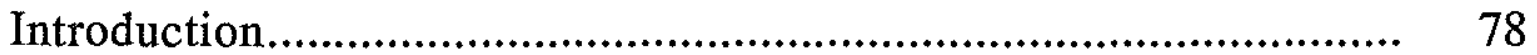

Materials and Methods................................................................ 80

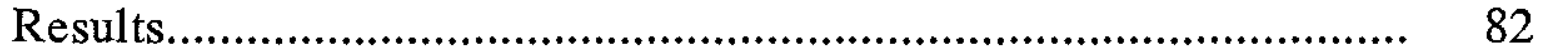

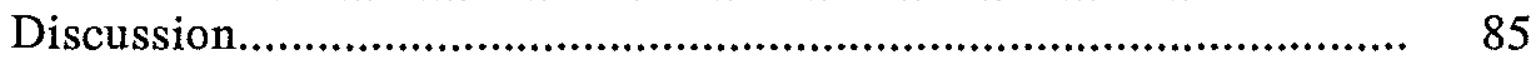

Literature Cited........................................................................ 88

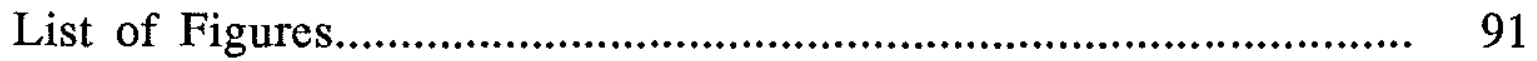

Chapter 4 Chemosensory behavior of two genera of hyperiid amphipods ( Vibilia and Lycaea ) towards their salp hosts.............. 102

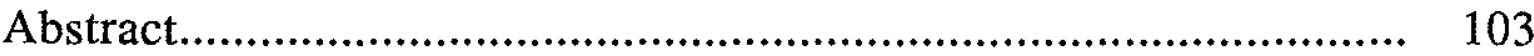

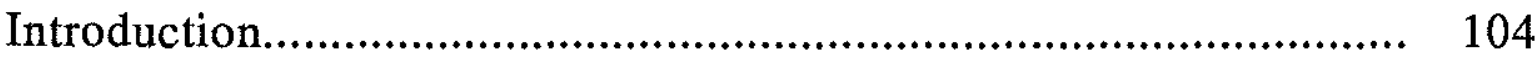

Materials and Methods............................................................ 109

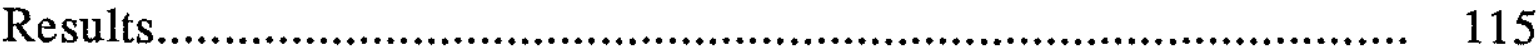

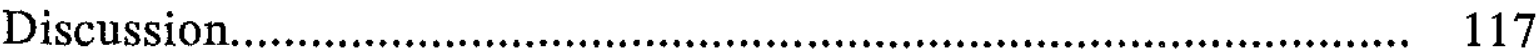

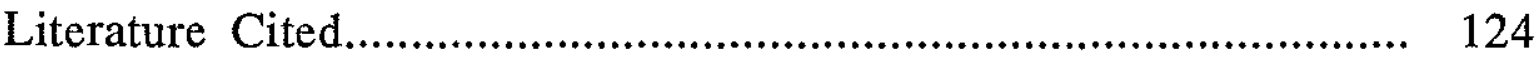

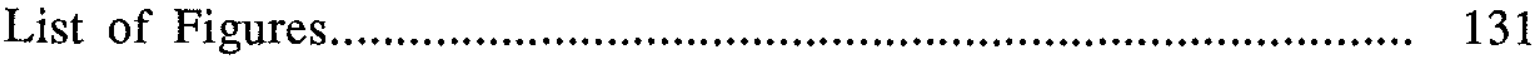

Chapter 5 Observations on the anatomy and behavior of Phronima sedentaria (Forskål)(Amphipoda: Hyperiidea)............................ 143

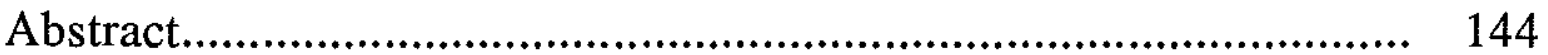

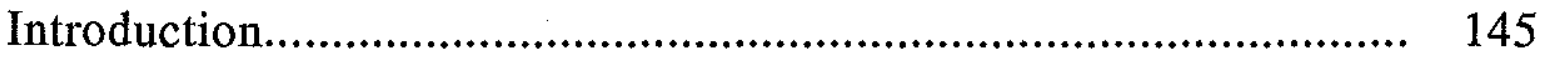

Materials and Methods............................................................. 147

Results.................................................................................... 149

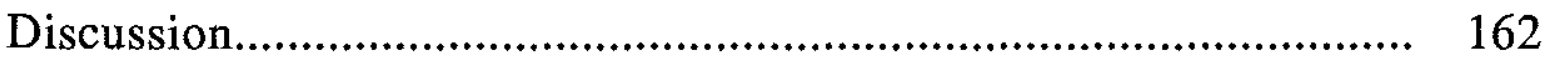

Acknowledgements............................................................... 164

Literature Cited...................................................................... 165

List of Figures................................................................... 169

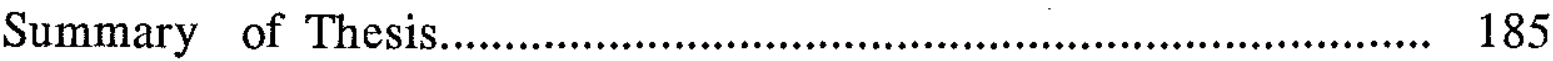


List of Figures and Tables

Chapter 2

Page

Fig. 1. General ecology of three genera of hyperiid amphipods:

Phronima, Lycaea, and Vibilia ...................................... 58

Fig. 2. Sensilla Types 1,2 and 3 found on hyperiid amphipods......... 60

Fig. 3. Sensilla Types 4 and 5 found on hyperiid amphipods............ 62

Fig. 4. Antennules of Phronima, Lycaea , and Vibilia .................. 64

Fig. 5 Distribution of sensilla on Phronima sedentaria................... 66

Fig. 6 Distribution of sensilla on Lycaea spp. .......................................68

Fig. 7 Distribution of sensilla on Vibilia spp. ..................................... 70

Table I Five morphological types of sensilla found on the antennules and dorsal exoskeleton of Phronima, Lycaea , and Vibilia .... 71

Table II Morphological characteristics of crustacean sensory hairs...... 72

Chapter 3

Fig. 1 Scanning electron microscopy of Vibilia sp. antennules and

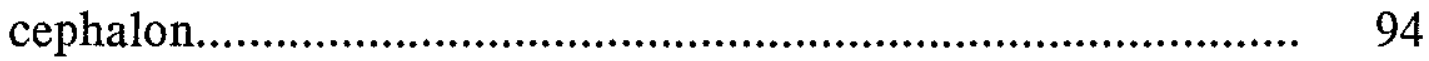

Fig. 2 Schematic representation of a longitudinal section through one

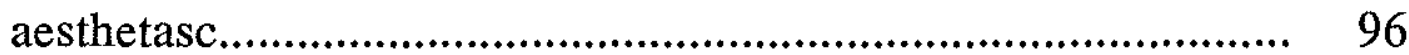

Fig. 3 Fine structure of Vibilia sp. aesthetasc, proximal and transitional area ................................................................ 98

Fig. 4 Fine structure of Vibilia sp. aesthetasc, distal area............... 100 
Chapter 4

Fig. 1 General ecology of two genera of hyperiid amphipods:

Lycaea , and Vibilia ........................................................................ 133

Fig. 2 Behavioral tests of Vibilia jeangarardi ............................. 135

Fig. 3 Behavioral tests of Lycaea spp. …............................................... 137

Fig. 4 Ammonium and amine concentrations of salp stimulus water and control sea water measured over time on the Calanus 8707 cruise

Table I Salp odor preparations used in behavioral tests expressed in grams of wet weight per liter of sea water....................... 140

Table II Total number of tests................................................... 141

Chapter 5

Fig. 1 Phronima sedentaria, female ....................................... 172

Fig. 2 Phronima, generalized female ...................................... 174

Fig. 3 Digestive system of Phronima ....................................... 176

Fig. 4 Female reproductive system of Phronima ......................... 178

Fig. 5 Nervous system of Phronima ...................................... 180

Fig. 6 Circulatory system of Phronima ................................... 182

Table I Gut passage time of salps consumed by

Phronima sedentaria. 


\title{
THE SENSORY MEDIATION OF SYMBIOSIS BETWEEN HYPERIID AMPHIPODS AND SALPS
}

by

\section{CAROL ELIZABETH DIEBEL}

Submitted in partial fulfillment of the requirements for the Degree of Doctor of Philosophy, March, 1988.

\begin{abstract}
Hyperiid amphipods are open ocean crustaceans which use gelatinous planktonic animals for food, shelter, and brooding space for their offspring. These associations involve varying degrees of host specificity; and there are few obvious correlations between gross morphology of the amphipods and the types of host they choose. The mechanisms which allow hyperiids to find and select specific hosts in the water column were investigated through the sensory and behavioral basis of these symbioses in three genera of hyperiids, Vibilia , Lycaea , and Phronima, which differ in the nature of their association with a common host - salps. The investigation included the description of the distribution and morphology of sensilla on the dorsal surface of the exoskeleton and antennules of the three genera of hyperiids with speculation on their functions. The ultrastructure of the aesthetasc sensilla of Vibilia sp. was determined for comparison with other crustacean aesthetasc sensilla, making a chemosensory function plausible. Behavioral experiments were conducted at sea which demonstrated a chemosensory basis for the host-specific associations between species of Vibilia and Lycaea and salps. Observations on the internal anatomy and behavior of Phronima are described which underscore the importance of salps to their general ecology. Although focussed for practical and logistic reasons, on three genera of hyperiids and their salp hosts, this coordinated study of ecology, sensory structure and function, and behavior provides considerable insight into the mechanisms maintaining the symbioses which allowed hyperiid amphipods to invade and radiate within the planktonic environment.

Thesis Supervisor: $\quad$ Dr. Laurence P. Madin Associate Scientist
\end{abstract}




\section{Acknowledgements}

Its difficult to not make this section a bit too emotional so we shall just have to see what happens. Thanks Larry for your patience, support and perhaps most importantly your sense of humor. Jelle, our many conversations made a difference and always made me think and work a little harder. To Judy and Penny I thank you for your patience in attending so many meetings and for keeping me on the right road. Kevin, you taught me electron microscopy-a skill and art that I enjoy and hope to continue working at; and, thanks for making the scopes available.

My research was made possible through the financial support I received from the WHOI Coastal Research Center (through a Graduate Research Grant), Lerner Gray Fund for Marine Research of the American Museum of Natural History, NATO Travel Fund, and the WHOI Education Office. Jake, did you have to make life so hard on me? Equally important were my parents who advanced the money for my computer and other necessities of life.

The divers on the cruises collected my animals for me and included: Gregg Dietzmann, Cathy Cetta, Dave Caron, Dan Richards, Harry Jenter, Paul Dragos, John Wilkin, Tim Stebbins and many others that I can't remember right now. Keith Stolzenbach deserves full credit for the salp trail visualizations and Cathy Cetta for helping me with the ammonium and amine tests. Pat Linley at Harbor Branch runs the best EM laboratory I have ever had the priviledge to work in. I would especially like to acknowledge the crew of the Oceanus who I think are the best around. Kevin and Rick taught me to play a mean game of cribbage and backgammon. Captains Mike and Paul tried to teach me a little about the stars. Cheryl Ann Butman gave me 
words of encouragement at precisely the right moments-it made a difference. Jake and Abbie its a tough job but you are there.

I was also a guest in a variety of different laboratories over the years. Mike Laverack and Sandy Williams were my guides through the Gatty in St. Andrews, Scotland; and, Philippe Laval was a kind host while I was at the Statione Zoologique, Villefranche-sur-Mer, France. Jenny Purcell and Mike Cimino allowed me to share some of their space at Friday Harbor Laboratory, Washington; and Claudia Mills provided moral support at both Villefranche and Friday Harbor. Thanks Claudia! I would also like to thank the technician at the EM facility at Oregon State University, Corvallis, Oregon; your professionalism was evident. Some of my best and perhaps most productive times were spent in these various laboratories, and all of these people were both very generous with their time and equipment.

As for my Humboldt friends, Steve and Jim taught me cynicism in science, an invaluable lesson that kept me going. Tim offered his unique sense of humor and along with Dan sympatique. Gary Brusca provided a set of standards that I am still striving towards; I only hope that I may be as good a teacher as he is some day.

My friends here at WHOI certainly added to my lot in life. Melissa, together we might be crazy but life is always interesting with you around. You have been greatly missed this last year. John, you helped to keep me calm and provided companionship, insight into world politics, editorial comments, and great cooking. Ross, I can really talk to you and I am eternally grateful that there is another lateral thinker around. Dave, you filled that all important "I need a good discussion (a polite form of the verb 'to fight') with someone" void. Sophie, I loved our friday night French sessions even though I am sure they tried your patience. Your friendship and 
support are greatly valued. Summer softball and winter football teammates taught me a lot about the different sports. Larry you are in here too as well as Kate because I consider you both to be valued friends. Who else would lend me furniture, help me light pilot lights, and provide me with fresh eggs?

I really don't know what to say about my family. Dad has been consistently supportive and positive. Mom has understood my dilemmas. I was very touched at my brother Stephens' efforts to understand what the heck I was working on. The rest of the family: Andrea, Paul, Philip, Rita and Tom keep my head in the real world. I know this is silly but the loyalty and companionship of my dog Tally (Talofa) was an enormous comfort throughout this effort. Its too bad she was never allowed to go on a cruise. 
Chapter 1

General Introduction 


\section{General Introduction}

Hyperiid amphipods commonly rank third in abundance after the copepods and euphausiids as members of the marine crustacean zooplankton. They are entirely marine and planktonic, and mostly oceanic with a few species found in coastal waters. Their ecological place is distinct from that of most other pelagic crustaceans; almost all species are symbionts for at least part of their lives with gelatinous organisms such as salps, medusae, siphonophores and ctenophores, which are used as a platform for feeding, a food source, and as a nursery for developing young (Pirlot, 1932; Harbison et al., 1977; Madin and Harbison, 1977; Laval, 1980).

Morphological comparisons of several genera of hyperiid and gammarid amphipods led Pirlot (1932) to propose that the Hyperiidea is a polyphyletic group comprising different lineages of amphipods, the convergent hyperiidean form resulting from their symbiosis with zooplankton hosts. Laval (1980) states the hypothesis: "Hyperiid amphipods are the descendents of benthic crustaceans which have developed a benthiclike existence on the pelagic substratum, provided by gelatinous animals of the zooplankton". If these theories are correct, the association with gelatinous animals has been a central selective force in the ecology and evolution of the Hyperiidea.

The present investigation was stimulated by the observation that previous studies of marine symbioses have by necessity focussed on benthic or coastal marine organisms with very little known about pelagic symbioses. Hyperiid amphipods are an exciting group to study in this regard. They display a great diversity in form, occupy a unique ecological niche within the 
open ocean, and depend, for most of their life functions, upon finding and recognizing their gelatinous zooplankton hosts. The mechanisms by which they do this has been essentially unknown. Although their symbiotic ecology is one of the most fascinating behavioral studies in the plankton, the study of hyperiids is difficult because they occur in the open ocean and are associated with delicate gelatinous animals. Collection and observation by SCUBA divers now make it possible to record their behavior in the field, and bring back suitable material for experimentation. The goal of this study was to address the general question of how these hyperiids maintain their specific associations with salps. This was accomplished through behavioral experiments conducted at sea which demonstrated the chemosensory basis for the host-specific associations between species of hyperiids and salps. In addition a comparative description of the distribution and morphology of sensilla on the dorsal surface of the exoskeleton and antennules of three genera of hyperiids and to deduce their probable functions. The comparison of the ultrastructure of the aesthetascs of Vibilia sp. with those of Crustacea aesthetasc supports the notion of their chemosensory function.

Although focussed for practical and logistic reasons, on three genera of hyperiids and their salp hosts, this research is related to general issues in plankton ecology, including the co-evolution of symbiosis between pelagic animals, the role of sensory information in creating structure in the water column, and the coordination of feeding biology, reproductive behavior and life cycles between taxonomically disparate but ecologically coupled organisms.

Hyperiid behavior may be described as 'parasitoid' (Laval, 1980) i.e. intermediate between a parasite and a predator. Many hyperiids are freeliving as adults, but in all known cases their progeny grow and develop in or 
on a host, requiring that a female locate an appropriate host during her lifetime. Hosts may be widely distributed or patchy, and a female hyperiid needs effective mechanisms for host recognition. The male hyperiid may also need these mechanisms if he is to locate a female. Thus, hyperiid amphipods present an excellent opportunity for the study of host-oriented behavior in a pelagic symbiotic organism.

Symbiosis was formally defined by De Bary (1879) as a "living together" of dissimilar organisms. There is an enormous diversity and complexity of species interactions in symbiotic relationships and many of them affect entire ecosystems. The recognition that symbiotic relationships are widespread, persistent through time, and with profound consequences for the partners has led to a reexamination of the evolutionary implications of symbiosis (Margulis, 1976, 1981).

Basic to the biology of symbioses are the mechanisms which bring correct partners together and maintain their associations (Margulis, 1981). Because of their specific and often obligate nature, symbioses are particularly good situations for the investigation of interspecific communication and associated behavior. There are many strategies that symbionts use to recognize their potential hosts. These strategies depend on the biology of the host, the environment in which the host lives, the host's mode of life and the relationship the host has with other organisms around it. Among many potential cues in the environment, however, the host is usually the primary source of stimuli controlling behavior of the symbiont (Davenport, 1955, 1966). A host must feed, reproduce and defend itself in order to survive. These activities involve the release of different signals that can supply the sensory information needed by the symbiont to locate and properly identify its proper host (Davenport, 1966; Wilson, 1970; Ache, 
1974). Therefore the maintenance of highly specific host-symbiont relationships must involve both sensory and behavioral adaptations of the symbiont to characteristic signals or stimuli produced by the host.

There are few obvious relationships between the gross morphology of the hyperiids and their associations with particular kinds of hosts. Frequently, amphipods of similar appearance are found on hosts in different phyla, while amphipods of very different appearance can co-occur on the same hosts (Harbison et al., 1977). The life history and behavior of most species have not been examined in great detail because of the difficulty in obtaining and maintaining the hyperiid and their gelatinous hosts in good condition. What is known about their obligate and highly specific associations with gelatinous zooplankton strongly suggests that hyperiids can monitor, interpret and respond to their physical, chemical, and biological environment in specific ways. Such monitoring further implies the presence of a variety of sense organs.

On large scales, environmental factors such as currents or gyres, probably determine the distribution of both the host and the symbionts. For each organism the spatiotemporal scale of biological interest is bounded on the lower end (highest spatial frequencies) by the sampling volume and the adaptation/disadaption time constants of its sensory receptors and on the upper end (lowest spatial frequencies) by the adaptation rate of searching strategies and integration characteristics of the organism (see Table 2.1 in Atema, 1988). It is assumed that hyperiids could use sensory cues only for recognizing hosts within the scale of their swimming range.

Host recognition could be based on visual, mechanical, or chemical cues. Possible visual signals include shape, color, size and pattern of movement of the host. What little research has been done on the sensory 
physiology or anatomy of hyperiids has been mainly concerned with their eyes. The size and structure of the apposition compound eyes in most hyperiids suggests the importance of vision in their behavior (Ball, 1975; Land, 1981b, 1984; Nillson, 1982), but visual detection is limited in range and accuracy by the absorption and scattering of light (Lythgoe, 1988). Nilsson (1982) calculated from optical considerations that Hyperia (a genus of hyperiid amphipods similar to Lycaea ) may be able to discriminate their scyphozoan hosts ( $30 \mathrm{~cm}$ across) at a distance of about $10 \mathrm{~m}$. Salps are generally about $5-10 \mathrm{~cm}$ in length and their bodies are transparent except for their small stomachs $(5-10 \mathrm{~mm})$ which are often shaped in genus specific fashion. Densitometer measurements show that a salp is virtually indistinguishable from its background when observed from any angle (measurements from photographic slides). Visual detection by a hyperiid from a long range would therefore be highly unlikely, although it may be very important at shorter ranges.

Mechanical signals may be vibrations, pressure waves or currents (possibly specific) which are created by the host while moving through the water (Atema, 1980, 1985; Wilcox, 1988; Bleckmann, 1988); their importance has been demonstrated in other planktonic crustaceans (Strickler and Bal, 1973; Ball and Cowan, 1977). The exhalent water of salps may be characterized as a pulsed jet, combining a continuous column of water with periodic vortex rings produced by each contraction of the salp's body muscles (Diebel et al., 1985). In the aquarium and the field, individual vortices were visible for at least 15 secs, implying that the associated wake might persist for at least 60 secs in the field (Diebel et al., 1985). Swimming speeds of salps range up to $10 \mathrm{~cm} / \mathrm{sec}$ (Madin 1974 and unpublished data), which means that a wake can still be hydrodynamically distinct when the salp 
is as much as $6 \mathrm{~m}$ away (Diebel et al., 1985). These observations were made on individual solitary salps. The aggregate generation of salps occurs in chains or whorls of various forms which may contain several hundred individuals. Chemical properties of the wake, if any, would decay by diffusion, and might persist much longer than the physical properties.

Chemical signals could be any substances produced and released by the host intentionally or as byproducts of feeding, metabolism or reproduction (Davenport, 1966). Chemical information is probably important in the maintenance of aquatic partnerships in general (Davenport, 1966). Specific chemical information regulates countless predator-prey and herbivore-plant relationships, as well as mate recognition and location, and has been shown to have a similar role in symbiotic associations (Davenport 1966; Wilson, 1970; Ache, 1974).

By analogy with other benthic and pelagic crustaceans (e.g., Ache, 1974; Hamner and Hamner 1977; Meador, 1980) one might expect chemical cues to be of primary importance in mediating the behavior of hyperiid amphipods. Preliminary analyses of amino acids released by salps into the water have been made (C. Cetta, unpublished data). The results show that salps do excrete several amino acids, some of which reached concentrations 10 to 100 times above background during a $4 \mathrm{hr}$ incubation. The concentrations of these compounds that might be present in a salp's wake, assuming excretion was continuous, are estimated to be very low, about 109M. This is close to background levels, but the significance of a chemical cue may depend more on its distinctiveness (uniqueness to a particular species) than on its concentration.

In general crustaceans possess a well-developed chemical sense mediated by chemosensory sensilla located on various parts of the body. A 
sensory organ that occurs on the antennules of many hyperiids and other crustaceans has been defined by Lowry (1986) as a "callynophore". This sense organ bears transverse rows of aesthetascs (olfactory sensilla) usually grouped together in one or two longitudinal fields to form a brush. The aesthetascs are considered a distinct class of sensilla clearly differing from other setae commonly found on crustaceans. Studies on the fine structure of these aesthetascs help to indicate the specific function of these sensilla. The fine structure of aesthetascs is now known for a few species of crustaceans (for review see Heimann, 1984; Spencer and Linberg, 1986; Grünert and Ache, 1988). These studies collectively show that aesthetascs of different species have many morphological features in common, yet there are species specific differences. Antennular responsiveness to chemical stimuli has been attributed to these numerous, porous, cuticular aesthetascs (Ache, 1982; Devine and Atema, 1982; Derby and Ache, 1984; Spencer, 1986; Laverack, 1987, 1988).

The integument of amphipods and other arthropods bears numerous organs that vary in pattern, number, variability and taxonomic significance (Fleminger, 1973; Mauchline and Ballantyne, 1975; Mauchline, 1977). These organs fall into two general classes: sensory receptors or sensilla, and glands. The term sensillum is used for any hair-like seta that protrudes, through a pore in the integument, onto the surface of the integument and which is presumed to be innervated. On the body of copepods (Fleminger, 1973) and other crustaceans (Mauchline and Ballantyne, 1975; Mauchline, 1977), sensilla and glands are in general distributed in bilaterally symmetrical patterns that tend to repeat on successive body segments. Mauchline and Ballantyne (1975) found that the integumental organs of some species of hyperiids are distributed in distinctive patterns but occur more 
randomly in the gammaridean species. However, the method used to map the pores (treatment with potassium hydroxide) destroyed the sensilla thus making the mapping of different types of sensilla impossible, and preventing definitive distinction between sensillar and glandular pores.

The first clue to the function of sensory hairs is their external morphology. The interpretation of function is not usually possible on morphological grounds alone but will depend partly on the microenvironment in which the sensillum is situated. For example, Hindley (1975) mapped particular areas on the body of a decapod Penaeus merguiensis that exhibited a chemosensitivity to meat extract. However, if one combined the morphology of the sensilla along with their location on the body, their ultrastructure and physiology and the behavior of the organism, their function can be deduced.

The three genera of hyperiids examined here are widely distributed and spend at least a part of their life cycle associated with salps. Most salps are colonizing or opportunistic species, and their populations are variable in size and patchy in distribution. Phronima, Lycaea, and Vibilia are in three different Superfamilies within the Infraorder Physocephalata of the Hyperiidea; they differ greatly in external morphology, behavior, and probably, phyletic history.

Phronima is an omnivorous predator, free-swimming in the water, which uses salps, pyrosomes or siphonophores as a food source, feeding platform, and brood chamber (Bowman and Grüner, 1973; Laval, 1980; Diebel, 1988). It is in the Superfamily Phronimoidea and has large compound eyes and filiform antennules. The mouthparts are reduced and the mandible has a large molar process and incisor but no palp (Bowman and Grüner, 1973). The female forms a barrel from the bodies of salps or 
pyrosomes which it occupies and uses as a platform for feeding and for deposition of its young (Minkiewicz, 1909; Richter, 1978; Laval, 1980; Diebel, 1988). The female cares for her young through two molts after their removal from the marsupium onto the barrel walls (demarsupiation) (Richter, 1978; Laval, 1980; Diebel, 1988).

Lycaea is in the Superfamily Platysceloidea and has well-developed eyes which occupy most of the surface of the head. Their shape varies among different species (Harbison and Madin, 1976). Lycaea moves freely inside and outside of a salp or salp chain and feeds intermittently on parts of the salp's body (Madin and Harbison, 1977). The mouthparts are much reduced; the mandible has a palp in the male but not in the female. There is no incisor or molar process evident on the mandible (Bowman and Grüner, 1973). The young are released from the marsupium as juveniles with undifferentiated pereopods, and are unable to swim (Harbison, 1976). Juveniles of Lycaea are rarely found without adults present in the same salp (Madin and Harbison, 1977).

Vibilia is in the Superfamily Vibilioidea and has two small eyes and broadly flattened antennules. It lives inside the salp, and diverts food from the salp's mucous feeding strand to its mouth (Madin and Harbison, 1977). The mouthparts are reduced relative to a gammarid, and the mandible has a palp, a molar process and an incisor (Bowman and Grüner, 1973). Vibilia females will deposit their young as larvae directly onto a salp host (Laval, 1963). The larvae, which cannot swim since the pleopods and uropods are not yet developed, move inside the salp and feed on its tissue while developing further (Laval, 1963). 


\section{Literature Cited}

Ache, B. 1974. The experimental analysis of host recognition in symbiotic marine invertebrates. In: Symbiosis in the Sea. W. B. Vernberg (ed.). Bella Baruch Library in Marine Science Number 2. U. South Carolina Press, Columbia. pp 45-60.

Atema, J. 1980. Smelling and tasting underwater. Oceanus 23: 4-18. Atema, J. 1988. Distribution of Chemical Stimuli. In: Sensory Biology of Aquatic Animals, (J. Atema, R. R. Fay, A. N. Popper, and W. N. Tavolga (eds.)). Springer-Verlag, New York. pp. 29-56.

Ball, E. E. and A. N. Cowan. 1977. Ultrastructure of the antennal sensilla of Acetes (Crustacea, Decapoda, Natantia, Sergestidae). Philos. Trans. Roy. Soc. London, Ser. B, 277: 429-457.

Bleckmann, H. 1988. Prey Identification and Prey Localization in Surfacefeeding Fish and Fishing Spiders. In: Sensory Biology of Aquatic Animals, (J. Atema, R. R. Fay, A. N. Popper, and W. N. Tavolga (eds.)). Springer-Verlag, New York. pp. 619-642.

Bowman, T. E. and H. E. Grüner. 1973. The families and genera of Hyperiidea (Crustacea: Amphipoda). Smithsonian Contr. to Zool. 146: 1-64.

Davenport, D. 1955. Specificity and behavior in symbioses. Quart. Rev. Biol. 30: 29-46.

Davenport, D. 1966. The experimental analysis of behavior in symbioses. In: Symbiosis Vol. I, S. M. Henry (ed). Academic Press: New York. pp. 381-429.

De Bary, A. 1879. Die Erscheinung die Symbiose. Tubner, Strassburg. 243pp. 
Derby, C. D. and J. Atema. 1980. Induced host odor attraction in the pea crab Pinnotheres maculatus. Bio. Bull. 158:26-33.

Devine, D. V. and J. Atema. 1982. Function of chemoreceptor organs in spatial orientation of the lobster, Homarus americanus: differences and overlap. Bio. Bull. 163: 144-153.

Diebel, C. E. 1988. Observations on the anatomy and behavior of Phronima sedentaria (Forskål)(Amphipoda: Hyperiidea). J. Crust. Biol. 8(1): 79-90.

Diebel, C. E., K. Stolzenbach, L. P. Madin and J. Atema. 1985. Multisensory trail detection in oceanic amphipods? Biol. Bull. 169 (2): 533-534.

Fleminger, A. 1973. Pattern, number, variability, and taxonomic significance of integumental organs (sensilla and glandular pores) in the genus Eucalanus (Copepoda, Calanoida). Fishery Bulletin 71: 965-1010.

Grünert, U. and B. W. Ache. 1988. Ultrastructure of the aesthetasc (olfactory) sensilla of the spiny lobster, Panulirus argus. Cell and Tiss. Res. 251 (1): 95-103.

Hamner, P. P. and W. H. Hamner. 1977. Chemosensory tracking of scent trails by the planktonic shrimp Acetes sibogae australis. Science 193: 886-888.

Harbison, G. R. 1976. Development of Lycaea pulex (Marion, 1874 and Lycaea vincentii Stebbing, 1888 (Amphipoda, Hyperiidea). Bull. Mar. Sci. 26: 152-164. 
Harbison, G. R., D. C. Biggs and L. P. Madin. 1977. The associations of Amphipoda Hyperiidea with gelatinous zooplankton. II. Associations with Cnidaria, Ctenophora, and Radiolaria. Deep Sea. Res. 24: 465488.

Heimann, P. 1984. Fine structure and molting of aesthetasc sense organs on the antennules of the isopod, Asellus aquaticus (Crustacea). Cell and Tiss. Res. 235: 117-128.

Hindley, J. P. R. 1975. The detection, location and recognition of food by juvenile prawns, Penaeus merguiensis de Man. Mar. Behav. Physiol. 3: 193-210.

Land, M. F. 1981. Optics and vision in Invertebrates. In: Handbook of Sensory Physiology. Comparative Physiology and Evolution of Vision in Invertebrates. H. Autrum (ed.), Springer Verlag, Berlin. pp.471-592.

Laval, P. 1963. Sur la biologie et les larves de Vibilia armata Bov. et de V. propinqua Stebb., Amphipodes Hyperides. Comp. Ren. Hebd. des Seances de l'Acad. des Sci., Paris 236: 1389-1392.

Laval, P. 1980. Hyperiid amphipods as crustacean parasitoids associated with gelatinous zooplankton. Oceanogr. Mar. Biol. Ann. Rev. 18: 1156.

Laverack, M. S. 1987. The nervous system of the Crustacea, with special reference to the organisation of the sensory system. In: Nervous systems of the invertebrates. (M. A. Ali, ed.). Proceedings, NAROASI, Lennoxville, Canada. Springer-Verlag, Berlin. pp. 1-30. Laverack, M. S. 1988. The diversity of chemoreceptors. In: Sensory Biology of Aquatic Animals, (J. Atema, R. R. Fay, A. N. Popper, and W. N. Tavolga (eds.)). Springer-Verlag, New York. pp. 287-312. 
Lowry, J. K. 1986. The callynophore, a eucaridan/peracaridan sensory organ prevalent among the Amphipoda (Crustacea). Zoo. Scrip. 15: 333-349.

Madin, L. P. 1974. Field observations on the feeding behavior of salps (Tunicata: Thaliacea). Mar. Biol. 24: 143-147.

Madin, L. P. and G. R. Harbison. 1977. The associations of Amphipoda Hyperiidea with gelatinous zooplankton. I. Associations with Salpidae. Deep Sea Res. 24: 449-463.

Margulis, L. 1976. The genetic and evolutionary consequences of symbiosis. Exp. Parasit. Rev. 39: 277-349.

Margulis, L. 1981. Symbiosis in Cell Evolution. W. H. Freeman and Company, San Francisco. 419 pages.

Mauchline, J. 1977. The integumental sensilla and glands of pelagic

Crustacea. J. mar. biol. Ass. U. K. 57: 973-994.

Mauchline, J. and A. R. S. Ballantyne. 1975. The integumental organs of amphipods. J. mar. biol. Ass. U. K. 55: 345-355.

Meador, J. P. 1980. Chemoreception in a lysianassid amphipod. Amer. Zool. 20: 754 .

Minkiewicz, R. 1909. Memoire sur la biologie du tonnelier de mer Phronima sedentaria Forsk.). Bull. dl'Ins. Ocean. 152: 1-21. Nilsson, D. E. 1982. The transparent compound eye of Hyperia (Crustacea): Examination with a new method for analysis of refractive index gradients. J. comp. Physiol. 147: 339-349.

Pirlot, J. M. 1932. Introduction a l'etude des Amphipodes Hyperides. Ann. de l'Inst. Ocean. 12: 1-36. 
Richter, G. 1978. Beobachtung zu Entwicklung und Verhalten von Phronima sedentaria (Forskål)(Amphipoda). Senck. Mari. 10: 229242 .

Ross, D. M. 1983. Symbiotic Relations. In: The Biology of Crustacea, Vol. 7 Behavior and Ecology (F. J. Vernberg and W. B. Vernberg eds.). Academic Press, New York. pp. 163-213.

Spencer, M. 1986. The innervation and chemical sensitivity of single aesthetasc hairs. J. Comp. Physiol. a 158: 59-68.

Spencer, M. and K. A. Linberg. 1986. Ultrastructure of aesthetasc innervation and external morphology of the lateral antennule setae of the spiny lobster Panulirus interruptus ( Randall). Cell. Tiss. Res. 245: 69-80.

Strickler, R. and A. K. Bal. 1973. Setae of the first antennae of the copepod Cyclops scutifer (Sars): Their structure and importance. Proc. Nat. Acad. Sci., U.S.A. 70: 2656-2659.

Wilcox, R. S. 1988. Surface Wave Reception in Invertebrates and Vertebrates. In: Sensory Biology of Aquatic Animals (J. Atema, R. R. Fay, A. N. Popper, and W. N. Tavolga (eds.)). Springer-Verlag, New York. pp. 643-664.

Wilson, E. O. 1970. Chemical communication within animal species. In: Chemical Ecology (E. Sondheimer and J. B. Simeone, eds.). Academic Press, New York. pp. 133-155. 


\section{Chapter 2}

The distribution and morphology of sensory hairs (sensilla)

on three genera of hyperiid amphipods

(Phronima, Lycaea, and Vibilia) 


\begin{abstract}
The arrangement and external morphology of the sensilla on the antennules and dorsal surface of the exoskeleton of three genera of hyperiid amphipods (Phronima, Lycaea , and Vibilia ) is described. Five distinct morphological types of sensilla were found. Typical crustacean aesthetascs were located on the antennules. Other types of sensilla were arranged in bilaterally symmetrical, serially homologous sets on successive body segments. One sensillum type has not been reported previously. The probable functions of these sensory hairs is discussed in relation to the symbiotic behavior of the amphipods. This information is also relevant to the behavior, ecology, systematics and evolution of hyperiid amphipods.
\end{abstract}




\section{Introduction}

Hyperiid amphipods commonly rank third in abundance after the copepods and euphausiids as members of the marine crustacean zooplankton. They are entirely marine and pelagic, and mostly oceanic with a few species found in coastal waters. Their ecological place is distinct from that of most other pelagic crustaceans; almost all species are symbionts for at least part of their lives with gelatinous organisms such as salps, medusae, siphonophores and ctenophores, which are used as a platform for feeding, a food source, and as a nursery for developing young (Pirlot, 1932; Harbison et al, 1977; Madin and Harbison, 1977; Laval, 1980).

Morphological comparisons of several genera of hyperiid and gammarid amphipods led Pirlot (1932) to propose that the Hyperiidea is a polyphyletic group comprising different lineages of amphipods, the convergent hyperiidean form resulting from their symbiosis with zooplankton hosts. Laval (1980) states the hypothesis: "Hyperiid amphipods are the descendents of benthic crustaceans which have developed a benthiclike existence on the pelagic substratum, provided by gelatinous animals of the zooplankton." If these theories are correct, the association with gelatinous animals has been a central selective force in the ecology and evolution of the Hyperiidea.

The three genera of hyperiids examined here are widely distributed and spend at least a part of their life cycle associated with salps, are within the Infraorder Physocephalata but in three different Superfamilies of the Hyperiidea, and differ greatly in external morphology, behavior, and probably, phyletic history (Fig. 1).

Phronima is an omnivorous predator, free-swimming in the water, which uses salps, pyrosomes or siphonophores as a food source, feeding 
platform, and brood chamber (Bowman and Gruner, 1973; Laval, 1980;

Diebel, 1988). It is in the Superfamily Phronimoidea and has large compound eyes and filiform antennules. The mouthparts are reduced and the mandible has a large molar process and incisor but no palp (Bowman and Gruner, 1973). The female forms a barrel from the bodies of salps or pyrosomes which it occupies and uses as a platform for feeding and for deposition of its young (Minkiewicz, 1909; Richter, 1978; Laval, 1980; Diebel, 1988). The female cares for her young through two molts after their removal from the marsupium onto the barrel walls (demarsupiation) (Richter, 1978; Laval, 1980; Diebel, 1988).

Lycaea is in the Superfamily Platysceloidea and has well-developed eyes which occupy most of the surface of the head. Their shape varies among different species (Harbison and Madin, 1976). Lycaea moves freely inside and outside of a salp or salp chain and feeds intermittently on parts of the salp's body (Madin and Harbison, 1977). The mouthparts are much reduced; the mandible has a palp in the male but not in the female. There is no incisor or molar process evident on the mandible (Bowman and Gruner, 1973). The young are released from the marsupium as juveniles with undifferentiated pereopods, and are unable to swim (Harbison, 1977). Juveniles of Lycaea are rarely found without adults present in the same salp (Madin and Harbison, 1977).

Vibilia is in the Superfamily Vibilioidea and has two small eyes and broadly flattened antennules. It lives inside the salp, and diverts food from the salp's mucous feeding strand to its mouth (Madin and Harbison, 1977). The mouthparts are reduced relative to a gammarid, and the mandible has a palp, a molar process and an incisor (Bowman and Gruner, 1973). Vibilia females will deposit their young as larvae directly onto a salp host (Laval, 
1963). The larvae, which cannot swim since the pleopods and uropods are not yet developed, move inside the salp and feed on its tissue while developing further (Laval, 1963).

There are few obvious relationships between the gross morphology of the hyperiids and their associations with particular kinds of hosts. Frequently, amphipods of similar appearance are found on hosts in different phyla, while amphipods of very different appearance can co-occur on the same hosts (Harbison et al, 1977). The life-history and behavior of most species have not been examined in great detail because of the difficulty of obtaining and maintaining the hyperiid and their gelatinous hosts in good condition. What is known about their obligate and highly specific associations with gelatinous zooplankton strongly suggests that hyperiids can monitor, interpret and respond to their physical, chemical, and biological environment in specific ways. Such monitoring further implies the presence of a variety of sense organs in addition to eyes, statocysts, antennal (calynophore (Lowry, 1986)) and mouthpart receptors.

What little research has been done on the sensory physiology or anatomy of hyperiids has focussed primarily on their well developed eyes (Ball, 1975; Meyer-Rochow, 1978; Hallberg et al., 1980; Land, 1981; Nilsson, 1982). Antennal structures and activity have attracted the most attention in other crustaceans and yet the crustacean body is heavily provided with sensors over the entire surface. The integument of amphipods and other arthropods bear numerous organs that vary in pattern, number, variability and taxonomic significance (Fleminger, 1973; Mauchline and Ballantyne, 1975; Mauchline, 1977). These organs fall into two general classes: sensory receptors or sensilla, and glands. In this paper the term sensory hair or sensilla is used for any hairlike setae that protrudes, through a pore on the 
integument, onto the surface of the integument and which is presumed to be innervated. On the body of copepods (Fleminger, 1973) and other marine crustaceans (Mauchline and Ballantyne, 1975; Mauchline, 1977), sensilla and glands are in general distributed in bilaterally symmetrical patterns that tend to repeat on successive body segments. Mauchline and Ballantyne (1975) found that the integumental organs of some species of hyperiids are distributed in distinctive patterns but occur more randomly in the gammaridean species. However, the method used to map the pores (treatment with potassium hydroxide) destroyed the sensilla thus making the mapping of different types of sensilla impossible, and preventing definitive distinction between sensillar and glandular pores.

There have been several reviews on the classification of sensory hairs on arthropods (Laverack, 1968; Ball and Cowan, 1977; Altner and Prillinger, 1980; Altner et al., 1983; Bush and Laverack, 1983), as well as papers which relate the structure of these sensory hairs with their function (Ball and Cowan, 1977; Altner and Prillinger, 1980; Derby, 1982; Felgenhauer and Abele, 1982; Altner et al., 1983; Gnatzy et al., 1984). Almost all of these studies have focussed on the sensory hairs of benthic decapods; only Mauchline and Ballentyne (1975) studied pelagic crustaceans and provided a cursory description of sensory hairs on hyperiids.

The first clue to the function of sensory hairs is their external morphology. The interpretation of function is not usually possible on morphological grounds alone but will depend partly on the microenvironment in which the sensilla are situated. For example, Hindley (1975) mapped particular areas on the body of a decapod Penaeus merguiensis that exhibited a chemosensitivity to meat extract. However, if one combines the morphology of sensilla along with their location on the body, their 
ultrastructure and physiology and the behavior of the organism, their function can be deduced.

In this study, I map the distribution of each sensillum type on the dorsal surface of the exoskeleton and antennules on the three genera of hyperiid amphipods. The external morphology of five distinct types of sensilla is described and the distribution of aesthetascs on the antennules of both the male and female are compared. The results are discussed in relation to their behavior, ecology, systematics, and evolution. 
Materials and Methods

Animal collection and handling

All amphipods were collected with their salp hosts in individual jars by SCUBA divers working in the top $30 \mathrm{~m}$ of water. Collections were made while on cruises in the western north Atlantic, central north Atlantic, and Tongue of the Ocean. Animals from the dives were numbered, identified to genus, and transferred with or without their hosts to 1-5 1 glass or plastic containers filled with ambient seawater that was changed daily. Ambient sea water $\left(20-25^{\circ} \mathrm{C}\right)$ was either bucketed or pumped aboard through an uncontaminated seawater intake system.

Mapping of sensory pores:

The pores of sensory hairs with probable chemo- and/or mechanosensory functions have been described on the dorsal surface of several pelagic crustaceans (including amphipods) by examination of cleaned and stained cuticles under a light microscope (Fleminger, 1973; Mauchline and Ballantyne, 1975; Mauchline, 1977). I used a modification of their technique to survey and map integumental pores on species of Vibilia and Lycaea. Arrangement of pores on Phronima has been previously described by Mauchline and Ballantyne (1975), but I also made my own survey of Phronima as a check.

All tissue was removed from within the amphipod's integument by heating specimens in a $10-25 \%$ aqueous potassium hydroxide $(\mathrm{KOH})$ solution at $80-100^{\circ} \mathrm{C}$ for $24 \mathrm{hr}$ or as long as was necessary to produce a clean cuticle. The ratio of $\mathrm{KOH}$ solution to specimens was maintained at about $50 \mathrm{ml}$ per individual. The empty, intact, cuticle was then washed with distilled water 
until clean and briefly immersed in $70 \%$ ethanol. The cuticle was stained with a $1 \%$ solution of chlorazol black $\mathrm{E}$ in $70 \%$ ethanol for about a minute. The cuticles were then transferred dorsal side up to a drop of glycerol on a glass slide, covered with a glass coverslip, and examined under a microscope. The black staining of the cuticle makes these pores relatively easy to see as pinpoints of light under the microscope. Drawings of the distributions of these pores in the different specimens were made with the aid of a stereomicroscope. These preliminary drawings were used as maps when surveying the animals with a scanning electron microscope.

Scanning Electron Microscopy:

Amphipods were also surveyed using scanning electron microscopy (SEM). The animals examined had been fixed on board ship by various methods (including: 3\% glutaraldehyde, $6 \%$ formalin, Bouins solution, and Karnovskys (paraformaldehyde-glutaraldehyde), postfixed in $2 \%$ osmium tetroxide (OsO4) in $0.1 \mathrm{~mol} / 1$ phosphate buffer ( $\mathrm{pH} 7.1$ ) for two hours at $24 \circ \mathrm{C}$, taken through a graded dehydration, and stored in $70 \%$ ethanol at $10^{\circ} \mathrm{C}$. They were then taken through the remaining ethanol series, critical point dried, mounted on stubs, coated with gold/palladium, and observed in a Zeiss Novascan SEM, or a JSM $35 \mathrm{CF}$ at $15 \mathrm{kV}$. 


\section{Results}

The best resolution of the external morphology of the exoskeleton of crustaceans is usually achieved by using freshly molted animals because encrustation by epibionts and debris, and abrasion, often lead to breakage of setae during intermolt (Bauer, 1977; Felgenhauer and Schram, 1978; Hamilton, 1983). However, the difficulty of obtaining and keeping hyperiid amphipods in a healthy state precluded this step. As a result, the examination of the exoskeleton of the three genera was often hindered by encrusting debris and bacteria. Another problem was that the cuticle of Lycaea and Phronima was thin and delicate and often collapsed during the preparation for SEM. Consequently, the descriptions are derived from less than perfect specimens, but every effort was made to confirm the observations by surveying several different individuals within the three genera. Description of Sensory Hairs

There were five distinct morphological types of sensory hairs (sensilla) found on the dorsal exoskeleton and antennules of the three different genera (Figs. 2,3, Table I). All sensilla open through pores or well defined sockets ( 1 to $6 \mu \mathrm{m}$ in diameter) in the exoskeleton. The other class of cuticular perforations are formed by the ducts of underlying integumental glands. The openings of the integumental glands are 1 to $2 \mu \mathrm{m}$ in diameter and common over the whole cuticle in all species (Mauchline and Ballantyne, 1975).

Type 1 (Fig. 2A,B,C,D, Table I) is typical of sensilla commonly referred to as "aesthetascs" (Ache, 1982; Heimann, 1984; Grünert and Ache, 1987; Laverack, 1988) an anatomically distinct class of sensilla within crustaceans. They are located on the antennules of crustaceans and are functionally considered to be chemoreceptors (Heimann, 1984; Spencer, 
1986; Lowry, 1986). The opening of the sensilla into the cuticle may have raised or asymmetric edges as in Vibilia (Fig. 2C), or no edges as in Lycaea (Fig. 2B,D) or Phronima (Fig. 2A). Figure 2D shows that the aesthetascs, at least in Lycaea females, are not solid.

Type 2 (Fig. 2E, Table I) are a previously undescribed sensilla that have been found only on species of Vibilia and not Phronima or Lycaea . They have also been found on stomatopods (Laverack, pers. comm.), but their function is unknown. Morphologically, these sensilla flair out from the base ("fluted") and have a long slit-like opening at the tip. The pores or openings for the sensilla into the cuticle have a raised edge and are from 1 to $2 \mu \mathrm{m}$ in diameter.

Type 3 (Fig. 2F, Table I) are simple unbranched sensilla that are widespread in occurrence on the crustacean body (Mauchline and Ballantyne, 1973; Factor, 1978; Bush and Laverack, 1982; Hamilton, 1983a,b; Laverack and Barrientos, 1985). There may be a raised symmetric or asymmetric edge surrounding the pore, and the pore size varies with the size of the sensilla.

Type 4 (Fig. 3A-E, Table I) are branched sensilla that are also widespread in occurrence on the crustacean body and believed to be mechanosensory in function (Mauchline and Ballantyne, 1973; Bush and Laverack; Felgenhauer and Abele, 1983). They may be bifid (Type 4a) as those on the dorsal midline of the eyes of all three genera (Fig. 3A-C), or on the dorsal surface of the exoskeleton of Vibilia and Lycaea. These sensilla may also have multiple branches (4b) as on the base of the antennules of Vibilia (Fig. 3D) and the dorsal surface of the exoskeleton of Phronima (Fig. $3 \mathrm{E})$. There is often an asymmetric edge surrounding the pore into the cuticle on both types of branched sensilla. 
Type 5 (Fig. 3F, Table I) are peg-like sensilla found only on Vibilia and which are similar to those found by Coudras (1982) in gammarid amphipods. They are very small protruding hairs that are irregularly distributed along the lateral surface of the pereonites and pleonites. There is no obvious rimmed pore from which they emerge from the exoskeleton. Description of antennules

The antennules among hyperiid amphipods are often sexually dimorphic and morphologically diverse (Bowman and Gruner, 1973; Vinogradov, 19821; Lowry, 1986). Lowry (1986) has coined the term "callynophore" for the completely or partially fused proximal articles of the outer flagellum of the antennule which bear transverse rows of aesthetascs, usually grouped together in one or two longitudinal fields. The callynophore is always present in males and nearly always present in females of hyperiid amphipods.

Figure 4 shows the male and female antennules of the three different genera. The callynophore of Vibilia is modified into a large, lanceolate structure with the medial surface slightly concave and bearing two longitudinal fields of aesthetascs (Fig. 4A,D). The sockets of the aesthetascs look similar to a keyhole (Fig. 2C), and are approximately $5 \mu \mathrm{m}$ in length and $3 \mu \mathrm{m}$ in width. The sockets are formed by the constriction of two raised edges in the center that serve to limit the aesthetascs to an anterior-posterior direction of movement. The lateral surface of the antennule is thicker in cross section than the medial surface and bears rows of simple setae (Type 3) along the anterior-posterior axis (Fig. 4E). The first segment of the peduncle has a grouping of branched setae (Type $4 \mathrm{~b}$ ) along the ventral lateral surface and, a line along the dorsal lateral surface (Fig. 3D). There does not 
appear to be a strong sexual dimorphism, but there may be a more dense field of aesthetascs in the male.

Females of Lycaea spp. have small antennules and reduced callynophores with only one longitudinal row of aesthetascs on segments of the flagellum (Fig. $4 \mathrm{C}, \mathrm{H}$ ). The pores are round and approximately $3 \mu \mathrm{m}$ in diameter (Fig. 2B,C). The males have a dense concentration of aesthetascs, formed from two ventromedial fields along the swollen base of the reniform peduncle (Fig. 4C,G). At the proximal end of the aesthetascs where they emerge from the socket the walls of the aesthetascs have a rougher looking appearance for the first $2 \mu \mathrm{m}$ (Fig. 2B). There are also several single longitudinal rows of aesthetascs on the three articles of the flagellum of the male (Fig. 4G). The terminal article of the flagellum of each sex appears to have 4 aesthetascs at the distal end (Fig. 2D).

Phronima spp. have sexually dimorphic antennules (Bowman and Gruner, 1973; Vinogradov, 1982), including the callynophores (Lowry, 1986) (Fig. 4B). The exoskeletal pore is $7 \mu \mathrm{m}$ is diameter and devoid of any external sculpturing (Fig. 2A). Among males of Phronima sedentaria the large swollen callynophore is positioned in such a way that the two fields of ventrally located aesthetascs face directly ahead of the amphipod (Lowry, 1986). The male Phronima sp. callynophore shows a dense concentration of aesthetascs, while the female callynophore has 10-14 aesthetascs inserted longitudinally along the medial surface (Fig. 4B,F).

Distributional pattern of sensory hairs

The sensilla occur in a bilaterally symmetrical pattern in all three genera. There was very little variation in the patterns between the different individuals, species or sexes examined. In fact, there was a pronounced 
constancy to the detailed distribution of the sensilla between the different individuals. In many other crustaceans the number and size of the sensilla varies with the size and maturity of the specimen (Thomas, 1970; Hamilton, 1983; Laverack and Barrientos, 1985). The maps here show the general pattern of distribution of the sensilla on the dorsal surface of the three genera (Figs. 5,6,7,). Each symbol does not necessarily represent one individual sensilla, but is positioned to represent the general location, density and pattern of the sensilla on the dorsal surface of the exoskeleton.

Phronima sedentaria

Only female specimens were examined (Fig. 5A). Two rows of multiple branched (Type $4 \mathrm{~b}$ ) hairs are located on the median dorsal surface of the cephalon between the pair of dorsal eyes but do not extend down along the frontal face of the cephalon. Branched hairs are also found on the pereon, pleon, urosome and telson (Fig. 5B,C,E,F,G). They are approximately $20 \mu \mathrm{m}$ long and may have multiple branches (Fig. 3E). The rim of the pores may be asymmetrical with a slightly raised edge along one side. Simple setae (Type 3) are found on the first pereonite and the pleon (Fig. 5D). These setae may be up to $50 \mu \mathrm{m}$ in length and appear to have an apical pore.

Lycaea spp.

Male and female specimens of $\underline{L}$. nasuta and $\underline{L}$. vincentii were surveyed (Fig. 6A). Branched bifed hairs (Type 4a) occur on every segment of the dorsal surface of Lycaea (Fig. 6B-G). These sensilla are approximately $20 \mu \mathrm{m}$ in length, branching $5 \mu \mathrm{m}$ from the base. The exoskeletal pore has an asymmetrical raised edge (bump) with an opening from 1 to $2 \mu \mathrm{m}$ in diameter. This bump is medially placed on the sensilla that are located along the dorsal medial line. 


\section{Vibilia spp.}

Male and female specimens of $\underline{V}$. jeangarardi and $\underline{\mathrm{V}}$. viatrix were surveyed (Fig. 7A). Three different types of sensilla were found on the dorsal surface. Fluted hairs (Type 2) were found along the dorsal midline of the pereon and pleon (Fig. 7B,E,F,G); and, in small arrays on urosomites 2-3 and the telson. Simple hairs (Type 3) were found on the cephalon (Fig. 7C), various segments of the pereon, the dorsal medial line of the first urosomite, anterior lateral line of urosomite 2-3 (females only) and the lateral edge of the telson. These sensilla are approximately $15 \mu \mathrm{m}$ in length and appear to have an apical pore. The exoskeletal pore of these simple hairs is approximately $4 \mu \mathrm{m}$ in diameter and has a raised edge with a pronounced bump usually along the medial side of the pore. Branched hairs (Type 4a) are found on the pereon, pleon and urosome (Fig. 8B,E,F,H). These sensilla are from 20 to $50 \mu \mathrm{m}$ in length and become bifid 8 to $10 \mu \mathrm{m}$ from the base (Fig. 3C). The exoskeletal pore has an asymmetrical raised edge (bump) with a pore opening approximately $2 \mu \mathrm{m}$ in diameter. This bump is medially placed on the sensilla that are located along the dorsal medial line. Peg-like hairs (Type 5) are irregularly distributed along the lateral surface of the pereonites and pleonites (Figs. 3F,7H). There is no obvious rimmed pore from which they emerge from the exoskeleton. The number of sensilla was greater in the anterior pereonites and decreased in more posterior segments of the pereon and pleon. 


\section{Discussion}

Sensilla on the body of the hyperiids described here as well as in copepods and other crustaceans, are generally distributed in bilaterally symmetrical patterns that are repeated on successive body segments (Figs. 68 ), i.e. they appear to be homologous (Fleminger, 1973; Mauchline and Ballentyne, 1975; Mauchline, 1977). Developmental studies have shown that the numbers and sizes of setae on the appendages of decapods are related to the individuals' sizes (Hamilton, 1883) and that the density or diversity of setae may change with successive instars (Thomas, 1973; Factor, 1978) or molts (Hamilton, 1983b). Within the three genera of hyperiids there was very little variation in pattern between individuals of the same species, but they had noticeably fewer sensilla than gammarid amphipod species that have been described (Mauchline and Ballentyne, 1977; Cuadras, 1982). In females of Vibilia there tended to be a greater number of simple (Type 3) hairs on the urosomites than on the males.

The density of aesthetascs on the antennules differed dramatically between the males and females of Lycaea and Phronima but not Vibilia (Fig.5). Lowry (1982) suggested four possible functions for the aesthetascs composing the callynophore: detection of sexually receptive females, detection of carrion in demersal scavengers, prey detection in predators and host detection in parasitoids. Any of these functions suggested by Lowry (1982) may apply to hyperiids although none of the three genera are known to be scavengers but are clearly parasitoids (Laval, 1980). The sexual dimorphism in the antennules of Phronima and Lycaea suggests a sex (pheromone) detection function. The salp hosts solve many survival problems for the hyperiids and their presence appears to be required for 
completion of the hyperiid's life cycle (Madin and Harbison, 1977).

Detection of the correct salp host in the plankton would appear to be a likely role for the chemosensory callynophore.

There were also differences between the three genera in the distribution of sensilla on the dorsal surface of the exoskeleton. Phronima had the fewest number of sensilla on the surface of the dorsal exoskeleton when compared with Lycaea and Vibilia. The map of Phronima by Mauchline and Ballantyne (1975) showing the distribution of integumentary sensilla differs from Fig. 6 in this paper in that they show a greater number of sensilla present on the dorsal exoskeleton. This may be due in part to the difference in molt stage examined as at each molt stage there is an increase in sensilla (Laverack, 1976, 1978; Spencer, 1986; Hamilton, 1983a). The pore size of the sensilla on the specimens I examined was also smaller (generally 2$6 \mu \mathrm{m}$ ) rather than $8 \mu \mathrm{m}$ size that Mauchline and Ballentyne (1975) mapped, possibly indicating that I examined younger specimens. The presence of sensilla may have been obscured by encrustation or abrasion, however even if the sensilla on the specimens I examined were so abraded that only their bases remained the integumentary pore was obvious.

Lycaea has only one hair type (Type 4a) distributed on every segment of the dorsal surface of the exoskeleton (Fig. 7). Vibilia has both the greatest diversity and density of sensilla on the dorsal exoskeleton (Fig. 8). The peglike sensilla (Type 5) are similar in morphology and general location to those found in gammarid amphipods (Cuadras, 1982) and isopods (Needham, 1942), however the ones I found on Vibilia do not arise from rimmed sockets. Based on their distribution, organization and relationship with larger sensilla Cuadras (1982) suggests that these peg-like sensilla are specialized in detection of slow or weak water currents and may be analogous 
to the "microtrich system" (peg-like sensilla) of isopods (Needham, 1942) and the integumental scales of shrimp (Mauchline et al., 1977).

Laverack (1987) has classified sensory receptors on crustaceans as being either chemoreceptors, mechanoreceptors, or bimodel receptors. Chemoreceptors have dendrites of the sensory neurons that ascend into the shaft of the seta (eg Grünert and Ache, 1987) and contact stimulatory substances that gain access either through the wall of the cuticular hair or via apertures, usually apically or sub-terminally placed, or through porous canals in the cuticle. Mechanoreceptors have sensory neurons that are attached to the base of the projecting hairs (eg Felgenhauer and Abele, 1983). Deflection of such setae leads to depolarization, and stimulation of the afferent neurons. Bimodal or combined receptors are a combination of chemo- and mechanoreceptors in the same hair. In this case the spatial relationships of the two types of sensors are as previously defined, but are both represented in the same structure. In some cases it seems that the mechanoreceptors may ascend the hair shaft rather than end at the basal insertion (Laverack, 1987).

Atema (1977) proposed a consideration of the function of the chemical senses with regard to their role in survival. Two functional domains were separated: 1) food localization and feeding mediated by localized reflex actions; and, 2) complex behavioral patterns such as host and sex recognition. In crustaceans, the organs which serve these functions seem to be localized on different body regions or appendages; those for food handling on dactyls and maxillipeds and those for detection of mates or hosts on antennules (Altner and Prillinger, 1977). Table $I$ is an attempt to compare these functions with what is known about the different morphological and physiological characteristics of sensory hairs that have been described on the dorsal and 
lateral surfaces of crustaceans. The available data suggests that sensilla which are purely chemoreceptive or mechanoreceptive are at opposite ends of the descriptive continuum in Table I. Bimodal hairs tend to possess characteristics intermediate between chemosensory and mechanosensory hairs. For example, based on their external morphology and location the fluted hairs (Type 2) and simple hairs (Type 3) may be bimodal receptors. Such interpretations must be treated with caution and Table I should be considered an "in progress" attempt to catagorize these sensory hairs. Surveys of sensilla provide useful information to taxonomists, functional morphologists, and physiologists. Using the external morphology of sensilla for taxonomic or functional purposes must be viewed with caution as some structural variations may reflect only differences between molt and developmental stages (Hamilton, 1983b). Only through combined physiological and ultrastructural studies of single sensilla as have been done for insects (Altner and Prillinger, 1980) can the functional or adaptive significance of inter- or intraspecific differences between sensilla be determined. This study is unique in that it not only describes the different morphological types of sensilla but it also maps their location on the animals. When combined with ultrastructural, physiological and behavioral studies this study should provide a framework in which to determine the function of sensilla and their taxonomic potential. 


\section{Literature Cited}

Ache, B. W. 1982. Chemoreception and thermoreception. In: The biology of Crustacea Vol. 3 (H. L. Atwood and D. C. Sandeman eds.) . Academic Press, New York. Pp. 369-398.

Altner, H. and L. Prillinger. 1977. Ultrastructure of invertebrate chemo-, thermo-, and hygroreceptors and its functional significance. Int. Rev. Cytol. 67: 69-139.

Altner, I., H. Hatt, and H. Altner. 1983. Structural properties of bimodal chemo and mechanosensitive setae on the pereiopod chelae of the crayfish, Austropotamobius torrentium. Cell. Tiss. Res. 228: 357374.

Ball, E. E. 1977. Fine structure of the compound eyes of the midwater amphipod Phronima in relation to behavior and habitat. Tiss. and Cell 9: 521-536.

Ball, E. E. and A. N. Cowan. 1977. Ultrastructure of the antennal sensilla of Acetes (Crustacea, Decapoda, Natantia, Sergestidae). Phil. Trans. Roy. Soc. B 277: 429-456.

Barrientos-Chacon, Y. 1984. The dorsal organ and other cuticular structures in larval and adult Crustacea: An ultrastructural study. Ph.D. thesis: The University, St. Andrews, Scotland.

Bauer, R. T. 1975. Grooming behavior and morphology of the caridean shrimp Pandalus danae Stimpson (Decapoda: Natantia: Pandalidae). Zoo..J. Linn. Soc. 56: 45-71.

Bauer, R. T. 1981. Grooming behavior and morphology in the decapod Crustacea. J. Crust. Biol. I:153-173. 
Blades-Eckelbarger, P. and M. Youngbluth. 1984. The ultrastructure of oogenesis and yolk formation in Labidocera aestiva (Copepoda:

Calanoida). Journal of Morphology 179: 33-46.

Cuadras, J. 1982. Microtrichs of amphipod Crustacea. Morphology and distribution. Mar. Beh. and Physiol. 8: 333-343.

Dahl, E. 1973. Antennal sensory hairs in talitrid amphipods (Crustacea). Acta. Zool. (Stockholm) 54: 161-171.

Derby, C. D. 1982. Structure and function of cuticular sensilla of the lobster Homarus americanus. J. Crust. Biol. 2(1): 1-21.

Diebel, C. E. 1988. Observations on the anatomy and behavior of Phronima sedentaria (Forskål)(Amphipoda: Hyperiidea). J. Crust. Biol.

Felgenhauer, B. E., and F. R. Schram. 1978. Differential epibiont fouling in relation to grooming behavior in Palaemonetes kadiakensis. Fieldiana, Zool. 72" 83-100.

Fleminger, A. 1973. Pattern, number, variability, and taxonomic significance of integumental organs (sensilla and glandular pores) in the genus Eucalanus (Copepoda, Calanoida). Fishery Bulletin 71: 965- 1010.

Fleminger, A. 1985. Dimorphism and possible sex change in copepods of the family Calanidae. Mar. Biol. 88: 273-294.

Ghiradella, H. T., J. F. Case, and J. Cronshaw. 1968. Structure of aesthetascs in selected marine and terrestrial decapods.

Chemoreceptor morphology and environment. Am. Zool. 8: 603-621.

Ghiradella, H. T., J. Cronshaw, and J. F. Case. 1968. Fine structure of the aesthetasc hairs of Pagurus hirsutiusculus Dana. Protoplasma 66: 120. 
Grünert, U., and B. W. Ache. 1988. Ultrastructure of the aesthetasc (olfactory) sensilla of the spiny lobster, Panulirus argus. Cell and Tiss. Res. 251 (1): 95-103.

Guse, G-W. 1978. Antennal sensilla of Neomysis integer (Leach). Protoplasma 95: 145-161.

Guse, G-W. 1979. Feinstruktur der aesthetasken von Neomysis integer (Leach) (Crustacea, Mysidacea). Zool. Jb. Jena 203: 170-176.

Guse, G-W. 1983. Ultrastructure, development and moulting of the aesthetascs of Neomysis integer and Idotea baltica (Crustacea, Malacostraca). Zoomorph. 103: 121-133.

Hallberg, E., H. L. Nilsson and R. Elofsson. 1980. Classification of amphipod compound eyes - the fine structure of the ommatidial units (Crustacea, Amphipoda). Zoomorph. 94: 279-306.

Hamilton, K. A. 1983a. A topographical and typological comparison of the rodlike setae of ambulatory dactylopodites in decapod crustaceans. J. of Morph. 176: 351-364.

Hamilton, K. A. 1983b. Postlarval changes in the external morphology of dactyl setae in the kelp crab, Pugettia producta (Randall). J. of Exp. Zool. 226: 353-361.

Hamilton, K. A., K. A. Linberg and J. F. Case. 1985. Structure of dactyl sensilla in the kelp crab, Pugettia producta. J. Morph. 185: 349-366.

Heimann, P. 1984. Fine structure and molting of aesthetasc sense organs on the antennules of the isopod, Asellus aquaticus (Crustacea). Cell and Tiss. Res. 235: 117-128. 
Juberthie-Jupeau, L. and Y. Crouau. 1977. Ultrastructure des aesthetascs d'un Mysidace souterrain anophthalme. C. R. Acad. Sci. Paris 284: 2257-2259.

Land, M. F. 1981. Optics of the eyes of Phronima and other deep-sea amphipods. J. Comp. Physiol. 145: 209-226.

Laverack, M. S. 1962. Responses of cuticular sense organs of the lobster Homarus. I. Hair peg organs as water current receptors. Comp. Biochem. Physiol. 5: 319-325.

Laverack, M. S. 1987. The nervous system of the Crustacea, with special reference to the organisation of the sensory system. In: Nervous systems of the invertebrates (M. A. Ali, ed.). Proceedings, NATOASI, Lennoxville, Canada. Springer-Verlag, Berlin. pp. 1-30.

Laverack, M. S. 1988. The diversity of chemoreceptors. In: Sensory Biology of Aquatic Animals, J. Atema, R. R. Fay, A. N. Popper, and W. N. Tavolga (eds.). Springer-Verlag, New York. pp. 287-312. Laverack, M. S. and D. J. Ardill. 1965. The innervation of the aesthetasc hairs of Panulirus argus. Quart. J. Micr. Sci. 106: 45-60.

Laverack, M. S., and Y. Barriantos. 1985. Sensory and other superficial structures in living marine Crustacea. Trans. R. Soc. of Edin. 76: 123136.

Lowry, J. K. 1986. The callynophore, a eucaridan/peracaridan sensory organ prevalent among the Amphipoda (Crustacea). Zoo. Scrip. 15333-349.

Mauchline, J. 1977. The integumental sensilla and glands of pelagic Crustacea. J. mar. biol. Ass. U. K. 57: 973-994.

Mauchline, J. and A. R. S. Ballantyne. 1975. The integumental organs of amphipods. J. mar. biol. Ass. U. K. 55: 345-355. 
Mellon, D. 1963. Electrical responses from dually innervated tactile receptors on the thorax of crayfish. J. Exp. Biol. 40: 137-148.

Meyer-Rochow, V. B. 1978. The eyes of mesopelagic crustaceans II. Streetsia challengeri (Amphipoda). Cell Tiss. Res. 186: 337-349.

Needham, A. E. 1942. Microanatomical studies on Asellus. Q. J. Micros. Sci. London 84: 44-71.

Nilsson, D. E. 1982. The transparent compound eye of Hyperia (Crustacea): Examination with a new method for analysis of refractive index gradients. J. comp. Physiol. 147: 339-349.

Reynolds, E. S. 1963. The use of lead citrate at high $\mathrm{pH}$ as an electron opaque stain in electron microscopy. J. Cell Biol. 17: 208-212.

Risler, H. 1977. Die sinnesorgane der antennula von Porcellio scaber (Crustacea, Isopoda). Zool. Jb. Anat. 98: 29-52.

Risler, H. 1978. Die sinnesorgane der antennula von Ligidium hypnorum (Cuvier) (Isopoda, Crustacea). Zool. Jb. Anat. 100: 514-541.

Shelton, R. G. J., and M. S. Laverack. 1968. Observations on a redescribed crustacean cuticular sense organ. Comp. Bio. and Phys 25: 10491059.

Shelton, R. G. J., and M. S. Laverack. 1970. Receptor hair structure and function in the lobster Homarus gammarus (L.). J. Exp. Mar. Biol. Ecol. 4: 201-210.

Snow, P. J. 1973. Ultrastructure of the aesthetasc hairs of the littoral decapod Paragrapsus gaimardii. Z. zellforsch. 138: 489-502.

Snow, P. J. 1974. Surface structures of the antennal flagella of the hermit crab Pagurus alaskensis (Benedict): A light and scanning electron microscopy study. J. Morph. 144: 195-216. 
Spencer, M. 1986. The innervation and chemical sensitivity of single aesthetasc hairs. J. Comp. Physiol. A 158: 59-68.

Steele, V.J. and P. E. Oshel. 1987. The ultrastructure of an integumental microtrich sensillum in Gammarus setosus (Amphipoda). J. Crus. Biol. 7(1): 45-59.

Szuts, S. O., and J. Atema. 1977. Chemical senses of the lobster, $\underline{\text { Homarus }}$ americanus: fine structure of aesthetasc hairs. In: Workshop on lobster and rock lobster ecology and physiology (B. F. Phillips and J. S. Cobb, eds). Commonwealth Scientific and Industrial Research Organization, Melbourne, Australia. Div. Fish. Ocean. Circ. No. 7: 16-17.

Vedel, J. P. and Clarac, F. 1976. Hydrodynamic sensitivity by cuticular organs in the rock lobster Panilurus vulgaris. Morphological and Physiological aspects. Mar. Behav. Physiol. 3: 235-251.

Wiese, K. 1976. Mechanoreceptors for near field water displacements in crayfish. J. Neurophysiol. 39: 816-833.

Watson, M. L. 1958. Staining of tissue sections for electron microscopy with heavy metals. II. Application of solutions containing lead and barium. J. Biophys. Biochem. Cytol. 4: 727-729. 


\section{List of Figures}

Figure 1. General ecology of three genera of hyperiid amphipods: Phronima, Lycaea, Vibilia .

Figure 2. A. Aesthetascs on antennule of female Phronima sedentaria, X2200. B. Aesthetascs on antennule of male Lycaea vincentii, X5000. C. Aesthetascs on antennule of Vibilia jeangarardi,X4500. D. Aesthetascs on terminal article of flagellum of male Lycaea vincentii, X5000. E. Row of fluted hairs (Type 2) on mid-dorsal line of pereonite of female Vibilia jeangarardi, X6000. F. Simple hair with apical pore on urosome of female Vibilia jeangarardi, X7000.

Figure 3. A. Bifid hair (Type 4a) on third urosomite of male Lycaea vincentii, X4700. B. Bifid hair (Type 4a) on dorsal midline of eye of male Lycaea vincentii, X9000. C. Bifid hair (Type 4a) on pereonite 4 of female Vibilia jeangarardi, X6000. D. Multiple branched hairs (Type 4b) on base of antennules of male Vibilia viatrix, X650. E. Multiple branched hair on urosomite of female Phronima sedentaria, X2500. F. Peg-like hair on urosome of female Vibilia jeangarardi, X11,000.

Figure 4. A. Antennules of male and female Lycaea. B. Antennules of male and female Phronima. C. Antennules of male and female Vibilia. D. Medial side of antennule of female Vibilia jeangarardi, showing rows of aesthetascs, X180. E. Lateral side of antennule of male Vibilia viatrix, X140. F. Antennule of female Phronima sedentaria, 160X. G. Antennule of male Lycaea vincentii, X260. H. Antennules of female Lycaea, X400. 
Figure 5. A. Distribution of sensilla on Phronima sedentaria. B. Multiple branched hairs on pleonite X2,600. C. Multiple branched hairs on dorsal midline of pereonite X3,600. D. Overview of urosomite 2-3, X270. E. Simple hairs on pleonite 3, 630X. F. Telson showing two multiple branched hairs, X300. G. Close-up of multiple branched hairs on telson, X900.

Figure 6. A. Distribution of sensilla on Lycaea . B. Dorsal mid-line of eye on male Lycaea vincentii showing two rows of bifid hairs, X200. C. Close up of B showing two rows of bifid hairs, X1500. D. Dorsal mid-line of pereon on female Lycaea nasuta with bifid hairs, X2000. E. Coxal plate of pereonite 6 on female Lycaea showing a single bifid hair, X350. F. Field of bifid hairs on urosomite 2-3 of male Lycaea vincentii , X350. G. Telson showing " $V$ " arrangement of bifid hairs on male Lycaea vincentii , X200.

Figure 7. A. Distribution of sensilla on Vibilia (antennules not shown). B. Rows of fluted hairs on pereonite 1 of male Vibilia viatrix , X1200. C. Cephalon and antennules of male Vibilia viatrix , X70. D. Overview of pereon showing mid-dorsal line of sensilla on male Vibilia viatrix , X50. E. Mid-dorsal rows of hairs on pereonite 5 of female Vibilia jeangarardi, X300. F. Mid-dorsal rows of hairs on pereonite 3 of male Vibilia viatrix, X250. G. Overview of urosomite 2-3 and telson showing fields of fluted hairs on male Vibilia viatrix , X140. H. Field of bifid and peg-like hairs on urosomite 3 of male Vibilia viatrix , X2500. 
Figure 1. General ecology of three genera of hyperiid amphipods: Phronima ,Lycaea , Vibilia . 


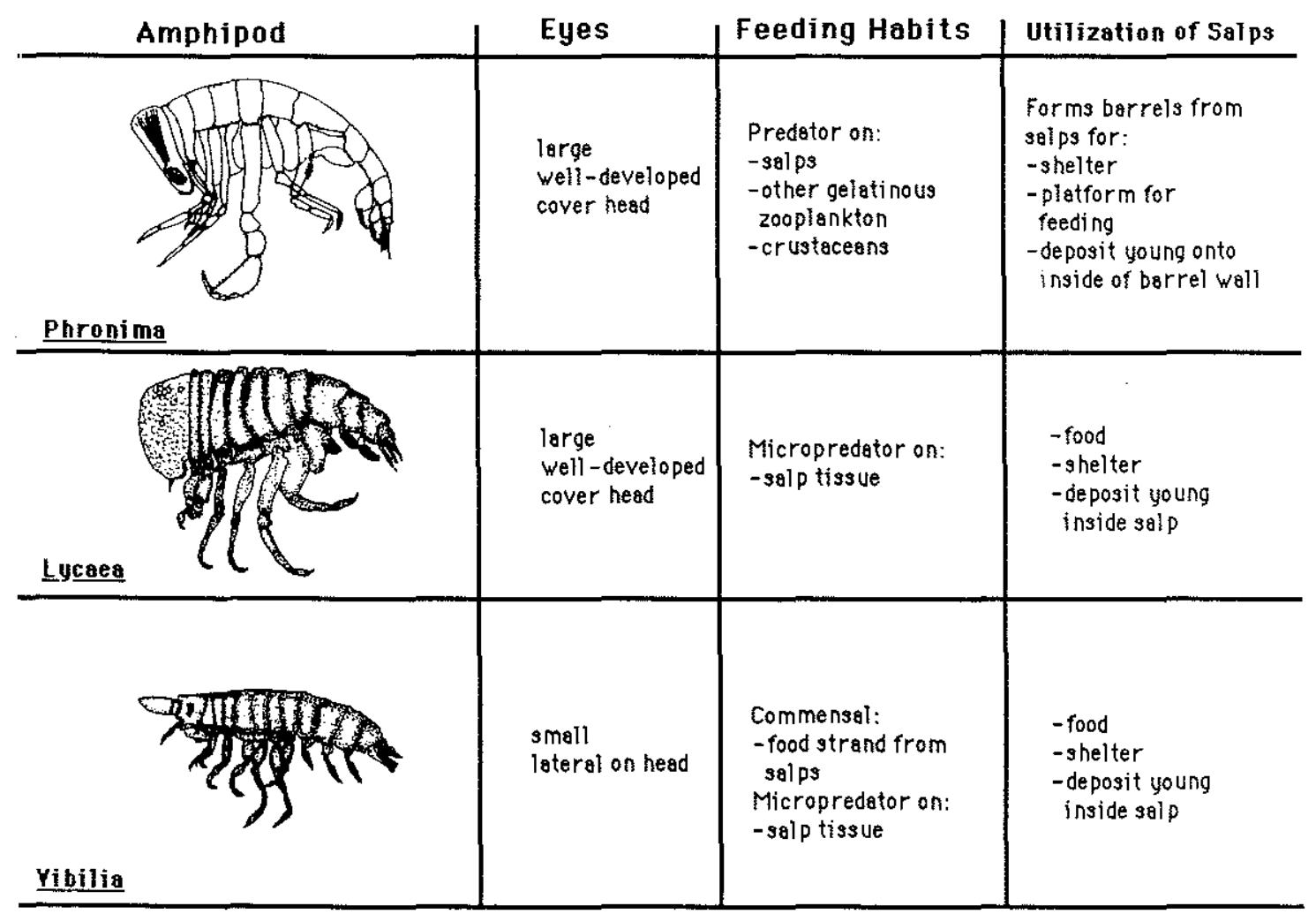

Figure 1. General ecology of three genera of hyperiid amphipods Phronims, Lycaeg, and Vibilia. 
Figure 2. A. Aesthetascs on antennule of female Phronima sedentaria, X2200. B. Aesthetascs on antennule of male Lycaea vincentii, X5000. C. Aesthetascs on antennule of Vibilia jeangarardi,X4500. D. Aesthetascs on terminal article of flagellum of male Lycaea vincentii, X5000. E. Row of fluted hairs (Type 2) on mid-dorsal line of pereonite of female Vibilia jeangarardi, X6000. F. Simple hair with apical pore on urosome of female Vibilia jeangarardi, X7000. 

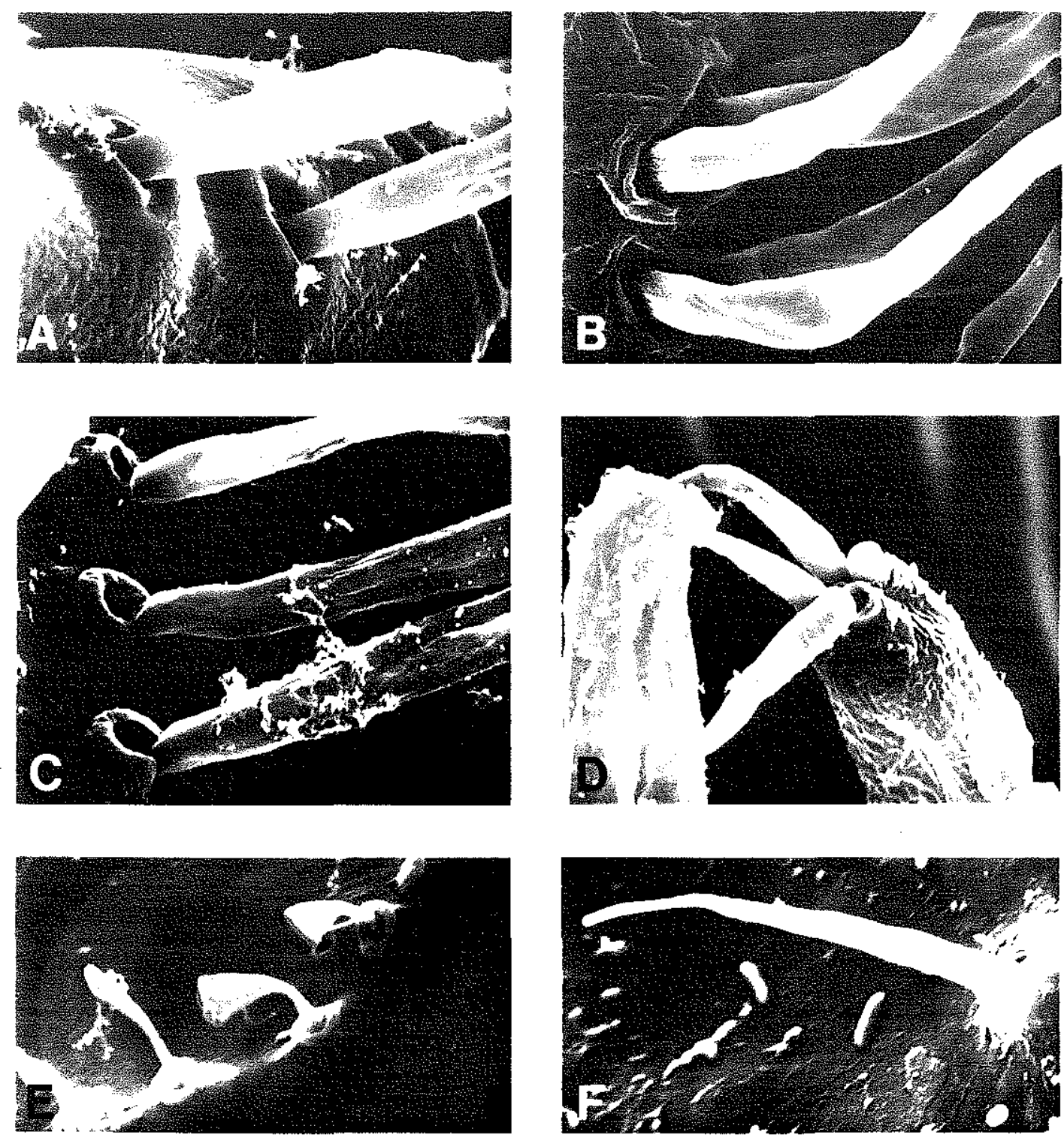
Figure 3. A. Bifid hair (Type 4a) on third urosomite of male Lycaea vincentii, X4700. b, bifed hair. B. Bifid hair (Type 4a) on dorsal midline of eye of male Lycaea vincentii, X9000. C. Bifid hair (Type 4a) on pereonite 4 of female Vibilia jeangarardi, X6000. D. Multiple branched hairs (Type $4 \mathrm{~b}$ ) on base of antennules of male Vibilia viatrix, X650. mb, multiple branched hair. E. Multiple branched hair on urosomite of female Phronima sedentaria, X2500. ep, epiphitic growth. F. Peg-like hair on urosome of female Vibilia jeangarardi, $\mathrm{X} 11,000$. 

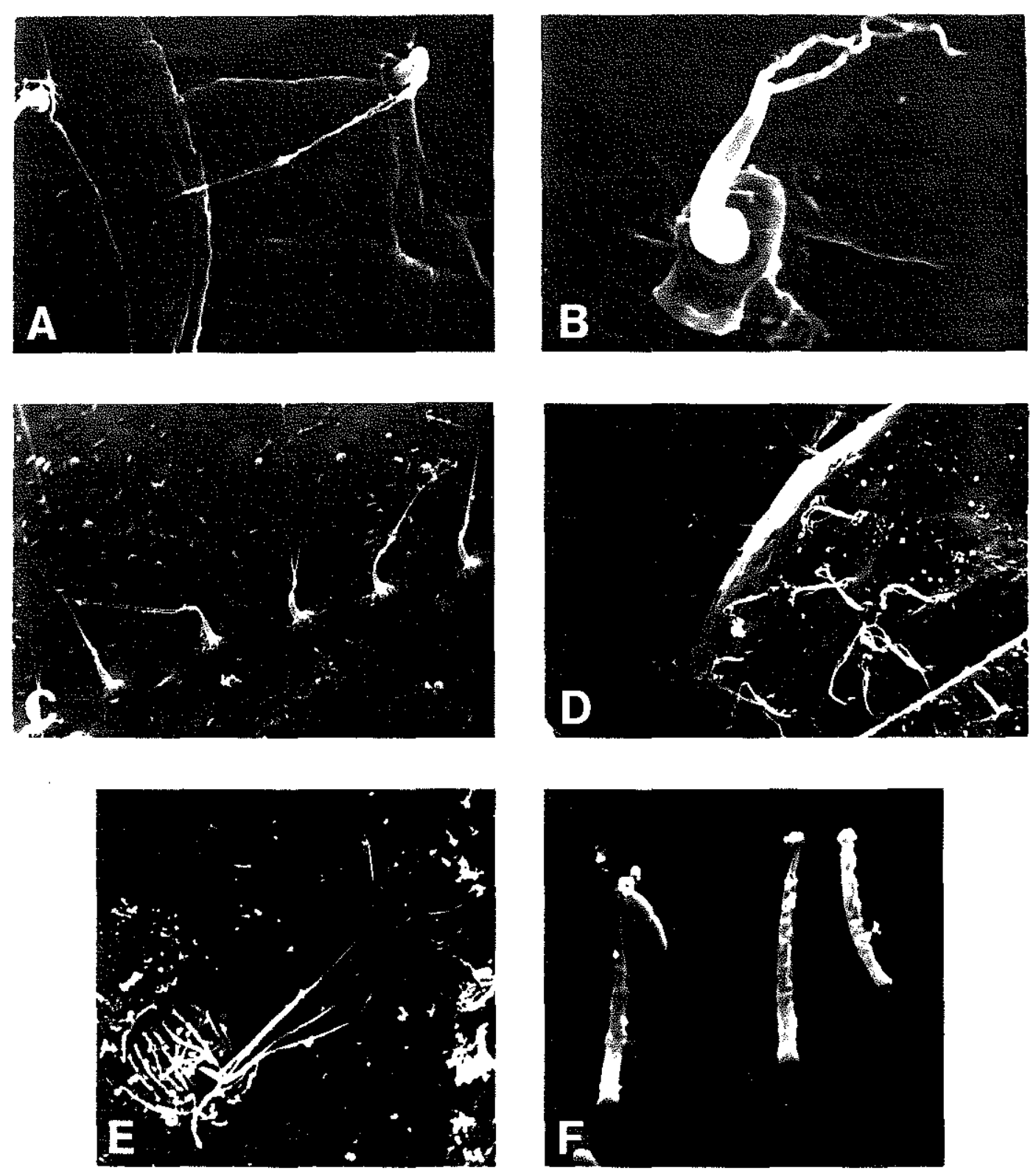

62 
Figure 4. A. Antennules of male and female Lycaea. B. Antennules of male and female Phronima. C. Antennules of male and female Vibilia. D. Medial side of antennule of female Vibilia jeangarardi, showing rows of aesthetascs, X180. E. Lateral side of antennule of male Vibilia viatrix, X140. F. Antennule of female Phronima sedentaria, 160X. G. Antennule of male Lycaea vincentii, X260. H. Antennules of female Lycaea, X400. 


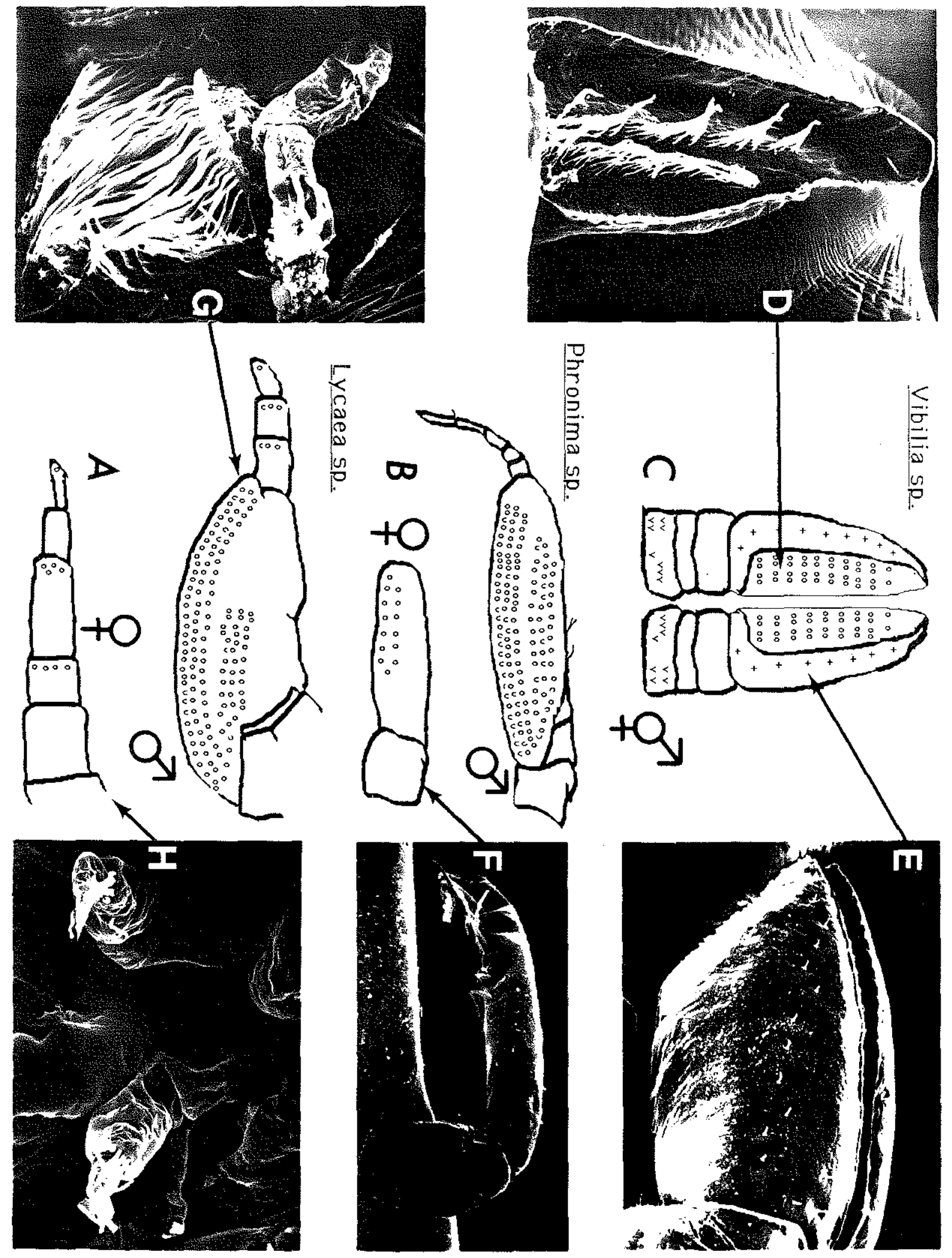


Figure 5. A. Distribution of sensilla on Phronima sedentaria. B. Multiple branched hairs on pleonite X2,600. C. Multiple branched hairs on dorsal midline of pereonite $\mathrm{X}, 600$. D. Overview of urosomite 2-3, X270. E. Simple hairs on pleonite 3,630X. F. Telson showing two multiple branched hairs, X300. G. Close-up of multiple branched hairs on telson, X900. 


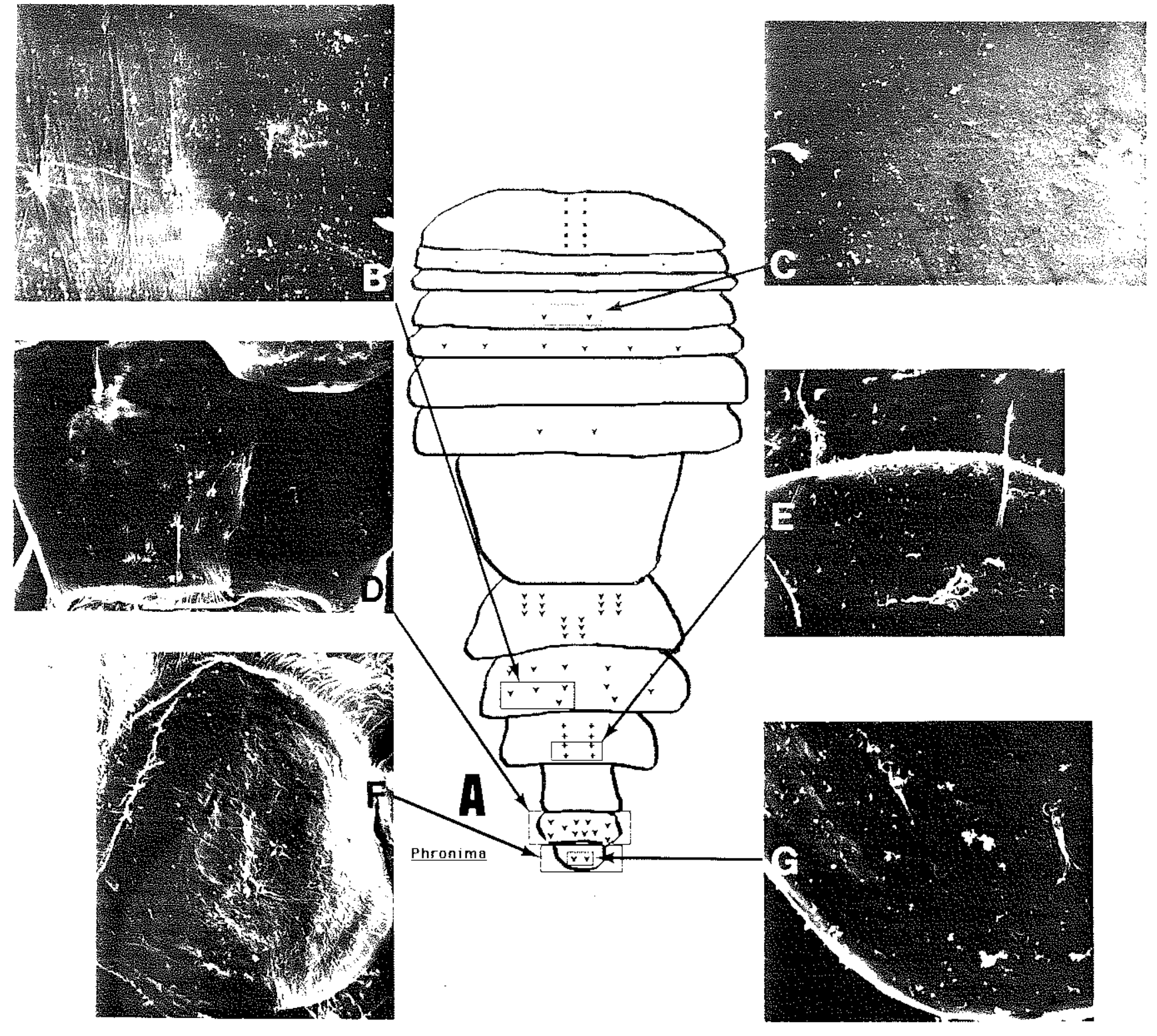


Figure 6. A. Distribution of sensilla on Lycaea . B. Dorsal mid-line C. Close up of B showing two rows of bifid hairs, X1500. D. Dorsal mid-line of pereon on female Lycaea nasuta with bifid hairs, X2000. E. Coxal plate of pereonite 6 on female Lycaea showing a single bifid hair, X350. F. Field of bifid hairs on urosomite 2-3 of male Lycaea vincentii , X350. G. Telson showing "V" arrangement of bifid hairs on male Lycaea vincentii , X200. 


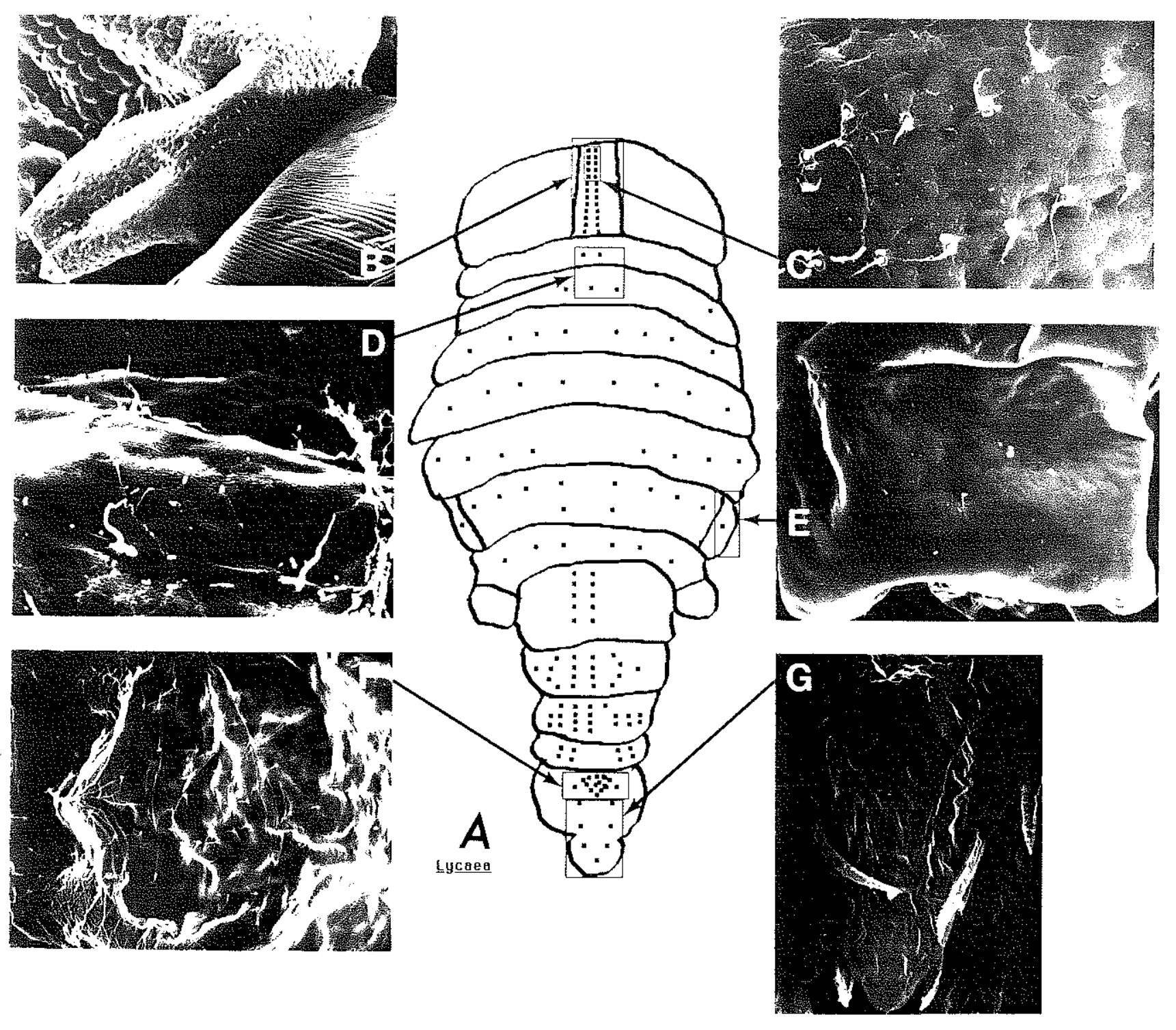


Figure 7. A. Distribution of sensilla on Vibilia (antennules not shown). B. Rows of fluted hairs on pereonite 1 of male Vibilia viatrix , X1200. C. Cephalon and antennules of male Vibilia viatrix, $X 70$. D. Overview of pereon showing mid-dorsal line of sensilla on male Vibilia viatrix , X50. E. Mid-dorsal rows of hairs on pereonite 5 of female Vibilia jeangarardi, X300. F. Mid-dorsal rows of hairs on pereonite 3 of male Vibilia viatrix , X250. G. Overview of urosomite 2-3 and telson showing fields of fluted hairs on male Vibilia viatrix, $\mathrm{X} 140$. H. Field of bifid and peg-like hairs on urosomite 3 of male Vibilia viatrix , X2500. 


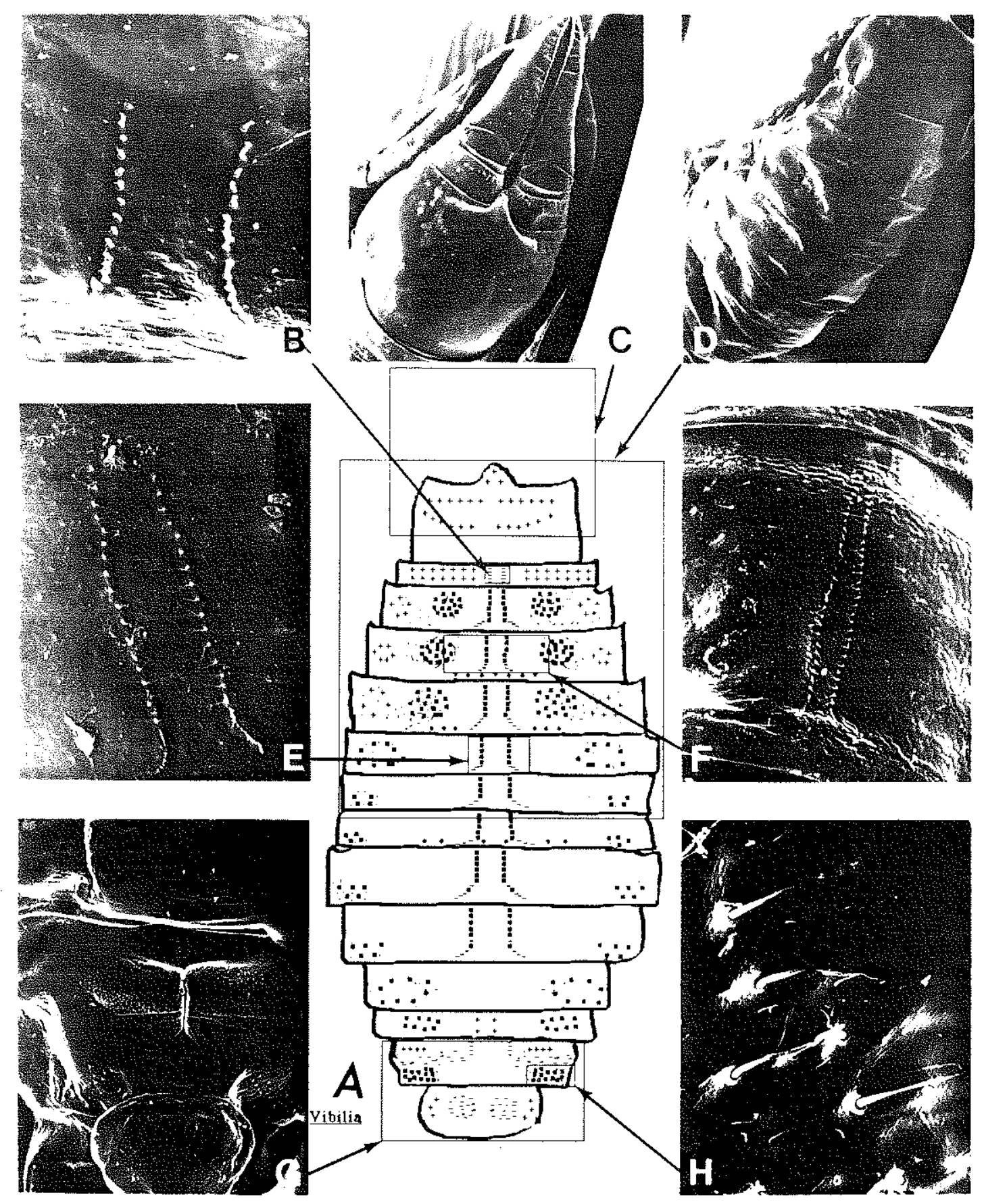


Table 1. Five morphological tupes of sensills found on the antennules and dorsal exoskeieton of Phronims, Vibilia and Lycseg. The symbols assigned to each morphological type are used in the maps of each genera.

\begin{tabular}{|c|c|c|c|c|c|}
\hline Sensory Hairs & Length (쓰) & Position on Body. & Genera & Probable Function & Symbol \\
\hline $\begin{array}{l}\text { AESTHETASCS } \\
\text { Fig. } 2 A, B, C, D\end{array}$ & $50-200$ & antennules & $\begin{array}{l}\text { Phronima } \\
\text { Lycaes } \\
\text { Yibilio }\end{array}$ & Chemosensory & $\begin{array}{r}\text { Type } 1 \\
0\end{array}$ \\
\hline $\begin{array}{l}\text { FLUTED HAIRS } \\
\text { Fig. } 2 E\end{array}$ & 5 & $\begin{array}{l}\text { pereon } \\
\text { plean } \\
\text { urosome } \\
\text { telson }\end{array}$ & Yibilio & $?$ & Type 2 \\
\hline $\begin{array}{l}\text { SIMPLE } \\
\text { Fig. } 2 F\end{array}$ & $10-50$ & $\begin{array}{l}\text { antennules } \\
\text { cephalon } \\
\text { pereon } \\
\text { pleon } \\
\text { telson }\end{array}$ & $\begin{array}{l}\text { Phronime } \\
\text { Yibilig }\end{array}$ & $?$ & Type 3 \\
\hline $\begin{array}{l}\text { BRANCHED: } \\
\text { A) bifed } \\
\text { Fig. } 3 A, B, C\end{array}$ & $15-50$ & $\begin{array}{l}\text { cephalon } \\
\text { pereon } \\
\text { pleon } \\
\text { urosome } \\
\text { telson }\end{array}$ & $\begin{array}{l}\text { Phronimg } \\
\text { Lycaes } \\
\text { Yibilia }\end{array}$ & Mechenosensory & Type 4a \\
\hline $\begin{array}{l}\text { B) multiple } \\
\text { Fig. } 30, E\end{array}$ & $15-50$ & $\begin{array}{l}\text { antennule bese } \\
\text { pereon } \\
\text { pleon } \\
\text { urosome } \\
\text { telson }\end{array}$ & $\begin{array}{l}\text { Phronims } \\
\text { Yibilis }\end{array}$ & Mechenosensory & $\begin{array}{c}\text { Type 4b } \\
V\end{array}$ \\
\hline $\begin{array}{l}\text { PEG-LIKE } \\
\text { fig. } 3 F\end{array}$ & $2-6$ & $\begin{array}{l}\text { pereon } \\
\text { pleon }\end{array}$ & Vibilia & $\begin{array}{c}? \\
\text { Mechanosensory }\end{array}$ & $\begin{array}{c}\text { Type } 5 \\
-\end{array}$ \\
\hline
\end{tabular}


Table II Morphological characteristics of crustacean sensory hairs. Numbers below receptor type represent recognizable stages in morphological continuum between chemosensors and mechanosensors.

\section{RECEPTOR TYPE}

CHEMOSENSORY

BIMODAL

MECHANOSENSORY

1

2

3

4

5

Location:

antennules

mouthparts,

pereopods

mouthparts, pereopods,

mouthparts,

antennules,

carapace, antennules

antennae

pereopods

antennae,

carapace

\section{Cuticular Wall:}

flexible,

thin w/ pores

spongy

$\begin{array}{ll}\text { stiff, } & \text { stiff, } \\ \text { thick, } & \text { thick, } \\ \text { permeable tip } & \text { permeable tip }\end{array}$

stiff,

thick,

short, stout, smooth, serrate, squamous

flexible?

thick, not

permeable,

long, and

slender

\section{Socket:}

inflexible

flexible

\section{Neurons:}

$>20$

$1<\mathrm{n}<20$

$1<\mathrm{n}<20$

?

$1-4$

\section{Dendrites:}

branch,

extend into

setal lumen

do not branch

extend into

setal lumen

do not branch

extend into

setal lumen do not branch terminates at base do not branch, terminates

at base

\section{Scolopale:}

not present

$$
?
$$

$?$

? present

\section{Function:}

smell, orientation

\begin{abstract}
taste, tactile, regulate food acceptance
\end{abstract}

tactile, general arousal water movement water movement and vibration, orientation 


\section{References:}

\section{1}

Grünert and Ache, 1987 lobster

Laverack and Ardill, 1965 lobster

Snow, 1973, 1974 crab, hermit crab

Heimann, 1979, 1984 isopod

Guse, 1979, 1983 mysid

Juberthie-Jupeau and Crouau, 1977 mysid

Diebel, in prep. hyperiid amphipod

Szuts and Atema, 1977 lobster

2

Steele and Oshel, 1987 gammarid amphipod

Dahl, 1973 gammarid amphipod

Shelton and Laverack, 1968 lobster 3

Guse, 1979 mysid

Ball and Cowan, 1977 sergestid shrimp

Risler, 1978 isopod

Altner et al, 1983 crayfish 
Derby, 1982 lobster

Hamilton et al, $1985 \mathrm{crab}$

Bauer, 1975 shrimp

Cuadras, 1982 gammarid amphipod

Needham, 1942 isopod

5

Risler, 1977, 1978 isopod

Guse, 1978 mysid

Laverack, 1962 lobster

Mellon, 1963 crayfish

Wiese, 1976 crayfish

Ball and Cowan, 1977 sergestid shrimp

Hamilton et al, $1985 \mathrm{crab}$

Szuts and Atema, 1977 lobster 
75 


\section{Chapter 3}

Ultrastructure of the aesthetasc (olfactory) sensilla of the hyperiid amphipod, Vibilia spp. 


\begin{abstract}
The aesthetascs of the hyperiid amphipod Vibilia are hair sensilla located on the first segment of the antennules in distinct arrays. Each hair is about $100 \mu \mathrm{m}$ long and innervated by about 30 bipolar sensory neurons, the dendrites of which project as a bundle into the hair shaft. Each of the dendrites develops two cilia. Within a short distance these cilia increase in the number of microtubules present which separate into about 219 outer dendritc segments per hair, or about 4 branches per cilium. Inner and outer auxiliary cells surround the sensory neurons.
\end{abstract}




\section{Introduction}

Crustaceans possess a well-developed chemical sense mediated by chemosensory sensilla located on various parts of the body. Among the Eucarida and the Peracarida a sensory organ is found on the outer flagellum of the antennule that has been defined by Lowry (1986) as a "callynophore". This sense organ bears transverse rows of aesthetascs, a distinct class of sensilla clearly differing from other setae commonly found on crustaceans and which are usually grouped together in one or two longitudinal fields to form a brush. Antennular responses to chemical stimuli have been attributed to these numerous, porous, cuticular aesthetascs (Ache, 1982; Devine and Atema, 1982; Derby and Ache, 1984; Spencer, 1986; Laverack, 1987, 1988).

Species of Vibilia are hyperiid amphipods in the Superfamily Vibiliodea, that have two small eyes and broadly flattened antennules. They live inside salps, and divert food from the salp's mucous feeding strand to the

mouth (Madin and Harbison, 1977). Vibilia females will deposit their young as larvae directly onto a salp host (Laval, 1963). A recent behavioral study of Vibilia spp. demonstrates its ability to detect their salp hosts by chemosensory means(Diebel et al, in prep.). Morphological studies have shown the presence of a callynophore with fields of aesthetascs on each antennule (Lowry, 1986; Diebel, in prep.) the functions of which may include host recognition.

Studies on the fine structure of these aesthetascs help to define the specific function of these sensilla. The fine structure of aesthetascs is now known for a few species of crustaceans (for review see Heimann, 1984; Spencer and Linberg, 1986; Grünert and Ache, 1988). These studies collectively show that aesthetascs of different species have many morphological features in common, and some species-specific differences. 
There have been no previous studies on the ultrastructure of the aesthetascs on the callynophores of hyperiid amphipods. This study allows a comparison between Vibilia a representative of a planktonic crustacean group, with other published studies on benthic crustaceans. This study complements previous studies by describing the fine structure of the aesthetascs in Vibilia spp., with particular emphasis on the distal aspect of the sensilla. 
Materials and Methods

Animal Collection and Handling

All amphipods were collected with their salp hosts in individual jars bu SCUBA divers working in the top $30 \mathrm{~m}$ of water. Collections were made while on cruises in the western north Atlantic, central north Atlantic, and Tongue of the Ocean. Individuals were examined under a stereomicroscope, and identified using the keys of Bowman and Gruner (1973), Brusca (1981) and Vinogradov (1982). Dissections were performed with jewelers' forceps and fine dissecting needles.

Light Microscopy

Animals used for light microscopy were placed in a variety of fixatives incliding Bouin's, 3\% glutaraldehyde, Karnavosky's (paraformaldehydeglutaraldehyde), and $4 \%$ formalin. For paraffin sections the animals were dehydrated through an ethanol series, transferred to cedarwood oil, and infiltrated and embedded in paraffin at $56.5^{\circ} \mathrm{C}$. Serial longitudinal sections $(5-7 \mu \mathrm{m})$ were made on a rotary microtome, mounted on slides and differentially stained with Dealfields hematoxylin and eosin (Clark, 1973). Scanning Electron Microscopy

The antennules of Vibilia spp. were surveyed using scanning electron microscopy (SEM). The animals examined had been fixed on board ship by various methods described previously. Specimens were then postfixed in $2 \%$ osmium tetroxide (OsO4) in $0.2 \mathrm{~mol} / 1$ phosphate buffer ( $\mathrm{pH} 7.4$ ) for two hours at $24{ }^{\circ} \mathrm{C}$, taken through a graded dehydration, and stored in $70 \%$ ethanol at approximately $10^{\circ} \mathrm{C}$. They were then taken through the remaining ethanol series, critical point dried, mounted on stubs, coated with gold palladium, and observed in a Zeiss Novascan SEM at $15 \mathrm{kV}$. 
Transmission Electron Microscopy

Living Vibilia were fixed on board ship by immersing them individually in a paraformaldehyde-glutaraldehyde mixture (Karnovsky, $1965)$ with $0.2 \mathrm{M}$ phosphate buffer ( $\mathrm{pH} 7.4)$ at room temperature $\left(20-23^{\circ} \mathrm{C}\right)$ following the procedure used by Blades Eckelbarger and Youngbluth (1984). To facilitate rapid penetration small cuts were made on the lateral side of the first and seventh pereonite with a sharp razor. The specimens were then transferred immediately into fresh fixative and held at room temperature $\left(20-23^{\circ} \mathrm{C}\right)$ for $2-2.5 \mathrm{~h}$ and stored for several months in a refrigerator at $10^{\circ} \mathrm{C}$. Specimens were processed for embedding by first rinsing them three times in $0.2 \mathrm{M}$ phosphate buffer ( $\mathrm{pH} 7.4$ ) and postfixing in $2 \% \mathrm{OsO}_{4}(0.2 \mathrm{M}$ phosphate buffer ( $\mathrm{pH} 7.4)$ ) for $2 \mathrm{~h}$. These specimens were then dehydrated rapidly in ascending concentrations of ethanol to $100 \%$, exchanged in propylene oxide and embedded in Araldite without Dibutylphthalate (plastisizer). Thin sections were cut with a diamond knife on a LKB Ultramicrotome (Type 4802A), stained with uranyl acetate (Watson, 1958) followed by lead citrate (Reynolds, 1963), and examined with a Philips EM 301 transmission electron microscope at $60 \mathrm{kV}$. 


\section{Results}

The antennules of Vibilia spp. consist of a short three segmented peduncle $(1=700 \mu \mathrm{m})$ and a large, straight, spatuliform or conical first segment $(1=1300 \mu \mathrm{m})$ (Fig.1). The medial surface of the first segment is slightly convex in life (concave after fixation) and bears two longitudinal fields of aesthetascs (each field: $1=900 \mu \mathrm{m}, \mathrm{w}=100 \mu \mathrm{m}$ ) (Fig. 1C). It has been defined as a "callynophore by Lowry (1986). The lateral surface of the first segment is about four times as thick in cross section than the medial surface and bears rows of simple unbranched setae along the anteriorposterior axis (Fig.1B). There are also simple unbranched setae along the suture between the medial and lateral surface (Fig. 1B). The most proximal segment of the peduncle has a grouping of multiple branched setae along the ventral lateral surface and, a line traversing the dorsal lateral surface (Fig. 1B). There does not appear to be a strong sexual dimorphism in the antennules although there may be a more dense field of aesthetascs in the male (pers. obs).

The aesthetascs of Vibilia are hair-like sensilla. There are about 100 aesthetascs per antennule and, each aesthetasc is approximately $100 \mu \mathrm{m}$ long and $3 \mu \mathrm{m}$ in diameter. The sockets of the aesthetascs are similar in appearance to a keyhole (Fig. 1D), and are about $5 \mu \mathrm{m}$ in length and $3 \mu \mathrm{m}$ in width. The sockets are formed by the constriction of two raised edges in the center that may limit the aesthetascs to an anterior-posterior direction of movement.

Each aesthetasc is innervated by about 30 (24-40) bipolar sensory neurons. Their cell bodies $(1=1.5 \mu \mathrm{m}, \mathrm{w}=3 \mu \mathrm{m})$ are oriented longitudinally along the anterior-posterior axis and situated in grape-like clusters from 3-6 $\mu \mathrm{m}$ below the base of the aesthetascs (Fig.2). The axons 
from each longitudinal field of aesthetascs extend along the length of the first segment and form bundles within the peduncle of the antennule (Figs. 3A,B). Cuticle

The cuticle of the aesthetasc varies in thickness over the length of the hair (Fig. 2). From the base to about $10 \mu \mathrm{m}$ the cuticle is $0.11 \mu \mathrm{m}$ thick while over the rest of the length of the aesthetasc the cuticle is $0.017 \mu \mathrm{m}$ thick (Figs. 4B,C,D). The cuticle lacks any distinct pores along its length or in the tip region.

Dendrites

Each dendrite consists of an inner, a ciliary and an outer dendritic segment (Figs. 2,3,4). The inner dendritic segments are contained within the lanceolate first segment and terminate about $3 \mu \mathrm{m}$ below the base of the aesthetasc socket. These inner segments contain mitochondria, microtubules and ciliary rootlets (Fig. 2,3D,E). The inner dendritic segment is $0.75-1.5$ $\mu \mathrm{m}$ in diameter over its length except the terminal part which is slightly reduced in diameter $(0.4 \mu \mathrm{m})$ where the ciliary segments originate (Figs. $3 \mathrm{D}, \mathrm{E})$.

The basal bodies mark the distal end of the inner dendritic segment(Fig. 3). The basal bodies (ca 0.1-0.2 $\mu \mathrm{m}$ ) are situated in the same plane with a single rootlet that originates from each at least $1.65 \mu \mathrm{m}$ proximally and displays a weak banding (spacing about $0.04 \mu \mathrm{m}$ ) (Figs. $3 \mathrm{E}, \mathrm{F})$. Each basal body consists of nine microtubule triplets embedded in an electron-dense matrix that gives rise to a ciliary segment. The ciliary segments out of which the outer segments arise do not originate in the same plane but over a distance of at least $6 \mu \mathrm{m}$. The ciliary segments contain nine peripheral microtubule doublets with no central pairs $(9 \times 2+0$ pattern) (Fig. 3). Distally the ciliary segment increases in diameter (up to about 0.57 
$\mu \mathrm{m}$ and forms the outer dendritic segments (Fig. 3,4). The diameter of the ciliary segments varies relative to the number of microtubules they contain. The outer dendritic segment shows an increase in the number of microtubules present that separate into individual branches of microtubules at various lengths in the shaft of the aesthetasc (Fig. 4C,D). The average number of outer dendritic segments found in the aesthetasc is 219 (119-276) with an increase in number in the distal region of the aesthetasc. The outer dendritic segments may have a total length of up to $95 \mu \mathrm{m}$ within the aesthetasc. The remaining lumenal space in the aesthetasc is filled with flocculant material, Auxiliary cells and lymph space

A presumed lymph space extends from the tip of the hair to the apical ends of the inner dendritic segments (Figs. 2,3,4). Proximally it is bordered by the inner auxiliary cells; distally by the cuticle. No cellular structures were observed in the lymph space except for the outer dendritic segments. Several layers of inner auxiliary cells surround the bundle of dendrites and extend for a short distance into the hair shaft (Fig.4A,B). Many layers of outer auxiliary cells wrap the inner ones. Septate junctions occur frequently between all inner auxiliary cells just proximal to the base of the hair. No junctions were observed between inner and outer auxiliary cells. 


\section{Discussion}

The aesthetascs of the hyperiid amphipod Vibilia have morphological features similar to those described for aesthetascs of other crustaceans (see review by Heimann, 1984). These include: (1) location on the distal part (callynophore) of the antennule; (2) thin, poreless cuticle in the distal region of the hair; (3) innervation by large numbers of sensory cells (>20); (4) absence of a dendritic sheath; (5) two ciliary segments per sensory cell; and (6) outer dendritc segments with multiple microtubules developing along their length. Recent studies of aesthetascs on decapods (Bauchau and Passelecq-Grin, 1984; Spencer and Linberg, 1986; Tierney et al., 1986; Grünert and Ache, 1988) and an isopod (Heimann, 1984) confirm these features. This study, as well as others (Grünert and Ache, 1988; Spencer and Linberg, 1986) also show that aesthetascs have distinct ciliary rootlets, a feature that has traditionally been correlated with mechanosensitivity in crustacean sensilla (Altner et al., 1983; Schmidt and Gnatzy, 1984).

For a number of insect sensilla not only the fine structure is known but the appropriate function also established by electrophysiological methods (cf. review by Altner and Prillinger, 1980). Altner and Prillinger (1977) compare the aesthetascs of four decapod species that live in different ecological niches and were not able to correlate structure with ecological conditions. Indeed, they state that the present state of knowledge of crustacean chemosensory organs -structure as well as function- is extremely low.

Only a few studies have been done on crustaceans that confirm the function of aesthetascs as chemosensory. Spencer (1986) found that the aesthetascs on the lateral antennule of the California spiny lobster Panulirus interruptus, are mediators of chemoreception. The breadth of 
responsiveness of single hairs for behaviorally relevant molecules was quite broad, which suggests that representatives of many classes of receptor cells innervate each aesthetasc. Thus individual aesthetascs (1200-1400 aesthetascs/ antennule) are uniformly competent to respond to chemical stimuli; this is consistent with what is known about insect olfactory and taste sensilla. However, insect chemosensory sensilla are innervated by fewer sensory cells (1-50) than crustacean aesthetascs (20-500), and in general have a narrower response spectrum than that described by Spencer (1986) for $\underline{P}$. interruptus (Altner and Prilinger, 1977; Ache, 1982). The agreement between the electrophysiological responses reported by Spencer (1986) and the behavioral data available for $P$. interruptus underscores the importance of sensory input from the lateral antennule to the behavior of the organism.

The $9 \times 2+0$ arrangement of microtubules in the ciliary segment is the same as that found in the majority of other crustacean aesthetascs (not in the spiny lobster P. argus; Grünert and Ache, 1988) and insect olfactory sensilla. The short ciliary segment (ca $0.6 \mu \mathrm{m}$ ) is consistent with those found in spiny lobsters and is believed by Grünert and Ache (1988) to correlate with chemosensitivity.

The finding that the outer dendritic segments are long and highly branched has also been reported in other crustaceans (Ghiradella, Cronshaw and Case,1968; Ghiradella Case and Cronshaw, 1968; Ghiradella Case and Cronshaw; 1968; Bauchau and Passelecq-Grin, 1984). It can be said that the outer dendritic segments in Vibilia increase in number as one proceeds distally in the aesthetasc, however dichotomous branching could not be confirmed. No branching was observed, however, in the aesthetascs of the isopod, Asellus aquaticus (Heimann, 1984). Some insect olfactory sensilla have branched dendrites while others remain unbranched (Altner and 
Prillinger, 1980). Since the outer dendritic segments of some but not all chemoreceptor cells branch, branching cannot be considered indicative of chemosensory function per se, even though it presumably enhances chemosensitivity in those instances where it occurs. Branching enhance chemoreceptivity by increasing the surface area that chemical may penetrate and trigger a neurological response.

The apparently ubiquitous presence of aesthetascs in crustaceans indicates that they represent a morphological type of sensillum that has been selectively retained through evolution. According to present knowledge, aesthetascs represent a morphologically distinct type of sensillum characterized by the critera discussed at the beginning of this section. Functionally, they can be defined as chemoreceptors of generally extremely high sensitivity, which serve in food, sex and host recognition and elicit complex search behavior (cf. review by Ache, 1982). The morphometric data presented in this paper provides evidence as to the chemosensory function of aesthetascs in the hyperiid amphipod Vibilia. It is the first such information offered for any hyperiid amphipod and offers a basis for comparison with benthic crustaceans. 


\section{References}

Ache, B. W. 1982. Chemoreception and thermoreception. In: The biology of crustacea (D. E. Bliss, ed.). Academic Press, New York. 3: 369398.

Altner, H. 1977. Insect sensillum specificity and structure: an approach to new typology. In: Olfaction and Taste VI (J. Le Magnen and P. Mac Leod, eds.). Information Retrieval, London. p. 295-303.

Altner, H. and L. Prillinger. 1980. Ultrastructure of invertebrate chemo-, thermo-, and hygroreceptors and its functional significance. Int. Rev. Cytol 67: 69-139.

Bauchau, A. G., and E. Passelecq-Grin. 1984. Ultrastructure des aesthetascs du crabe Carcinus maenas L. Cah. Biol. Mar. 25: 333-341.

Bowman, T. E. and H. E. Grüner. 1973. The families and genera of Hyperiidea (Crustacea: Amphipoda). Smith. Contr. Zoo. 146:1-64.

Brusca, G. J. 1981. Annotated keys to the Hyperiidea (Crustacea: Amphipoda) of North American coastal waters. Tech. Rpt. A. Hancock Found. 5:1-76.

Derby, C. D., and J. Atema. 1988. Chemoreceptor cells in aquatic invertebrates: peripheral mechanisms of chemical signal processing in decapod crustaceans. In: Sensory biology of aquatic animals (J.

Atema, R. R. Fay, A. N. Popper, and W. N. Tavolga, eds.). Springer, Berlin, Heidelberg, New York. pp. 365-386.

Devine, D. V. and J. Atema. 1982. Function of chemoreceptor organs in spatial orientation of the lobster, Homarus americanus: differences and overlap. Bio. Bull. 163: 144-153. 
Diebel, C. E. The distribution and morphology of sensory hairs (sensilla) on three genera of hyperiid amphipods (Phronima, Lycaea, and Vibilia) (in prep.)

Diebel, C. E., J. Atema and L. P. Madin. Chemosensory behavior of two genera of hyperiid amphipods ( Vibilia and Lycaea ) towards their salps (in prep.).

Ghiradella, H., J. Cronshaw and J. Case. 1968a. Fine structure of the aesthetasc hairs of Pagurus hirsutiusculus Dana. Protoplasma 66:1-20.

Ghiradella, H. T., J. F. Case and J. Cronshaw. 1968b. Structure of aesthetascs in selected marine and terrestrial decapods: chemoreceptor morphology and environment. Am Zoo. 8: 603-621.

Ghiradella, H., J. Case and J. Cronshaw. 1968c. Fine structure of the aesthetasc hairs of Coenobita compressus Edwards. J. Morphol. 124: 361-386.

Grünert, U. and B. W. Ache. 1987. Ultrastructure of the aesthetasc (olfactory) sensilla of the spiny lobster, Panulirus argus. Cell Tiss. Res. 251 (1): 95-103.

Heimann, P. 1984. Fine structure and molting of aesthetasc sense organs on the antennules of the isopod, Asellus aquaticus (Crustacea). Cell. Tiss. Res. 235: 117-128.

Laval, P. 1963. Sur la biologie et les larves de Vibilia armata Bov. et de V.propinqua Stebb., Amphipodes Hyperides. Compt. Ren. Heb. des Seances de l'Acad. Sci. 236: 1389-1392.

Laverack, M. S. 1987. The nervous system of the Crustacea, with special reference to the organisation of the sensory system. In: Nervous systems of the invertebrates (M>A>Ali, ed.). Proc. NATO-ASI, Lennoxville, Canada. Springer-Verlag, Berlin. pp. 1-30. 
Laverack, M. S. 1988. The diversity of chemoreceptors. In: Sensory biology of aquatic animals (J. Atema, R. R. Fay, A. N. Popper, and W. N. Tavolga, eds.). Springer, Berlin, Heidelberg, New York. pp. 287312.

Lowry, J. K. 1986. The callynophore, a eucaridan/peracaridan sensory organ prevalent among the Amphipoda (Crustacea). Zoo. Scripta 15: 333- 349.

Madin, L. P. and G. R. Harbison. 1977. The associations of Amphipoda Hyperiidea with gelatinous zooplankton. I. Associations with Salpidae. Deep Sea Res. 24: 449-463.

Reynolds, E. S. 1963. The use of lead citrate at high $\mathrm{pH}$ as an electron opaque stain in electron microscopy. J. Cell Biol. 17: 208-212.

Spencer, M. 1986. The innervation and chemical sensitivity of single aesthetasc hairs. J. Comp. Physiol. A 158:59-68.

Spencer, M. and K. A. Linberg. 1986. Ultrastructure of aesthetasc innervation and external morphology of the lateral antennule setae of the spiny lobster Panulirus interruptus (Randall). Cell Tiss. Res. 245: 69-80.

Watson, M. L. 1958. Staining of tissue sections for electron microscopy with heavy metals. II. Application of solutions containing lead and barium. J. Biophys. Biochem. Cytol. 4:727-729. 


\section{List of Figures}

Figure 1. Vibilia sp. A. SEM of antennules and cephalon of Vibilia spp. showing lateral side of antennules, X70. B. SEM of medial side of antennules showing two longitudinal fields of aesthetascs, X180. C. SEM of lateral side of antennules X180. D. SEM of sockets of aesthetascs, X4500.

Figure 2. Schematic representation of a longitudinal section through one hair. Structures inside lumen reconstructed from light and TEM sections. Proportions of structures inside hair not to scale. Only 4 of about 30 dendrites are shown. Inner and outer auxiliary cells shown as a single layer. Glial cells presumably surrounding sensory cell somata not drawn. Planes of cross sections in Figs. 3 and 4 indicated by arrows. a, axons; bb, basal body; c, cuticle; cl, cilium; CS, ciliary segment, eg, epidermal gland; iac, inner auxiliary cell; IDS, inner dendritic segment, 1, lymph space; $\mathrm{m}$, mitochondrion; oac, outer auxiliary cells; ODS, outer dendritic segment; r, ciliary rootlet; s, socket; sc, sensory cell soma. 
Figure 3. Aesthetascs, fine structure. A. proximal region, cross section through axon bundle area at level of peduncle. B. transitional zone of dendrites, cross section showing two cilia $(9 \times 2+0)$ near center of picture. C. transitional zone, cross section showing inner dendritic segments and three pairs of cilia in lymph space. D. area of receptor lymph cavity showing rootlets in ciliary segment. a, axon; bb, basal body; cl, cilium; IDS, inner dendritic segment, 1 , lymph space; $m$, mitochondrion; $r$, ciliary rootlet.

Figure 4. Fine structure of aesthetasc. A. cross section of ciliary dendrite bundle at base of aesthetasc. B. longitudinal section through proximal shaft of aesthetasc. C. cross section half way up shaft of aesthetasc. D. cross section through distal end of aesthetasc. c, cuticle; cl, cilium; mt, microtubule; ODS, outer dendritic segments; s, socket. 
Figure 1. Vibilia sp. A. SEM of antennules and cephalon of Vibilia spp. showing lateral side of antennules, X70. B. SEM of lateral side of antennules, X180. C. SEM of medial side of antennules showing two longitudinal fields of aesthetascs, X180. D. SEM of sockets of aesthetascs, X4500. 

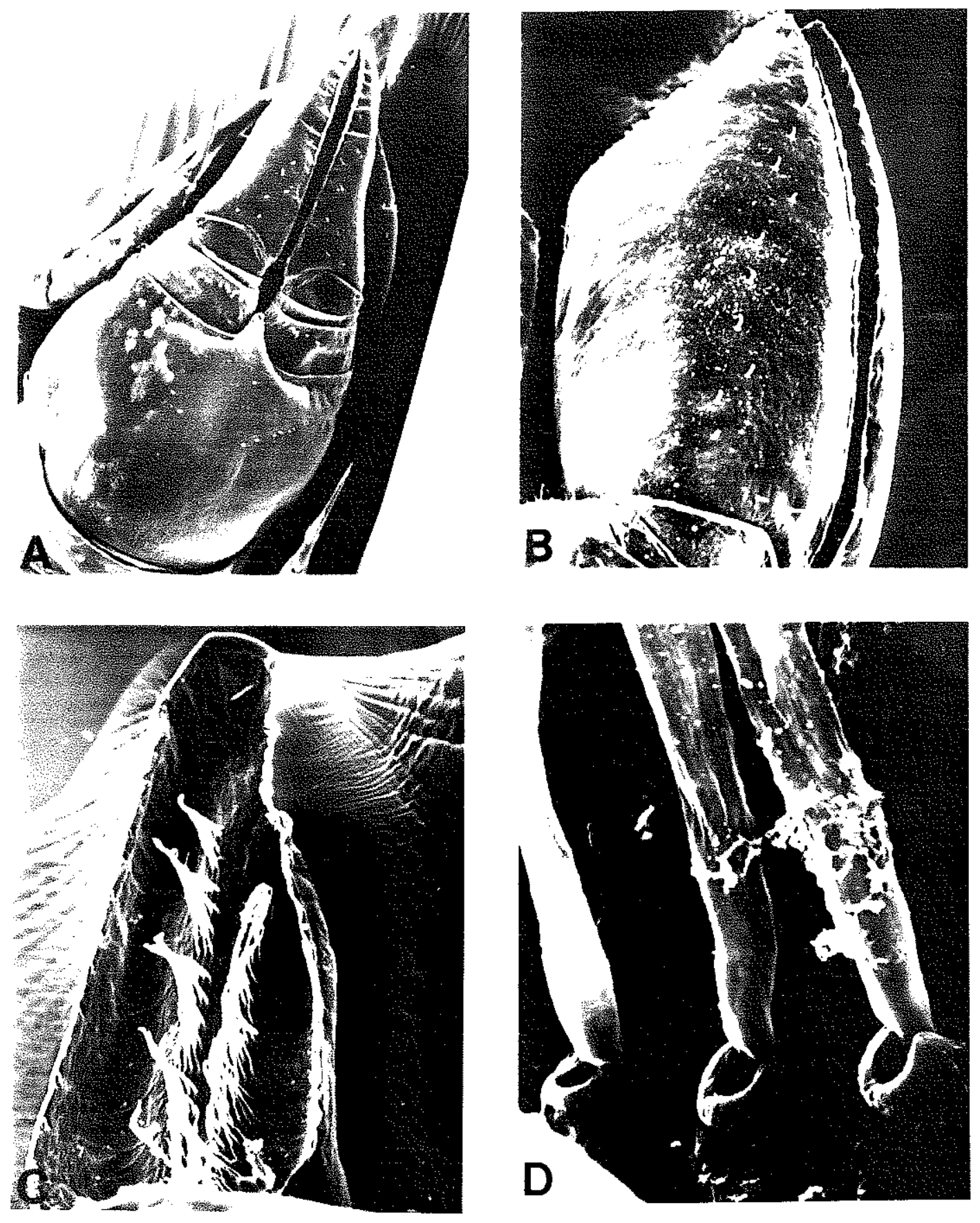
Figure 2. Schematic representation of a longitudinal section through one hair. Structures inside lumen reconstructed from light and TEM sections. Proportions of structures inside hair not to scale. Only 4 of about 30 dendrites are shown. Inner and outer auxiliary cells shown as a single layer. Glial cells presumably surrounding sensory cell somata not drawn. Planes of cross sections in Figs. 3 and 4 indicated by arrows. a, axons; bb, basal body; c, cuticle; cl, cilium; CS, ciliary segment, eg, epidermal gland; iac, inner auxiliary cell; IDS, inner dendritic segment, 1, lymph space; $\mathrm{m}$, mitochondrion; oac, outer auxiliary cells; ODS, outer dendritic segment; r, ciliary rootlet; s, socket; sc, sensory cell soma. 


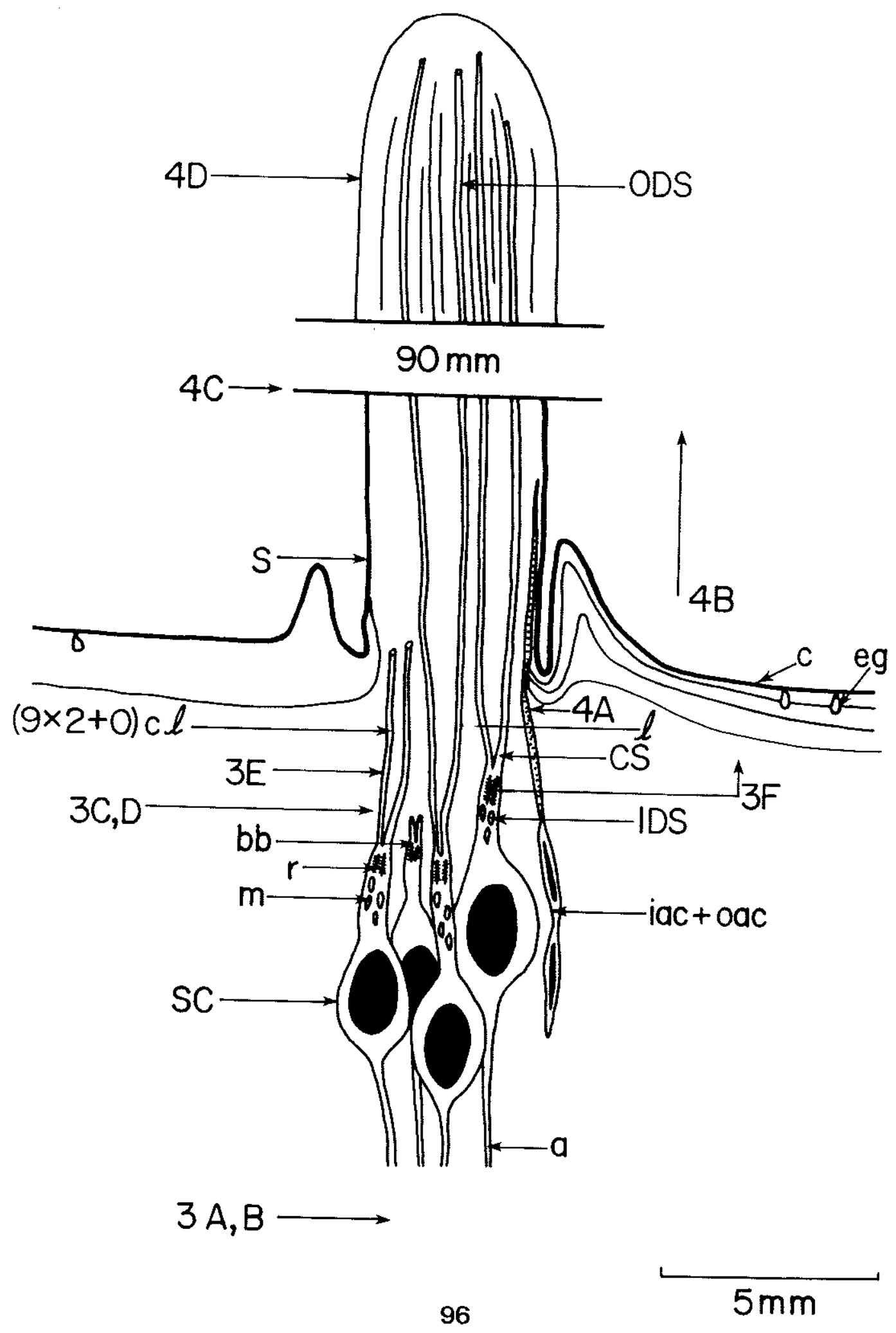


Figure 3. Aesthetascs, fine structure. A. proximal region, cross section through axon bundle area at level of peduncle. B. transitional zone of dendrites, cross section showing two cilia $(9 \times 2+0)$ near center of picture. C. transitional zone, cross section showing inner dendritic segments and three pairs of cilia in lymph space. D. area of receptor lymph cavity showing rootlets in ciliary segment. a, axon; bb, basal body; cl, cilium; IDS, inner dendritic segment, 1, lymph space; m, mitochondrion; r, ciliary rootlet. 

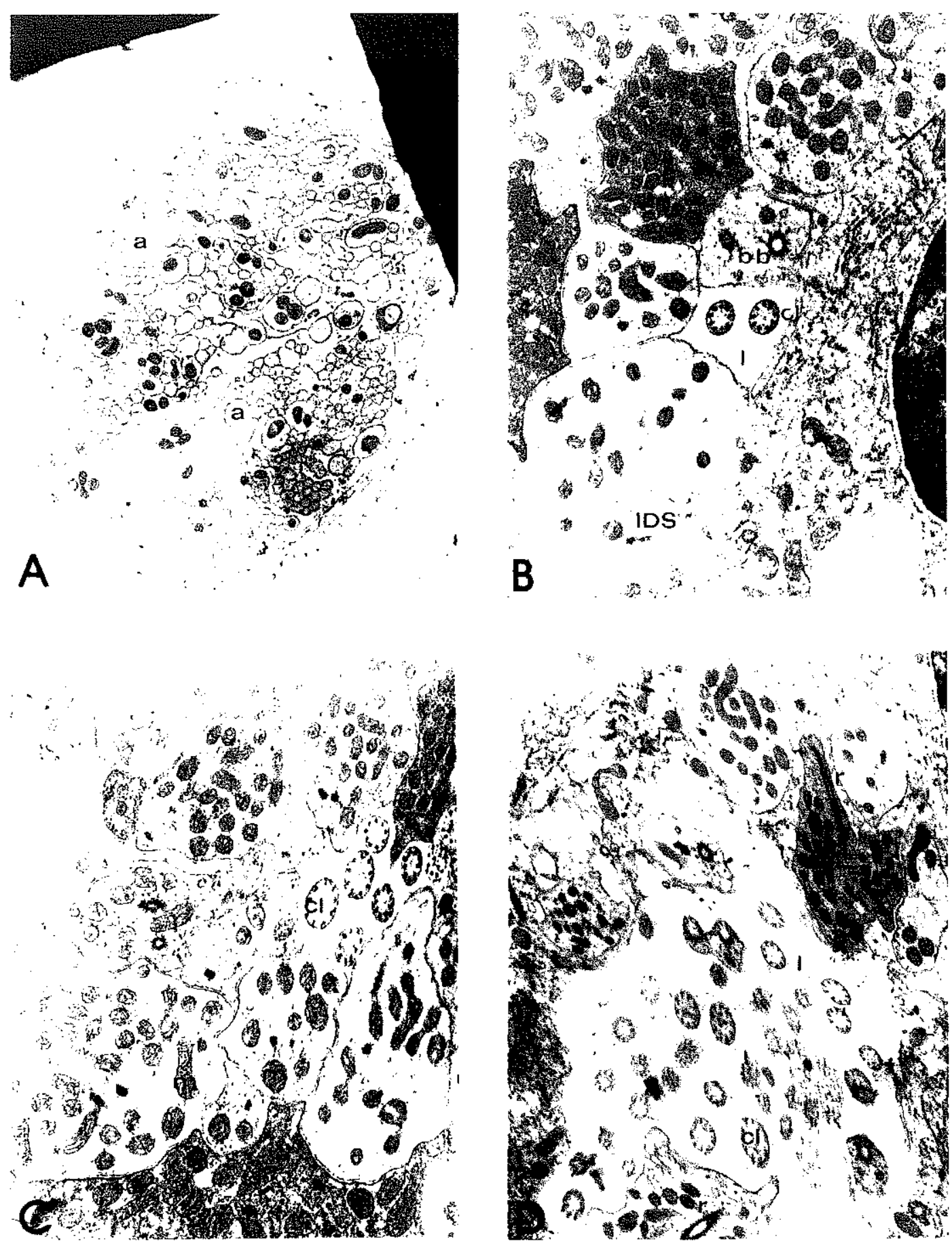
Figure 4. Fine structure of aesthetasc. A. cross section of ciliary dendrite bundle at base of aesthetasc. B. longitudinal section through proximal shaft of aesthetasc. C. cross section half way up shaft of aesthetasc. D. cross section through distal end of aesthetasc. c, cuticle; cl, cilium; mt, microtubule; ODS, outer dendritic segments; $\mathrm{s}$, socket. 

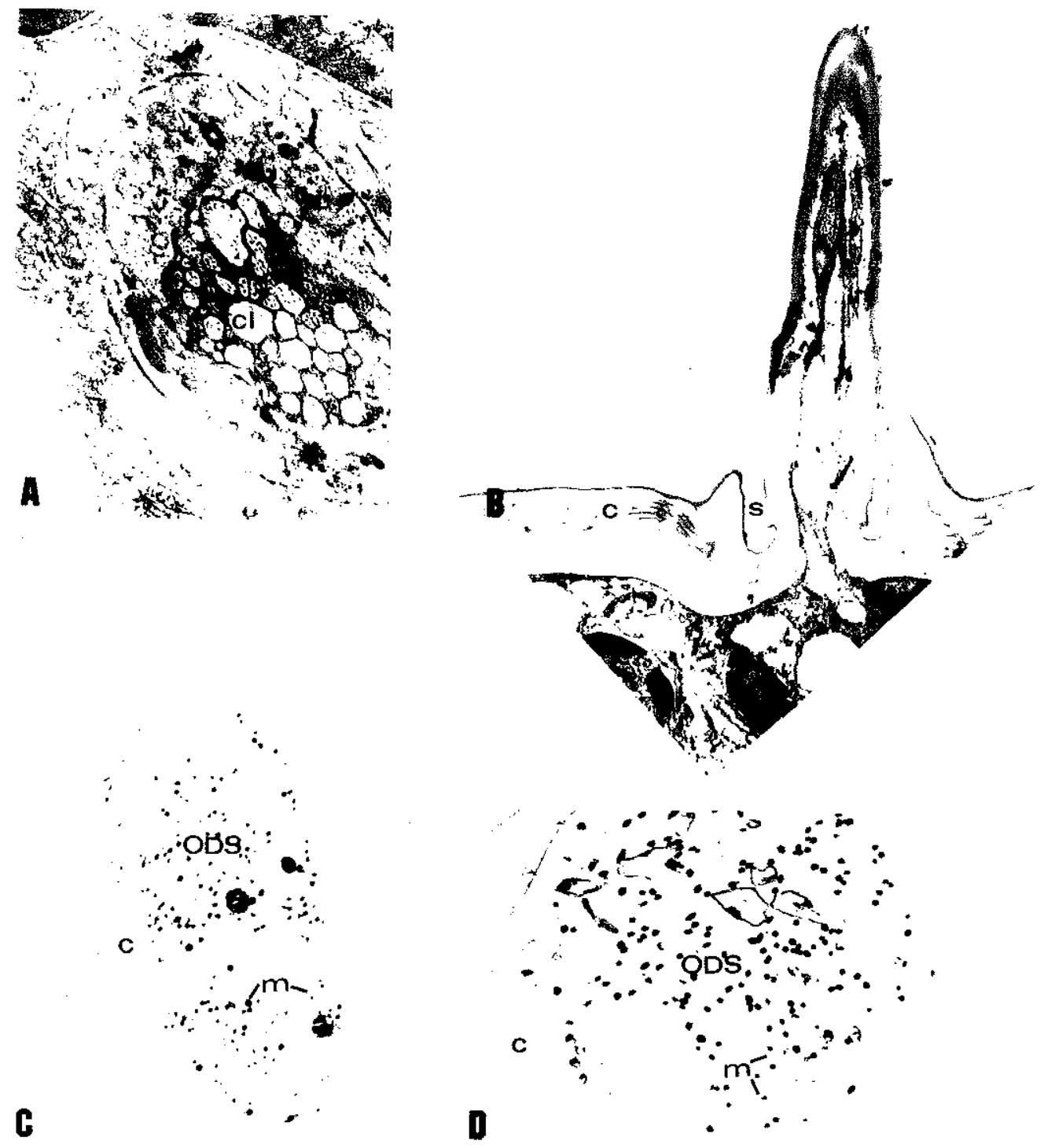
101 
Chapter 4

Chemosensory behavior of two genera of hyperiid amphipods

( Vibilia and Lycaea ) towards their salp hosts 


\begin{abstract}
Hyperiid amphipods are open ocean symbiotic crustaceans which use gelatinous planktonic animals for food, shelter, and brooding space for their offspring. These associations involve varying degrees of host specificity, but there are few obvious correlations between gross morphology of the amphipods and the types of host they choose. Using "Y" maze experiments, the chemosensory basis for the host-specific associations between species of Vibilia and Lycaea and five different genera of salps was tested. These tests show that species of Vibilia and Lycaea respond and orient to chemical stimuli (body odors) derived from various host species of salps. Vibilia jeangarardi also showed a significant response to an artificial and arbitrary mixture of seven amino acids. This demonstrated chemosensory behavior by species of Vibilia and Lycaea may represent an important mechanism for maintaining their symbioses with salps in the plankton.
\end{abstract}




\section{Introduction}

Hyperiid amphipods commonly rank third in abundance after the copepods and euphausiids as members of the marine crustacean zooplankton. They are entirely marine and pelagic, and mostly oceanic, with a few species found in coastal waters. Almost all species are symbionts for at least part of their lives with gelatinous organisms such as salps, medusae, siphonophores and ctenophores, which may be used as a platform for feeding, a food source, or as a nursery for developing young (Pirlot, 1932; Harbison et al., 1977; Madin and Harbison, 1977; Laval, 1980).

Hyperiid behavior may be described as 'parasitoid' (Laval, 1980) i.e. intermediate between a parasite and a predator. Many hyperiids are freeliving as adults, but in all known cases their progeny grow and develop in or on a host, requiring that a female locate an appropriate host during her lifetime. Hosts may be widely distributed or patchy, and a female hyperiid needs effective mechanisms for host recognition. The male hyperiid may also need these mechanisms if it is to locate a female. Thus, hyperiid amphipods present an excellent opportunity for the study of host-oriented behavior in a pelagic symbiotic organism. Previous studies of marine symbioses (see Ross, 1983 for review) have focussed on benthic or coastal marine organisms, because little is known about pelagic symbioses. One reason for this has been the difficulty in obtaining pelagic organisms. Using SCUBA diving we have been able to collect hyperiid amphipods with their delicate gelatinous hosts on cruises, thus allowing us to study their symbiotic relationship. 
Symbiosis may be defined as an "association, for a significant portion of the life cycle, of individuals that are members of different species" (Margulis, 1981). There is an enormous diversity and complexity of species interactions in symbiotic relationships and many of them affect entire ecosystems. The recognition that symbiotic relationships are widespread, persistent through time, and have profound consequences for the partners has led to a reexamination of the evolutionary implications of symbiosis (Margulis, 1976; 1981).

Basic to the biology of symbioses are the mechanisms which bring correct partners together and maintain their associations (Ache, 1974). Because of their specific and often obligate nature, symbioses are particularly good situations for the investigation of interspecific communication and associated behavior. There are many strategies that symbionts use to effectively recognize their potential hosts. These strategies depend on the biology of the host, the environment in which the host lives, the host's mode of life and the relationship the host has with other organisms around it. There are many potential cues in the environment that a parasite could use to maintain its symbiosis; however, the host is usually the primary source of stimuli controlling the behavior of the symbiont (Davenport, 1955; 1966). A host must feed, reproduce and defend itself in order to survive. These activities involve the release of chemicals that can supply the sensory information needed by the symbiont (Davenport, 1966; Wilson, 1970; Ache, 1974; ). Therefore the maintenance of highly specific host-symbiont relationships must involve both sensory and behavioral adaptations of the symbiont to characteristic stimuli produced by the host.

Host recognition could be based on visual, mechanical, or chemical cues. Possible visual signals include shape, color, size and pattern 
of movement of the host. The size and structure of the compound eyes in most hyperiids suggests the importance of vision in their behavior (Ball, 1975; Land, 1981b,1984; Nillson, 1982), but visual detection is limited in range and accuracy by the absorption and scattering of light (Lythgoe, 1988). Mechanical signals may be vibrations, pressure waves or currents possibly specific which are created by the host while moving through the water (Atema, 1980, 1985; Wilcox, 1988; Bleckmann, 1988); their importance has been demonstrated in other planktonic crustaceans (Strickler and Bal, 1973; Ball and Cowan, 1977). Chemical signals could be any substances produced and released by the host intentionally or as byproducts of feeding, metabolism or reproduction (Davenport, 1966). By analogy with other benthic and pelagic crustaceans (e.g., Ache, 1974; Hamner and Hamner, 1977; Meador, 1980) one might expect chemical cues to be of primary importance in mediating the behavior of hyperiid amphipods.

Chemical information is probably important in the maintenance of aquatic partnerships in general (Davenport, 1966). Specific chemical information regulates countless predator-prey and herbivore-plant relationships, as well as mate recognition and location, and has been shown to have a similar role in symbiotic associations (Davenport, 1966; Wilson, 1970; Ache, 1974). In this paper we will examine the role of chemical cues for the location and recognition of salp hosts by hyperiid amphipods, a symbiont .

On large scales, environmental factors such as currents or gyres, probably determine the distribution of both the host and the symbionts. For each organism the spatiotemporal scale of biological interest is bounded on the lower end (highest spatial frequencies) by the sampling volume and the adaptation/disadaption time constants of its chemoreceptors and on the upper 
end (lowest spatial frequencies) by the adaptation rate of searching strategies and integration characteristics of the organism ( see Table 2.1 in Atema, 1988). We assume that hyperiids could use sensory cues only for recognizing hosts within the scale of their swimming range.

The two genera of hyperiids we studied here both live on salps, but exhibit different degrees of dependence on them during their life history. Vibilia spp. have two small eyes and broadly flattened antennules with sensory hairs densely packed inside (Fig.1A), and seldom leaves its salp host. Lycaea spp. have well-developed eyes which occupy most of the surface of the head (Figure 1B), and will leave their salp hosts more readily than Vibilia spp.

Most salps are colonizing or opportunistic species, and their populations are variable in size and patchy in distribution. The process of host recognition by hyperiids may include long range orientation to a salp community, followed by a steady narrowing of the search guided by short range, and eventually contact, cues. In each stage host recognition requires an active, overt response of the symbiont toward the host or signals its produces.

Filter feeding, respiration and swimming by the salp are all accomplished simultaneously by pumping water through an anterior mouth, filtering particles from it, and expelling it from a posterior atrial siphon (Madin, 1974; Bone, 1980; Alldredge and Madin, 1982). The exhalent water leaves the salp as a pulsed jet, combining a continuous column of water with periodic vortex rings produced by each contraction of the salp's body muscles (Diebel et al., 1985). These wakes of swimming salps could constitute 'scent trails' (Hamner and Hamner, 1977) in the water column that lead hyperiids to the salps. 
Previous experimental investigations on the role of chemoreception in marine symbioses have focussed on distant host recognition. In "Y" maze experiments polychaetes associated with echinoderms (Dimock and Davenport, 1971) and molluscs (Gerber and Stout, 1968; Webster, 1968), crustaceans associated with molluscs (Webster, 1968; Ache and Davenport, 1972) and polychaetes (Carlton, 1968) all respond to the arm of the "Y" containing effluent of their host. Ache and Davenport (1972) showed that the symbiotic shrimp Betaeus macginitieae could effectively locate their host urchins either chemically or visually. The chemical sense was more specific; visually B. macginitieae did not respond specifically to its host, but exhibited simple form recognition of a dark, solid shape.

In this paper we discuss "Y" maze experiments which demonstrate a chemosensory basis for the host-specific associations between species of Vibilia and Lycaea and five different genera of salps. All the hyperiids tested were able to use the chemical signals released by their salp hosts as recognition cues. Vibilia jeangarardi also showed a behavioral response to a mixture of amino acids. In all cases, orientation to the host was accomplished in the absence of visual or mechanical cues. Amphipods were tested for the response to different hosts, different concentrations of host effluent and artificial solutions of amino acids, and ammonium. By necessity, experiments were done as healthy study material presented itself in collection dives. 


\section{Materials and Methods}

Collection and Maintenance of Animals

All experimental work described here was carried out aboard ship on several different cruises. Most of the data come from two cruises: $R / V$ Oceanus 177 (western north Atlantic; August, 1986), and Calanus 87-07 (Tongue of the Ocean; April, 1987). Other cruises were the Oceanus 165 (Central North Atlantic; August, 1985), Oceanus 170 (Gulf Stream; July, 1985), and Calanus 85-07 (Tongue of the Ocean; April, 1985).

All amphipods were collected with their salp hosts in hand-held jars by SCUBA divers and brought aboard ship. The animals were then numbered, identified to genus, and transferred, with or without their hosts, to 1-5 liter glass or plastic containers filled with ambient seawater that was changed daily. Fecal pellets were removed with a large pipette from the bottom of aquaria containing salps. Ambient seawater (20-25० C) was either bucketed or pumped aboard through an uncontaminated seawater intake system. In order to conduct the behavioral tests the salp host had to be collected and maintained in good condition. Healthy salps swim continuously in order to feed, so regular swimming was used as the criterion for their condition. Since the salps usually remained healthy for only 24 hours, a constant supply was needed to perform the experiments. Animals collected were kept on a 12 hour light/dark cycle at an ambient laboratory temperature of $22-26^{\circ} \mathrm{C}$.

On a single day we might find one species of salp with or without amphipods on them, on another day, a completely different species of salp might be collected. This restricted the number and species of salps available for testing. Species of Vibilia and Lycaea were chosen because they both shared a symbiotic association with salps (often the same genus) and were consistently found on previous cruises. 
On Oceanus 177 all Vibilia jeangarardi collected were allowed to remain on their salp hosts at all times. On Calanus 87-07 Lycaea spp. were collected with their hosts, but once on board the ship they were removed from their hosts and allowed to swim freely in an aquariam. They were reunited with their natural host species every three days for 12 hours in order to feed . After feeding, the Lycaea spp. were moved to a clean aquarium and not used for testing for at least 24 hours.

In general, amphipods in the behavioral bioassays were tested against the hosts with which they were found. Specimens of Vibilia jeangarardi were tested on Pegea bicaudata and Salpa cylindrica only if they were originally found on those species. Since $\underline{V}$. jeangarardi does not often occur on Cyclosalpa polae, the $\mathrm{V}$. jeangarardi to be tested against Cyclosalpa polae were removed from their original host (Pegea socia), kept in plain sea water for 24 hours and then placed on Cyclosalpa polae for 24 hours prior to testing. Otherwise, test animals were left on their salp hosts (V.jeangarardi) or kept in separate aquaria ( Lycaea spp. ), in dim light or darkness for at least 8 hours before testing.

At the end of the experiments or when an animal died all animals were fixed in either a $3 \%$ glutaraldehyde solution, $10 \%$ formalin in seawater, or Karnovskys solution for later identification. Amphipods were identified at least to genus and usually to species before use in experiments. Species identifications were confirmed later using Bowman and Gruner (1973), Madin and Harbison (1977) and Vinogradov (1982).

Stimulus Preparation

The stimulus water (Salp tea) used in most of the behavioral tests was a known volume (4-12 1) in which healthy salps had been swimming for a known length of time (Table I). Priority was given to salp species which 
were known hosts to the hyperiids. Types of stimulus water were designated by host species and by the amount of time the hosts spent incubating in the water volume. Freshly collected salps were identified to species, measured and counted before being placed in the aquarium. One or two liter subsamples of this stimulus water were removed from the large aquarium at hourly intervals (eg. 2,4,6,8 hours) and placed in one of the reservoirs attached to the "Y" tube olfactometer. We assumed that incubation time was roughly equivalent to stimulus concentration, although composition may change with time as well. In addition to the salp odor stimulus water, an artificial chemical stimuli was used. This amino acid mixture contained glycine, glutamine, glutamate, serine, taurine, alanine and proline each at 10-6M. These compounds included some previously shown to be feeding or chemoreceptor stimulants in other crustaceans (Johnson and Atema, 1986; Ache, 1982), and from amino acids identified previously as excreted by salps (Cetta, unpubl.). All compounds were pre-weighed in amounts appropriate to prepare a $10^{-2} \mathrm{M}$ solution, and stored at $4{ }^{\circ} \mathrm{C}$ or frozen. Test solutions were prepared on the day of an experiment. When necessary the $\mathrm{pH}$ was adjusted to 7.8 with $\mathrm{NaOH}$ to that of seawater, and all subsequent dilutions were made with the seawater that was used in the behavioral experiments on that particular day.

As a rough estimate of odor concentration ammonium nitrogen concentration in the salp odor was determined (Solorzano, 1969) on fresh $5 \mathrm{ml}$ samples during several different series of experiments. In addition there was some concern that the ammonium concentration in the stimulus water subsample might change over the time period required to do a series of behavioral tests at specific incubation times (often over $2 \mathrm{hrs}$ ). We therefore took ammonium samples from the stimulus water being used at the beginning 
and end of each series of tests to determine if the concentration levels changed significantly in the stimulus water. The values were never significantly different and on occasion were almost identical. Determinations of dissolved primary amines were made on $5 \mathrm{ml}$ subsamples frozen at $-20^{\circ} \mathrm{C}$ for up to ten days prior to assay using the fluorometric assay for o-pthalaldehyde product (Parsons et al., 1984). These analyses were done at sea on the Calanus 87-07 cruise.

Behavioral Bioassay

Behavioral experiments to test the importance of chemical signals for host recognition by Vibilia jeangarardi and Lycaea spp. were carried out in a simple "Y" tube olfactometer similar to the one used by Davenport (1950). The apparatus consisted of two reservoirs of 4 liters, one for stimulus and one for plain seawater, connected to the arms of a glass " $Y$ " (12 mm diam, $140 \mathrm{~mm}$ long, and $25 \mathrm{ml}$ in volume) with tygon tubing. In-line flowmeters (Gilmont size No. 12, F-2200) allowed regulation of the flow of water into each arm and valves let water from either reservoir be directed to either arm of the "Y". The "Y" base was closed with plastic mesh screen $(1 \mathrm{~mm})$ to retain the amphipod. The entire " $Y$ " was tilted at an approximate angle of $60^{\circ}$ with the base end up. Checks of the system with dyed water confirmed that flow into each arm of the "Y" was equal, and without mixing throughout the length of the "Y".

Before an experimental run, reservoirs were filled and allowed to come to room temperature (4-8 hrs) and the entire apparatus was flushed with seawater for at least one hour. Experiments were run in dim red light $(650 \mathrm{~nm})$. Amphipods were removed from holding tanks and transferred with a spoon or poured directly onto the plastic screen removed from the base of the "Y". The screen was then replaced over the end of the "Y" with 
the amphipod inside. The "Y" was filled with water equally from each side arm forcing air out through the screen at the base. When the "Y" was filled with water, the hyperiid would come off the screen and swim up the base of the "Y" into either the left or right arm. Only rarely did an amphipod cling to screen at the base of the "Y".

A test began when the hyperiid had advanced $2 / 3$ of the distance up the base of the "Y" and continued for 3 minutes. Control and stimulus tests, and stimulus side of the " $Y$ " were randomized, but with an equal number of stimulus tests run on each arm of the "Y". At the end of each 3 min test the amphipod was removed from the apparatus by gently washing it onto the screen; it was then placed in a small dish and allowed to swim freely until the next test. The entire "Y" was emptied of water, washed for 3 min with seawater, refilled and another test was performed.

For each 3 minute test, the data recorded included total time spent in each arm and at the base of the "Y" ("time spent"), the arm the animal swam into first ("initial choice"), the arm it was in at the end of the run ("final choice"), and the number of times the animal switched arms ("turns").

Three different control tests $(A, B, C)$ were used to determine that the amphipods were responding to the differences in chemical stimuli alone. To test for inherent left-right preferences, separate control tests ( Control A)were run using either ambient sea water or stimulus water through both arms of the "Y". Such separate tests take precious time away from other shipboard behavioral testing. Since these tests showed randomness and because the availability of animals was often a limiting factor, possible leftright preference was determined subsequently during stimulus testing by using each in several tests and by alternating the stimulus arm for each test semi-randomly (Control B). In order to test (Control C) whether the 
amphipods were influenced in their left-right choice by the red light (650nm, 40 watts) used for testing, one arm of the " $\mathrm{Y}$ " was darkened with tape; control experiments with sea water in both arms were run to determine if there was a preference for either the light or darkened arm. An equal number of tests were run with the darkened arm on the left or right side. Statistical tests

For data analysis the arm of the "Y" where the animal spent the most time was scored as "+". In control experiments the " $\mathrm{Y}$ " arms were designated as either left or right; in stimulus experiments the arms were designated as either stimulus or sea water. All test results for each species of amphipod and each type of stimulus (e.g. $2 \mathrm{hr}$ Cyclosalpa affinis odor) were totaled, and analyzed with a binomial test. This test allows for individual animals to be used more than once. Binomial tests were also performed on the "initial choice" data. Since results based on these data were not significantly different from those based on "time spent" data all results presented in this paper are for "time spent". 
Results

During the behavioral tests a hyperiid might move up the " $\mathrm{Y}$ " either directly in the center of a "Y" arm or in a forward spiral motion along the wall of the "Y". Once the hyperiid had reached the end of the "Y" arm and could progress no further it might hover in one place or swim in a circular motion at the end of the arm for the remainder of the test; or, it might swim down the arm and up into the other arm or base of the "Y". A hyperiid could switch its position in the "Y" many times during a 3 minute test. Table II shows the total number of tests run and whether or not there was a significant response towards a particular host or chemical stimulus. Control tests $\mathrm{A}$ (Figs. 2A,B,C) and B (Figs. 3A,B,C,D) showed that none of the hyperiid species tested had directional bias in the "Y" maze. Control test $\mathrm{C}$, done on both Vibilia jeangarardi and Lycaea spp., showed no preference for either the covered or uncovered side (Fig. 2D).

A total of 26 individuals of Vibilia jeangarardi ranging from 5-10 $\mathrm{mm}$ in length were tested against three different salp species from different genera (Fig. 2A,B,C,D). Vibilia jeangarardi showed a significant preference for the stimulus water from Pegea bicaudata and Salpa cylindrica (Figure2A,B) but not Cyclosalpa polae (Fig. 2C); a significant response was not seen until the water had been incubated for at least 4-5 hours (Figs. $2 A, B) . \underline{V}$.jeangarardi also showed a significant response to the amino acid mixture (Fig. 2D).

Vibilia jeangarardi showed the strongest response to $\underline{S}$. cylindrica (Fig. 2A), significant at every stimulus level except the 2 hour. The next strongest response was to Pegea bicaudata (Fig. 2B), with significant results 
from the 5-6 hr and $8 \mathrm{hr}$ stimuli. The $2 \mathrm{hr}, 9 \mathrm{hr}$ and $8 \mathrm{hr}$ half dilution show a much more random response, and the $4 \mathrm{hr}$ dilution $(\mathrm{P}(\mathrm{k})=0.92)$ was not quite significant. When results of all tests from both salp species were summed, they showed a strongly significant response to the stimulus test water. There was no significant response to any of the stimulus levels from Cyclosalpa polae (Fig. 2C) even when all the data were pooled. However the 4hr incubation was almost significant $(\mathrm{P}(\mathrm{k})=0.94)$. In other tests, $\underline{\mathrm{V}}$. jeangarardi showed no discrimination between Salpa maxima on which it was found, and Cyclosalpa affinis, on which these particular individual hyperiids were not found at the time, but others had been previously (Fig. 2D).

A total of 32 individuals of Lycaea spp. ranging from 5-10 $\mathrm{mm}$ in length were used in the behavioral tests. Lycaea nasuta showed a significant response to Cyclosalpa affinis (Fig. 3A) at all incubation times except 9-10 hrs $(P(k)=0.93)$. Lycaea pulex also showed a significant response to $\underline{S}$. maxima and Pegea bicaudata (Figs. 3B,C), except for the $3 \mathrm{hr}$ test with $\underline{\mathrm{P}}$. bicaudata. In a choice between two species from two different genera of salps ( . maxima and $\underline{\text { C. affinis) }}$ ) there was no significant preference for either species (Fig. 3D).

There was generally a greater concentration of ammonium in the stimulus water $(>2 \mu \mathrm{M})$ than in the control sea water $(<1 \mu \mathrm{M})$. Concentration increased with time (except SLM 21; Fig. 4). Amine values varied from 1-10 $\mu \mathrm{M}$ glycine equivalents but most were not more than $2 \mu \mathrm{M}$ glycine equivalents. Control sea water amine values were less than the stimulus water values with the exception of the 24 Apr 0 time. 


\section{Discussion}

This study has investigated the role of chemical signals in a pelagic marine symbiosis, in which the hyperiid amphipod is the active host seeking member. We assume that the hyperiid amphipods had already gone through an imprinting, dispersal or migratory phase and were primed physiologically to use salp hosts. Species of Vibilia and Lycaea respond and orient to chemical stimuli derived from various host species of salps. We cannot rule out the possibility that other cues such as mechanical and visual stimuli may be used in addition. While all species of hyperiids tested showed a significant chemosensory response to at least one species of salp host, there were interesting differences in the behavior of the two genera. Lycaea nasuta is a specific symbiont of $\mathrm{C}$. affinis, and the results show a strong response at almost all incubation times (and thus perhaps odor concentration, see below) to the salp water (Fig. 3A). The only time when there was no significant response was at the 9-10 hour incubation. This was also time when the ammonium concentration declined in the $\mathrm{C}$. affinis stimulus water (Fig. 4A), indicating removal of free ammonium, possibly through biological activity.

When $\underline{L}$. pulex (symbiotic on $\underline{S}$. maxima) were given a choice of $\underline{S}$.

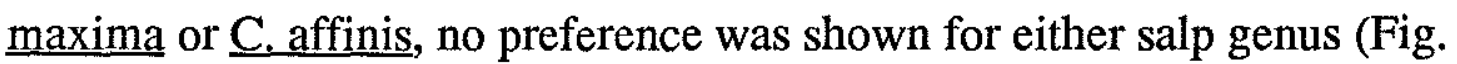
4D). Lycaea pulex has been found on both genera. Two possible interpretations of this behavior are that $\mathrm{L}$. pulex was not able to differentiate between the two different salps, or that it had no preference for one genus of salp over the other.

Vibilia jeangarardi did not show the same immediate response to the stimulus water that Lycaea spp. did (Fig. 3), as there was never a significant response earlier than $4 \mathrm{hrs}$. This may indicate a higher behavioral threshold of this species, or may have been a result of the different treatment of 
amphipods. Vibilia jeangarardi was kept with its host at all times while

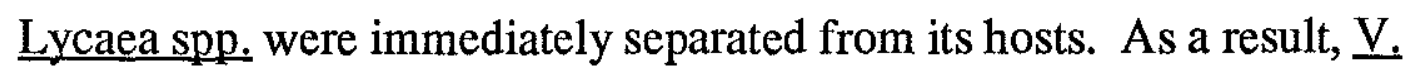
jeangarardi was continually exposed to a much higher background concentration of salp stimulus water. Lycaea spp. may have responded at a lower threshold of chemical cues because it was not constantly exposed to the higher background concentration. Alternatively, different thresholds may reflect intrinsic differences in behavior between the two species. Vibilia spp. spend the majority of their time within the confines of the posterior branchial bar or esophagus of the salp and seldom leave their salp hosts. They feed by diverting food from the salp's mucous feeding strand to their mouth (Madin and Harbison, 1977); and, they may also be a micropredator on salp tissues. Thus, Lycaea spp., on the other hand, are found anywhere on the body of the salp, and will leave their salp hosts more readily (Madin and Harbison, 1977). They feed intermittently on parts of the salp's body (Madin and Harbison, 1977). Lycaea spp. may be more accustomed to encountering lower levels of stimulus within the environment.

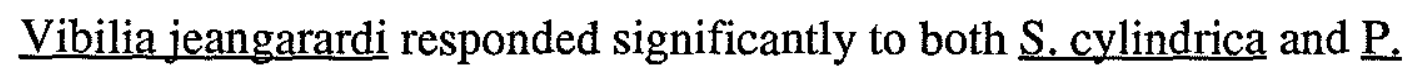
bicaudata, but not to $\underline{\mathrm{C}}$. polae, even if all the data are pooled. In many years of collecting, we have seldom seen a hyperiid amphipod associated with $\underline{\mathrm{C}}$. polae.

It is interesting to note that although $\mathrm{V}$.jeangarardi did not show a significant response to ammonium it did respond to a mixture of seven different amino acids. Ammonium is a principal product of excretion among salps (Cetta et al., 1986) as well as most other zooplankton (Parsons et al., 1984). Figure 5A shows that the ammonium concentration in the stimulus water increased over time with a decrease occurring after 8 hours (for CAF6 and CAF12). When compared with the behavioral results (i.e. compare Fig. 
3A with CAF6 and CAF12 NH4+ data) the concentration of ammonium does not appear to reflect any baseline value that triggers a significant behavioral response. Lycaea nasuta responded significantly at the $2 \mathrm{hr}$ incubation time when $\mathrm{NH} 4+$ was at its lowest concentration and at the $7 \mathrm{hr}$ when the $\mathrm{NH} 4+$ was near its peak concentration. Therefore, ammonium concentrations alone, at least within this range, do not produce nor correlate significant behavioral responses. Ammonium does not "track" odor concentration, nor its (bacterial) decomposition.

The significant response to the amino acid mixture by $\underline{\mathrm{V} \text {.jeangarardi }}$ is interesting. These tests were done towards the end of a cruise when no healthy salps were available, and the $\underline{V}$. jeangarardi had been kept in aquaria without hosts for at least 24 hours prior to testing. The amino acid mixture used as a stimulus was determined from amino acids identified as excreted by salps (Cetta, unpubl.) and from those previously shown to be feeding or chemoreceptor stimulants in crustaceans (Johnson and Atema, 1986) and pelagic crustaceans (Ache, 1982). Each organism passively leaks and actively excretes waste products, and is thus surrounded by a distinct body odor (Bryant and Atema, 1987; Atema, 1980,1988). The detectable spectrum of this odor varies among animals, and we can use behavioral responses as criteria for the ability to distinguish particular chemical odors. We have been able to show here that the salp host does produce some chemical cue to which the amphipods respond favorably. The low values of ammonium $(\mu \mathrm{M})$ and amino acids (pM, Cetta, unpubl.) that we measured in the stimulus water do not differ dramatically from the background concentrations (Figs. 5A,B); but, highly specific chemicals or mixtures may be present which are the actual triggers of observed behavior (Atema, 1988). 
Chemicals appear to play a major role as cues to host selection and acceptance (Vinson, 1977), due in part to the range of distances over which they can operate (Vinson, 1984). Investigators have generally agreed that body odors are a stimulus to crustacean chemoreceptors, and that specific mixtures are more successful than individual chemicals (Mackie and Shelton, 1972; Fuzessery and Childress, 1975; Borroni et al, 1986; Atema, 1987; Linn, 1987). Amino acids are often components of such mixtures (Mackie, 1973; Carr, 1988), as they often serve as appropriate signals for initiating aspects of feeding behavior because they are soluble in water, widely distributed in the aquatic environment, and present in large amounts in the cells of all organisms (Carr, 1988). Mixtures can serve as chemical pictures of particular animals that other organisms can detect and identify as to species, sex, stress level and perhaps size and individuality (Atema, 1980). Bryant and Atema (1987) demonstrated that general body odor, as well as specific pheromone signals, must be considered important in the regulation of social behavior.

Chemical cues for host recognition can be highly specific in their action (Dimock and Davenport, 1971; Gray et al., 1966; Carton, 1968). This means that the symbiont may only need to detect the presence of the attractant and not the small changes of concentration that would be required to cause a chemotactic response. Dimock and Davenport (1971) demonstrated in polychaetes that the specificity of response to chemical attractants can be modified by the previous experience of the symbionts. Chemical stimuli that are used by an animal to maintain a symbiosis may be different from the chemical stimuli which initiate that same relationship. Atema (1980) felt that smell provides information to an animal that stimulate it into behavior patterns such as home recognition, prey hunting, predator avoidance, and 
mate selection. Host recognition by symbionts, based on a "chemical search image" , may be another such response.

Previous work on chemoreception in pelagic crustaceans has focussed on its role in food detection (Hindley,1975; Hamner and Hamner,1977; Busdosh et al1982; Hamner et al,1983). Hyperiid amphipods utilize salps for food, shelter and depositing their young (Fig. 1). Salps solve many survival problems for the amphipods and their availability appears to be required for completion of the hyperiid's life cycle (Madin and Harbison, 1977). The ability to detect and orient to the unique signal of a salp in a complex chemical environment would therefore be of primary importance to the amphipod.

Even with the ability to recognize hosts chemically, amphipods face the problem of locating animals that are often sparsely or patchily distributed in vast volumes of water. The location of individual salps or populations may be difficult even after their "scent" has been detected. The source may move away, leaving the stimulus behind for a long time. A hyperiid amphipod lives in a patchy, turbulence dominated odor environment. In this environment chemical stimuli are not organized in one linear dimension; their distribution depends on molecular diffusion and fluid dynamics (Atema, 1988). A scent trail left behind a salp (Diebel et al., 1986) might be detected by an amphipod but the direction to the salp may not be obvious from the chemistry alone.

It would be simplistic to assume that host recognition by an amphipod is determined by a single stimulus. The presence of chemical cues may alter the amphipods' response to visual or mechanical cues, as it does for some insects (Kennedy, 1974). Most insects employ a combination of sensory mechanisms (Vinson, 1984). The host recognition process can involve multiple steps, each mediated by a relevant chemical, visual or mechanical 
stimulus. In the process, the amphipod for example, moves from searching a large area to searching successfully smaller areas that have a higher probability of containing a host. The use of all the different stimuli available for host recognition would maximize the information available to the symbiont while it would not demand excessive competence in its sensory system for any one modality. A particular sensory system may be dominant at different stages in host recognition.

We have described the trail left behind a salp as a potential signal for a hyperiid (Diebel et al, 1985). This trail has both chemical and mechanical components to it. Chemical stimuli are excellent signals in that they occur in large quantities, in dark or light, and are highly specific yet require simple receptors (Atema, 1980). However, the location of the chemical stimulus source can be difficult to determine. On the other hand, the spatial pattern or strength of mechanical signal in the vortex rings of the salp trail may provide the amphipod with important information about the distance from the source but not the specificity of the source. The more recently the odor trail was released the sharper the vortex ring boundary will be. These differences in turbulence could be measured independently by mechanoreceptors which when combined with chemical cues measured by chemoreceptors provide the amphipod with the necessary information for orientation towards the source.

When Hamner and Hamner (1977) excised the antennules (thought to be the chemoreceptive organs) from Acetes it was able to pick up the trail but did not persist in following it for long. Therefore these chemoreceptive organs may not have been entirely responsible for perceiving the trail but they were important for persistence in tracking them through the water column. It can be said from this study that Vibilia jeangarardi and Lycaea 
Spp. are able to use chemical signals released by the salp host as cues towards their recognition and location in the pelagic environment. This chemical perception of the salp trail may be very important ecologically, and provide us with an understanding of the mechanisms used by hyperiids to maintain their symbioses in the planktonic environment. 


\section{Literature Cited}

Ache, B. 1974. The experimental analysis of host recognition in symbiotic marine invertebrates. In: Symbiosis in the Sea. W. B. Vernberg (ed). Bella Baruch Library in Marine Science Number 2. U. South Carolina Press, Columbia. pp 45-60.

Ache, B.W. 1982. Chemoreception and thermoreception. In: The Biology of Crustacea, Vol. 3: Neurobiology: Structure and Function (H.L. Atwood and D.C. Sandeman, eds.). Academic Press, New York. pp. 369-398.

Ache, B.W. and D. Davenport. 1972. The sensory basis of host recognition by symbiotic shrimps, genus Betaeus. Biol. Bull. 143: 94-111.

Alldredge, A. L. and L. P. Madin. 1982. Pelagic tunicates: unique herbivores in the marine plankton. Bioscience 32: 655-663.

Atema, J. 1977. Function separation of smell and taste. In: Olfaction and Taste, J. Le Magnen and P. MacLeod (eds.). Information Retrieval Ltd., London. pp. 165-174.

Atema, J. 1980. Smelling and tasting underwater. Oceanus 23: 4-18.

Atema, J. 1985. Chemoreception in the Sea: Adaptations of chemoreceptors and behavior to aquatic stimulus conditions. Soc. Exp. Biol.

Atema, J. 1988. Distribution of Chemical Stimuli. In: Sensory Biology of Aquatic Animals, J. Atema, R.R. Fay, A. N. Popper, and W. N. Tavolga (eds.). Springer-Verlag, New York. pp. 29-56.

Ball, E. E. 1977. Fine structure of the compound eyes of the midwater amphipod Phronima in relation to behavior and habitat. Tissue and Cell 9: 521-536.

Ball, E.E. and A. N. Cowan. 1977. Ultrastructure of the antennal sensilla of Acetes (Crustacea, Decapoda, Natantia, Sergestidae). Philos. Trans. Roy. Soc. London, Ser. B, 277:429-457.

Bleckmann, H. 1988. Prey Identification and Prey Localization in Surfacefeeding Fish and Fishing Spiders. In: Sensory Biology of Aquatic Animals, J. Atema, R.R. Fay, A. N. Popper, and W. N. Tavolga (eds.). Springer-Verlag, New York. pp. 619-642. 
Bone, Q. and E. R. Trueman. 1983. Jetpropulsion in salps (Tunicate, Thaliacea). J. Zool. Lond. 201: 481-506.

Borroni, P.F., L.S. Handrich, and J. Atema. 1985. The role of narrowly tuned taste cell populations in lobster (Homarus americanus) feeding behavior. Behav. Neurosci.

Bossert, W.H. and Wilson, E.O. 1963. The analysis of olfactory communication among animals. J. Theor. Biol. 5: 443-469.

Bowman, T. E. and H. E. Gruner. 1973. The families and genera of Hyperiidea (Crustacea: Amphipoda). Smithsonian. Contr. to Zool. 146: 1-64.

Brown, W.L., Jr., T. Eisner and R.H. Whittaker. 1970. Allomones and kairomones: Transpecific chemical messengers. Bioscience 20: 2122.

Busdosh, M., G.A. Robilliard, K. Tarbox, and C.L. LBeehler. 1982. Chemoreception in an arctic amphipod crustacean: A field study. J. Exp. Mar. Biol. Ecol. 62: 261-269.

Carr, W. E. S. 1988. The Molecular Nature of Chemical Stimuli in the Aquatic Environment. In: Sensory Biology of Aquatic Animals, J. Atema, R.R. Fay, A. N. Popper, and W. N. Tavolga (eds.). Springer-Verlag, New York. pp. 3-28.

Carton, Y. 1968. Specificite parasitaire de Sabelliphilus sarsi, parasite de Spriographis spallanzani. III. Mise en evidence d'une attraction biochemique du copepode par l'Annelide. Arch. Zool. Exp. Gen., 109: 123-144.

Cetta, C.M., L.P. Madin and P. Kremer. 1986. Respiration and excretion by oceanic salps. Mar. Biol. 91: 529-537.

Davenport, D. 1950. Studies in the physiology of commensalism. I. The polynoid genus Arctonoe. Biol. Bull. 98: 81-93.

Davenport, D. 1955. Specificity and behavior in symbioses. Quart. Rev. Biol. 30: 29-46. 
Davenport, D. 1966. The experimental analysis of behavior in symbioses. pp. 381-429. In: Symbiosis Vol. I, S.M. Henry (ed). Academic Press: New York.

Derby, C.D. and J. Atema. 1980. Induced host odor attraction in the pea crab Pinnotheres maculatus. Biol. Bull. 158: 26-33.

Diebel, C.E., K. Stolzenbach, L.P. Madin and J. Atema. 1985. Multisensory trail detection in oceanic amphipods? Biol. Bull. 169 (2): 533-534.

Dimock, R.V. and D. Davenport. 1971. Behavioral specificity and the induction of host recognition in a symbiotic polychaete. Biol. Bull. 141: $472-484$.

Finch, S. 1980. Chemical attraction of plant-feeding insects to plants. In: Applied Biology, Vol. 5 ( T.H. Coaker ed.). Academic Press. pp. 67143.

Fuzessery, Z. M. and J. J. Childress. 1975. Comparative chemosensitivity to amino acids and their role in the feeding activity of bathypelagic and littoral crustaceans. Biol. Bull. (Woods Hole, Ma) 149: 522-538.

Gerber, H. and J. Stout. 1968. Sensory basis of the symbiotic relationship of Arctone vitta (Grube) (Polychaeta, Polynoidae) to the keyhole limpet, Diodora aspera. Physiol. Zool. 41: 169-79.

Gray, I.E., L.R. McClosky and S.C. Wiehe, 1968. The commensal crab, Dissodactylus mellitac, and its reaction to sand dollar host-factor. J. Elisha Mitchell Sci. Soc., 84: 472-481.

Hamner, P.P. and W.H. Hamner. 1977. Chemosensory tracking of scent trails by the planktonic shrimp Acetes sibogae australis. Science 193: 886-888.

Hamner, W.H., P.P. Hamner, S.W. Strand, and R.W. Gilmer. 1983. Behavior of antarctic krill, Euphausia superba: Chemoreception, feeding, schooling and molting. Science 220: 433-435.

Harbison, G.R. 1976. Development of Lycaea pulex (Marion, 1874 and Lycaea vincentii Stebbing, 1888 (Amphipoda, Hyperiidea). Bull. Mar. Sci. 26: 152-164. 
Harbison, G.R. and L.P. Madin. 1976. Description of the female Lycaea nasuta Claus, 1879 with an illustrated key to the species of Lycaea Dana, 1852 (Amphipoda, Hyperiidea). Bull. Mar. Sci. 26: 165-171.

Harbison, G.R., D.C. Biggs and L.P. Madin. 1977. The associations of Amphipoda Hyperiidea with gelatinous zooplankton. II. Associations with Cnidaria, Ctenophora, and Radiolaria. Deep Sea Res. 24: 465488.

Heden, P.A., F. G. Maxwell, and J.N. Jenkins. 1974. Insect plant attractants, feeding stimulants; repellents, deterrents, and other related factors affecting insect behavior. In: Proceedings of the Summer Institute on Biological Control of Plant Insects and Diseases (F.G. Maxwell and F.A. Harris, eds.). University Press of Mississippi, Jackson. pp. 494527.

Hindley, J.P.R. 1975. The detection, location and recognition of food by juvenile prawns, Penaeus merguiensis de Man. Mar. Behav. Physiol. 3: $193-210$.

Hopkins, C.D. 1988. Social Communication in the Aquatic Environment. In: Sensory Biology of Aquatic Animals, J. Atema, R.R. Fay, A. N. Popper, and W. N. Tavolga (eds.). Springer-Verlag, New York. pp. 233-268.

Johnson, B.R., P.F. Borroni, and J. Atema. 1985. Mixture effects in primary olfactory and gustatory receptor cells from the lobster. Chem. Sens. 10: 367-373.

Johnson, B.R. and J. Atema. 198?. Chemical stimulants for a component of feeding behavior in the gulf-weed shrimp Leander tenuicornis (Say).

Kennedy, J.S. 1974. Changes of responsiveness in the patterning of behavioral sequences. In: Experimental Analysis of Insect Behavior (L. Barton Brown ed.). Springer-Verlag, New York. pp. 1-6.

Land, M.F. 1981. Optics and Vision in Invertebrates. In: Handbook of Sensory Physiology. Camparative Physiology and Evolution of Vision in Invertebrates. H. Autrum (ed.), Springer Verlag, Berlin. p. 471592. 
Laval, P. 1963. Sur la Biologie et les larves de Vibilia armata Bov. et de V.propinqua Stebbl, Amphipodes Hyperides. Comp. Ren. Hebd. des Seances de l'Acad. des Sci., Paris 236: 1389-1392.

Laval, P. 1980. Hyperiid amphipods as crustacean parasitoids associated with gelatinous zooplankton. Oceanogr. Mar. Biol. Ann. Rev. 18: 1156.

Law, J.H. and F.E. Regnier. 1971. Pheromones. A. Rev. Biochem. 40: 533548.

Linn, C.E., M.G. Campbell, and W. L. Roelofs. 1987. Pheromone components and active spaces: What do moths smell and where do they smell it? Science 237: 650-652.

Lythgoe, J. N. 1988. Light and Vision in the Aquatic Environment. In: Sensory Biology of Aquatic Animals, J. Atema, R.R. Fay, A. N. Popper, and W. N. Tavolga (eds.). Springer-Verlag, New York. pp. 57-82.

Mackie, A.M. and R.G.J. Shelton. 1972. A whole-animal bioassay for the determination of the food attractants of the lobster Homarus gammarus. Mar. Biol. 14: 217-221.

Madin, L.P. 1974. Field observations on the feeding behavior of salps (Tunicata: Thaliacea). Mar. Biol. 24: 143-147.

Madin, L.P. and G.R. Harbison. 1977. The associations of amphipoda hyperiidea with gelatinous zooplankton. I. Associations with Salpidae. Deep Sea Res. 24: 449-463.

Margulis, L. 1976. The genetic and evolutionary consequences of symbiosis. Exp. Parasit. Rev. 39:277-349.

Margulis, L. 1981. Symbiosis in Cell Evolution. W. H. Freeman and Company, San Francisco. 419 pages.

Meador, J.P. 1980. Chemoreception in a lysianassid amphipod. Amer. Zool. 20: 754 . 
Miller, J.R. and K.L. Strickler. 1984. Finding and Accepting Plant Hosts. In: Chemical Ecology of Insects, W.J. Bell and R.T. Carde (eds.). Sinauer Assoc. Inc., Sunderland, Mass. pp. 127-158.

Nilsson, D.E. 1982. The transparent compound eye of Hyperia (Crustacea): Examination with a new method for analysis of refractive index gradients. J. comp. Physiol. 147: 339-349.

Nordland, D.A. 1981. Semiochemicals: a review of the terminology. In: Semiochemicals Their Role in Pest Control (Nordland, D.A., R.L. Jones and W.J. Lewis eds.). John Wiley, New York. pp. 13-28.

Parson, T.R., M. Takahashi, and Hargrave. 1984. Biological Oceanographic Processes (3rd Ed.) Pergamon Press, New York. 330 pages.

Pirlot, J.M. 1932. Introduction a l'etude des Amphipodes Hyperides. Ann. de l'Inst. Ocean. 12: 1-36.

Ritter, F.J. (ed.). 1979. Chemical Ecology: Odour Communications in Animals. Elsevier/North Holland Biomedical Press, Amsterdam.

Solorzano, L. 1969. Determination of ammonia in natural waters by the phenolhypochlorite method. Limnol. Oceanogr. 14: 799-801.

Strickler, J.R. and A.K. Bal. 1973. Setae of the first antennae of the copepod Cyclops scutifer (Sars): Their structure and importance. Proc. Nat. Acad. Sci., U.S.A. 70: 2656-2659.

Vinogradov, M. E., A. F. Volkov, and T. M. Semjonova. 1984. Amphipods as hyperiids of the Ocean. Liningrad, Nauka. 491pp.

Vinson, S.B. 1977. Behavioral chemicals in the augmentation of natural enemies. In: Biological Control by Augmentation of Natural Enemies (R.L. Ridgeway and S.B. Vinson eds.). Plenum Press, New York. pp. 237-279.

Vinson, S.B. 1984. How parasitoids locate their hosts: A case of insect espionage. In: Insect Communication, (T. Lewis, ed.). Academic Press, New York. pp. 325-348. 
Vinson, S.B. 1984. Parasitoid-Host Relationship. In: Chemical Ecology of Insects, W.J. Bell and R.T. Carde (eds.). Sinauer Assoc. Inc., Sunderland, Mass. pp. 205-236.

Webster, S.K. 1968. An investigation of the commensals of Cryptochiton.

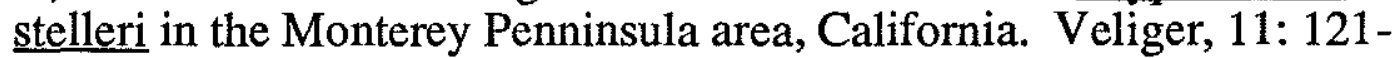
125.

Whittaker, R.N. 1970. Communities and Ecosystems. Macmillan, New York.

Wilcox, R. S. 1988. Surface Wave Reception in Invertebrates and Vertebrates. In: Sensory Biology of Aquatic Animals, J. Atema, R.R. Fay, A. N. Popper, and W. N. Tavolga (eds.). Springer-Verlag, New York. pp. 643-664.

Wilson, E. O. 1970 . Chemical communication within animal species. In: Chemical Ecology (E. Sondheimer and J.B. Simeone, eds.). Academic Press, New York. pp. 133-155.

Zimmer-Faust, R.K., J.E. Tyre, W.C. Michel, and J.F. Case. 1984. Chemical mediation of appetitive feeding in a marine decapod crustacean: the importance of suppression and synergism. Biol. Bull 167: 339-353. 


\section{List of Figures}

Figure 1. A morphological and ecological comparison between species of A. Lycaea and B. Vibilia .

Figure 2. Results of behavioral tests of Vibilia jeangarardi with different salps and stimuli. A: with Salpa cylindrica; B: with Pegea bicaudata; C: with Cyclosalpa polae; and D: in miscellaneous tests. $\mathrm{P}(\mathrm{k})$ is the probability of the number of successes counted as positive in the trials as being significant. The ratio above each column represents: \# of positive tests / total number of tests.

Figure 3. Results of behavioral tests of Lycaea spp. with different stimuli. A: with Cyclosalpa affinis; B: with Salpa maxima; C: with Pegea bicaudata; D: with two hosts Salpa maxima and Cyclosalpa affinis. $\mathrm{P}(\mathrm{k})$ is the probability of the number of successes counted as positive in the trials as being significant. The ratio above each column represents \# of positive tests / total number of tests. In 4D the number of positive tests were scored as those which were positive towards Salpa maxima as L. pulex was originally found on $\underline{\text { S. maxima. }}$.

Figure 4. Ammonium and amine concentrations of salp stimulus water and control sea water measured over time on the Calanus 8707 cruise. A: ammonium concentrations; B: amine concentrations. 
Figure 1. A morphological and ecological comparison between species of A. Lycaea and B. Vibilia . 


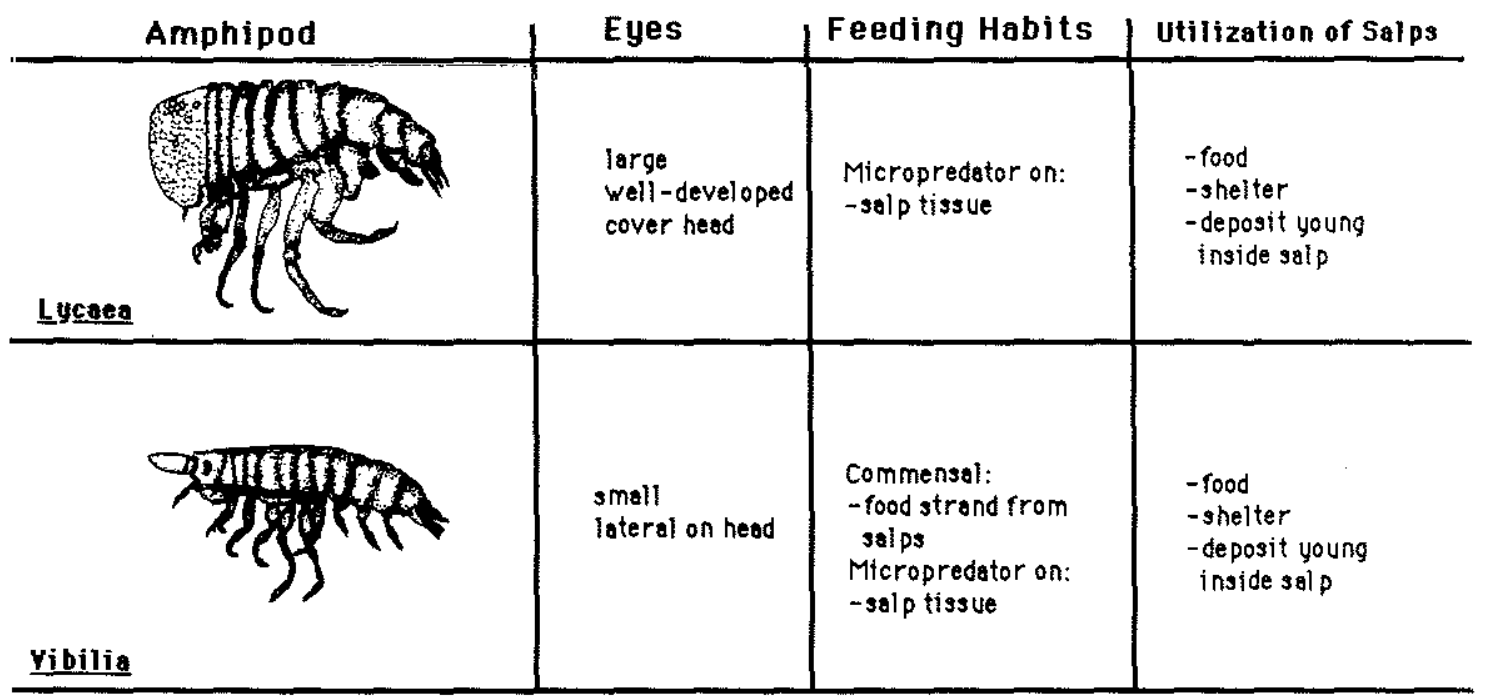


Figure 2. Results of behavioral tests of Vibilia jeangarardi with different salps and stimuli. A: with Salpa cylindrica; B: with Pegea bicaudata; C: with Cyclosalpa polae; and D: in miscellaneous tests. P (k) is the probability of the number of successes counted as positive in the trials as being significant. The ratio above each column represents: \# of positive tests / total number of tests. 

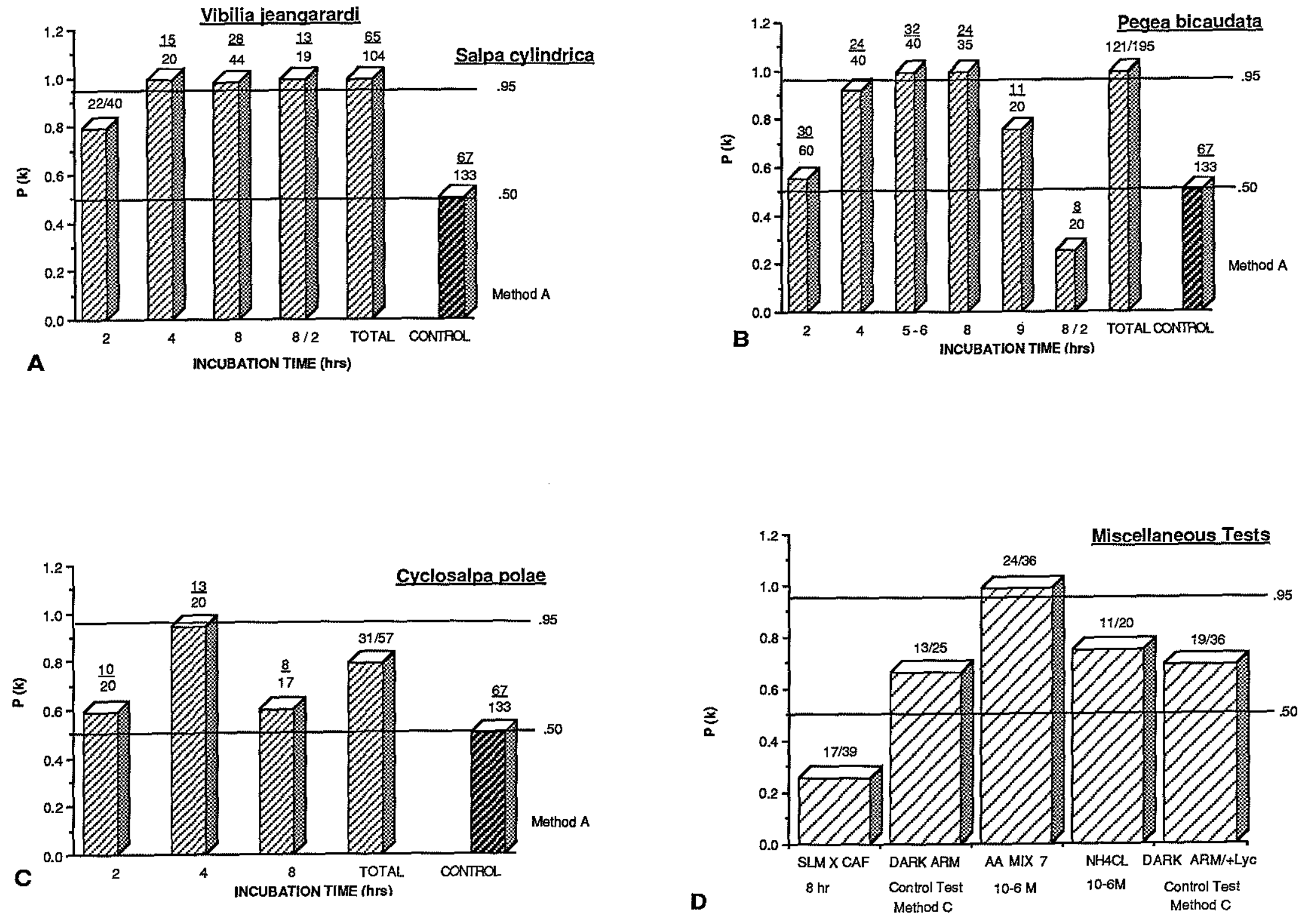
Figure 3. Results of behavioral tests of Lycaea spp. with different stimuli. A: with Cyclosalpa affinis; B: with Salpa maxima; C: with Pegea bicaudata; D: with two hosts Salpa maxima and Cyclosalpa affinis. $P(k)$ is the probability of the number of successes counted as positive in the trials as being significant. The ratio above each column represents \# of positive tests / total number of tests. In $4 D$ the number of positive tests were scored as those which were positive towards

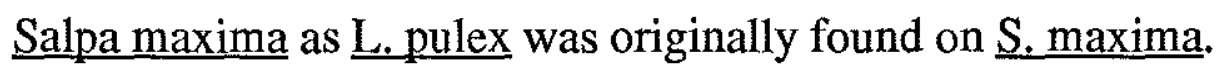



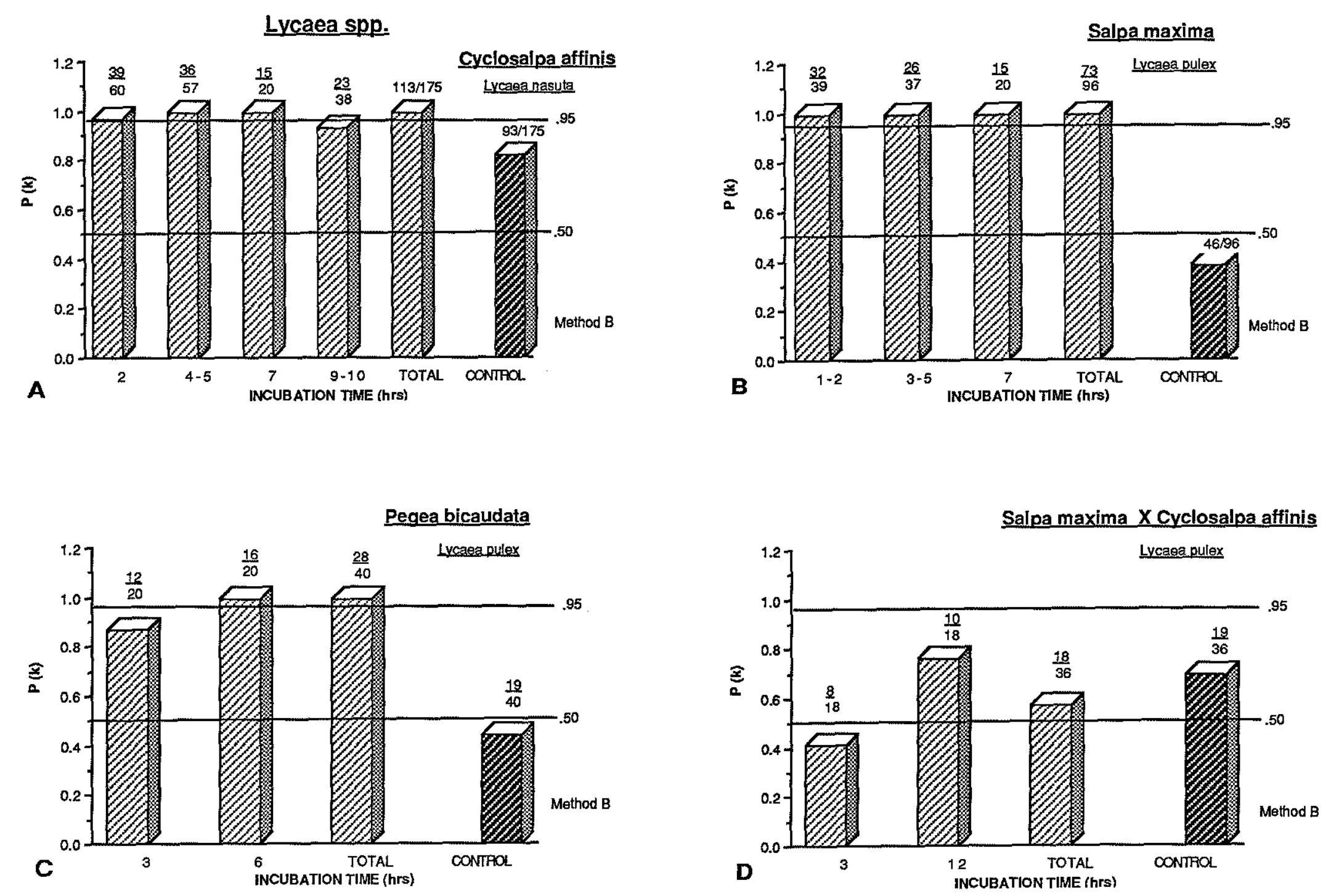
Figure 4. Ammonium and amine concentrations of salp stimulus water and control sea water measured over time on the Calanus 8707 cruise. A: ammonium concentrations; B: amine concentrations. 

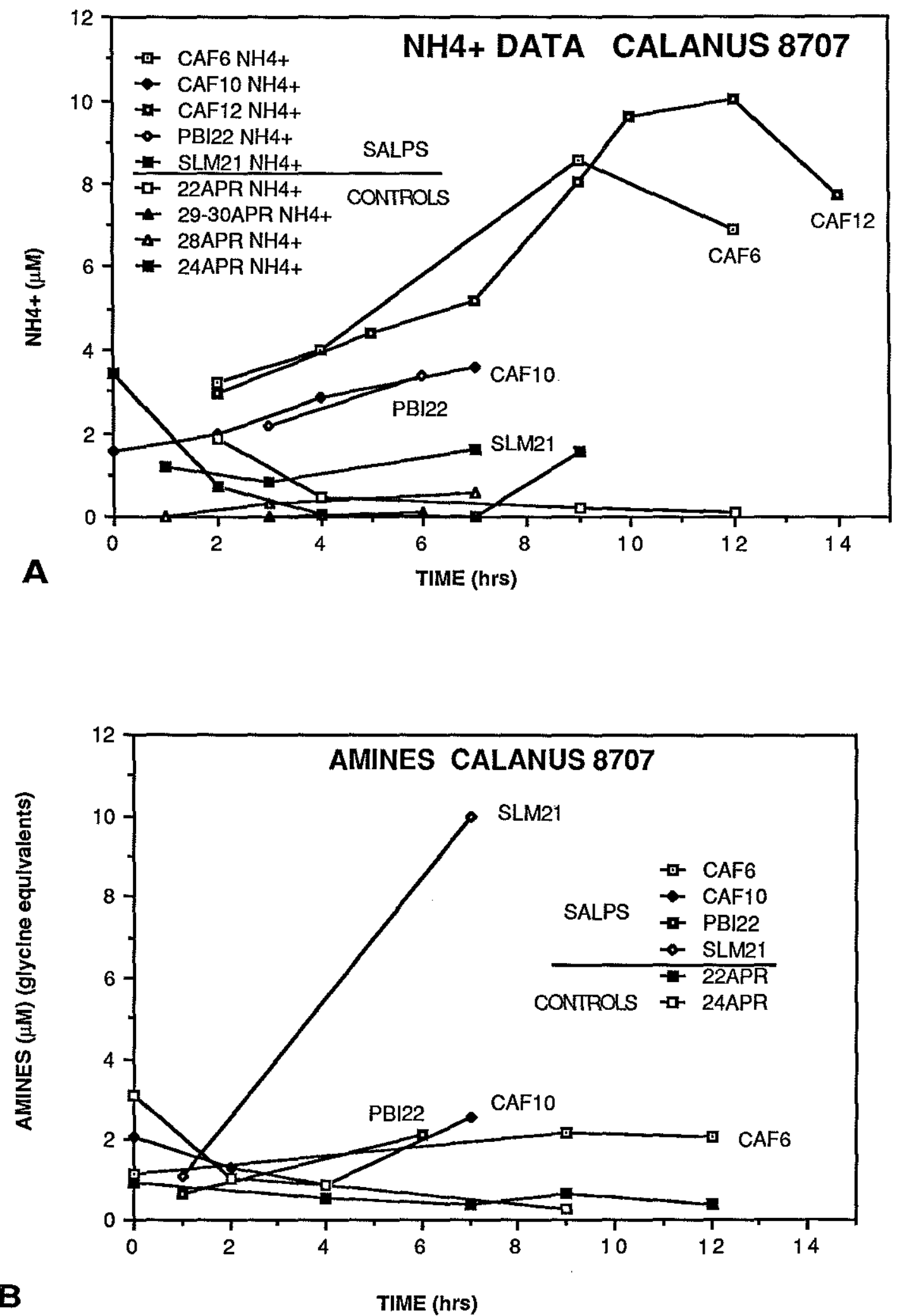
Table I Salp odor preparations used in behavioral tests expressed in grams of wet weight per liter of sea water.

Salp species (\#batches)

Range (g/l)

$\operatorname{Mean}(\mathrm{g} / \mathrm{l})$

Pegea bicaudata (5)

$0.1667-20.41$

11.120

Salpa cylindrica

$6.0125-15.20$

10.112

Salpa maxima

(1)

3.5967

3.597

Cyclosalpa affinis (3)

$10.631-14.929$

12.383

Cyclosalpa polae (1)

Values were calculated using the Regression where:

Volume $=0.134 \times$ length $-1.975, \mathrm{r}^{2}=0.61$, which shows the relationship between displacement volume and length for live salps (Madin et al, (1981). 
Table II Total number of tests

Salp

Vibilia jeangarardi

Lycaea spp

Significant \#tests

Response

Cyclosalpa affinis

Cyclosalpa polae

Pegea bicaudata

Salpa maxima

Salpa cylindrica

Salpa maximax

Cyclosalpa affinis

Amino Acid Mixture of $7-10^{-6}$

NH4 -10-6

Controls

Method A

Method B

Method C dark arm

Total Controls

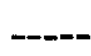

NO

YES

215

$-\cdots$

YES

NO

YES

NO

20

NO

133

NO

367

NO

36

NO

36
Significant \#tests Response

YES 175 (L. nasuta)

YES 40 (L.pulex)

YES 96 (L. pulex)

NO 36 (L.pulex $)$

$33 \quad$ NO 46 (L.

NO 347 (L. nasuta).

NO 4

(L. pulex)

NO 397 


\section{Chapter 5}

Observations on the anatomy and behavior of

Phromima sedentaria (Forskål)(Amphipoda: Hyperiidea) 


\begin{abstract}
Phronima sedentaria is one of the most well-known and common hyperiid amphipods in the plankton, and its relationship with gelatinous zooplankton such as siphonophores, pyrosomes and salps has been central to their invasion of the pelagic zone. These amphipods have adapted to the pelagic realm through various morphological, physiological and behavioral specializations. Behavioral specializations include the formation of transparent barrels from salps, which they pilot through the water and on which they deposit their young (demarsupiation).

Feeding behavior appears to vary with the consistency of the gelatinous organism being ingested. Pereiopods 3 and 4 are used to pick and pull soft-bodied prey toward the mouth, where the mouthparts may remove smaller pieces and push them into the esophagus. If the tissue is somewhat tough, pereiopods 1-3 hold the tissue across the mouthcone area where the mandible can bite and tear off small pieces. On the other hand, if the material is fairly fluid (e.g. salp stomach contents), the mouthparts flatten against the wall of the mouth cone and the contents are sucked into the foregut using the muscles of the esophagus and gut.

The internal anatomy is roughly similar to other described amphipods but differs in certain respects. The digestive system differs from the generalized amphipod as depicted by McLaughlin (1980) in that the foregut is reduced and completely enclosed by a midgut chamber. The midgut caeca are reduced in size. The brain is circumesophageal and has four pairs of major nerves, which lead to the dorsal and ventral compound eyes, ventral nerve cord, and antennules. The reproductive and circulatory systems are described.
\end{abstract}




\section{Introduction}

Hyperiid amphipods rank third in abundance following copepods and euphausiids as members of the marine crustacean zooplankton. They are entirely marine, pelagic, and mostly oceanic, with a few species found in coastal waters. The ecological place of hyperiids is distinct from that of most other pelagic crustaceans. They are almost all symbionts (for at least part of their lives) with gelatinous organisms such as salps, medusae, siphonophores and ctenophores, which may be used as a platform for feeding, a food source, or as a nursery for developing young (Harbison et al., 1977; Laval, 1980; Madin and Harbison, 1977; Pirlot, 1932).

Phronima sedentaria (Forskål,1775) is the most abundant species in the family Phronimidae and has a worldwide distribution (Shih, 1969). The characters of the family and genus have been described by Bowman and Gruner (1973). Phronima sedentaria exhibits diurnal vertical migration with no apparent differences among age classes, and is relatively abundant in epi- and mesopelagic waters. Its geographical distribution is related to water masses (Shih, 1969).

Phronima is a free-swimming carnivorous predator that uses salps, pyrosomes, or siphonophores as a food source, feeding platform, and brood chamber (Bowman and Gruner, 1973; Laval, 1980; Schaadt, 1982). The female has a slender, elongate body ranging from 5-40 $\mathrm{mm}$ long, large compound eyes and very short, 2 -segmented antennules. The mouthparts are reduced compared to gammarideans, and the mandible has a large molar process and incisor but no palp (Bowman and Gruner, 1973).

Claus (1879) wrote about the internal anatomy of Phronima in elegant detail but there are a number of confusing and inaccurate descriptions in his 
monograph. Although his text is difficult to understand and interpret, his illustrations are beautiful, precise and worthy of attention. There has been no subsequent work on the internal anatomy of the female of Phronima . Indeed, only a few anatomical studies have been done on any hyperiids and most of them emphasize the gut structure (e.g. Garbowski, 1896; Woltereck, 1927; Dunbar, 1946; Bowman, 1960; Agrawal, 1967; Sheader and Evans, 1975; Brusca, 1981a). The eyes have been studied in some detail by Ball (1977) and Land (1981). The purpose of this paper is to clarify some of Claus' descriptions with new data on internal anatomy, and to present new observations on feeding behavior, demarsupiation, and the formation of a barrel from a salp. These data are based on my own observations, dissections, and sections of Phronima sedentaria. 
Materials and Methods

Some of the material described here was collected by SCUBA divers on cruises in the western Atlantic; other specimens were from plankton tows made in the northeastern Pacific by the Oceanography Department at Humboldt State University, Arcata, California. Individuals were examined under a stereomicroscope, and identified using the keys of Bowman and Gruner (1973), Shih (1969), and Brusca (1981b). Dissections were performed with jewelers' forceps and fine dissecting needles. Animals used for histology were placed in a variety of fixatives including Bouin's, 3\% glutaraldehyde, Karnavosky's (paraformaldehyde-glutaraldehyde), and $4 \%$ Formalin. For paraffin sections the animals were dehydrated through an ethanol series, transferred to cedarwood oil, and infiltrated and embedded in paraffin at $56.5 \circ \mathrm{C}$. Serial transverse and sagittal sections $(5-7 \mu)$ were made on a rotary microtome, mounted on slides and differentially stained with either Delafields hematoxylin and eosin or Van Giesen tripan blue (Clark, 1973). These sections were used for description of the internal anatomy.

All behavioral observations were made at sea on healthy Phronima collected individually by SCUBA divers. These animals were kept on a 12 hour light/dark cycle and allowed to swim freely in 2-10 liter aquaria. Animals used for feeding experiments were starved for 24 hours then allowed to feed (time 0 ) on salps until satiated. Excess food was then removed and the aquarium was checked every half hour for the presence of fecal pellets. The time of release of the first fecal pellet was recorded as the 
gut-passage time. Fecal pellets were collected until all the food had passed through the digestive system. Details of feeding behavior were videotaped through a Tessovar macrophotograhic apparatus. 


\section{Results}

\section{Digestive System}

The mouthparts of Phronima have been described by various authors for taxonomic purposes (e.g. Shih, 1969; Bowman and Gruner, 1973), and the anatomy of the mouth and muscular arrangement are described in detail by Claus (1879). Claus mentions the presence of large glands located lateral to the esophagus and with excretory canals, some of which lead orally to the dorsal lip and maxillae. He incorrectly concluded that these glands produced digestive enzymes. Their function is more likely lubricative, since secretion of enzymes in crustaceans is limited to the midgut (Dall and Moriarty, 1983).

Figures 2 and 3 illustrate the digestive system and associated structures. The mouth joins a short esophagus, which leads into a saclike foregut with two ventral pouches. At the entrance to the foregut are two toothed cuticular plates (Fig. 3C,F), which help prevent food from being regurgitated and may aid in grinding and swallowing. Each plate has a separate muscle attached to it. These plates form part of the median walls of a pair of ventral pouches of the foregut. There are also several sclerotized sheets or folds, which are part of the foregut and bear various toothlike structures that may aid in the mechanical breakdown of food (Fig. 3B,F). These "foregut sheets" extend into the lumen of the midgut. Initial sorting and mechanical breakdown of food is accomplished by the mouthparts with the foregut breaking the food down further.

The foregut itself is not divided into cardiac and pyloric regions but consists of one chamber or sclerotized sac, which is completely surrounded by a midgut and connected to the midgut through an orally directed opening. 
From the orientation of this opening it appears that enzymes could be squeezed from the four ventral diverticula of the midgut into the foregut and mixed with the ingested food. I have observed peristaltic movement of the four ventral diverticula after the ingestion of food into the foregut.

The midgut is a large saclike structure completely enclosing the foregut. It has two pairs of ventral diverticula that arise anteriorly and orally from the midgut (Fig. 3A,B). These are probably involved in enzyme secretion. Sections through the diverticula show blisterlike cells lining their walls (Fig. 3D). The midgut wall is muscular as evidenced by the peristaltic movement (anteriorly and posteriorly directed) I observed during digestion. There are several ridges (Fig. 3B) that extend from anterior to posterior through the midgut. These ridges may help the midgut expand to accommodate more food, or may guide food posteriorly into the narrow tube that connects to the hindgut (Fig. 3A,B). This midgut tube, or anterior intestine, is separated from the main chamber of the midgut and from the hindgut by sphincter muscles. Its walls are lined with microvilli (Fig. 3E) and may be an area for further nutrient absorption. This area may also form the fecal pellets and secrete the peritrophic membrane which surrounds it, as has been suggested by Sheader and Evans (1975) for Parathemisto.

The sclerotized hindgut is thin-walled and somewhat extensible. It has rings of circular muscle that aid in movement of the fecal material, which passes quickly through it and out the ventrally directed anus (Fig. 3A). I have also observed anal uptake of water, which appears to facilitate the removal of fecal pellets from the long hindgut. 
Female Reproductive System

The ovaries are paired tubular organs that extend from the posterior end of the head region to the fifth pereionite, depending upon their stage of development (Fig. 4A,C). Anteriorly the ovaries are dorsolateral to the digestive chamber. They adhere closely to the digestive chamber as far as the first pereionite, where they continue posteriorly, ventral to the heart, to the fifth pereionite. At the anterior edge of the fifth pereionite each ovary constricts into a slender oviduct which curves laterally and ventrally to exit out the gonopores at the bases of the fifth pereiopods (Fig. 4 A-D). In the resting stage between egg production the ovaries show evidence of atrophy and they are positioned more lateral to the digestive tract and extend only from the first to the third pereionite (Fig. 4A,B). In this stage the oviducts and ovaries are transparent and threadlike in appearance (Fig. 2). In a more mature stage of egg development each ovary appears as a sheet of cells, one cell thick, surrounded by a thin epithelial layer (Fig. 4 C-E). The two sheets of cells may overlap slightly and extend dorsal to the digestive chamber and ventral to the heart (Fig. 4E). The oviducts of this stage are more swollen in appearance (Fig. 4C,D). 
Nervous System

The nervous system has been studied in detail by Claus (1879). I give here a general overview and description based on my observations and dissections. This description agrees with that of Claus and does not differ basically from that of other crustacean nervous systems.

The main elements of the nervous system are the cerebral ganglion (composed of a large supraesophageal ganglionic mass with optic lobes, a subesophageal ganglionic mass, and circumesophageal connectives) and the ventral nerve cord with a series of fused ganglia along its length (Fig. 5A, D). The supraesophageal ganglion and esophageal connectives form a ring around the esophagus, just anterior and oral to the dorsal and ventral midgut diverticula (Fig. 5E, F). Two winglike optic lobes arise dorsolaterally from the supraesophageal ganglionic mass and are composed of many nerve tracts (or optical nerves) that originate from the individual ommatidia of the dorsal and ventral eyes (Fig. 5B, D). These nerve tracts are easily separated into two distinct bundles, one originating from the dorsal eye and the other from the ventral eye. The antennular nerves arise from the anterior border of the supraesophageal ganglion near the optic lobes that serves the dorsal eyes (Fig. 5B, F).

The subesophageal ganglionic mass (Fig. 5C, D) is ventral to the supraesophageal ganglion and joined to it by circumesophageal connectives. It is about half the size of the supraesophageal ganglion and represents the fusion of the ganglia of the mouthparts, the second antennae, and the first two pairs of pereiopods. Close examination of the subesophageal ganglion 
reveals what appears to be a pair of nerve centers (nuclei) near its posterior end, reflecting the fusion of the original first and second thoracic ganglia with the subesophageal ganglion (Fig. 5C). Several small nerves from the anterior margin of the subesophageal ganglionic mass lead to the mouthparts and second antennae. The subesophageal ganglion is connected to the ventral nerve cord posteriorly by longitudinal connectives.

There are five segmental ganglia in the thorax and three in the pleon. Between each of the ganglia the ventral nerve cord separates and appears double or ladderlike (Fig. 5D). Each ganglion of the ventral nerve cord gives rise to lateral nerves serving the appendages and intersegmental muscles of the body wall. Figure 5D shows each ganglion and the appendages it innervates. The last abdominal ganglion gives rise to a group of nerves that extend into the urosome and innervate the muscles of the hindgut. 
Circulatory System

The circulatory system is shown in Fig. 6A. The heart of Phronima does not differ dramatically from that of other amphipods. It is confined to the thorax, extending from the second to the sixth thoracic segment, and is enclosed in a pericardial sinus. The posterior aorta is a simple tube that extends back from the sixth thoracic segment through the last abdominal segment where it opens beside the intestine. The anterior aorta extends into the head where it opens into a capillary-like net system or sinus that surrounds the eyes and brain. There are two pairs of lateral arteries connecting the heart to a large sinus surrounding the digestive system. At the origin of each of the arteries there is a one-way valve that helps to prevent the flow of blood back into the heart upon diastole (Fig. 6B, C). The sinus that surrounds the digestive system is subdivided into two sections, one around the anterior thoracic aspect of the intestine and one around the midgut or digestive chamber. The sinus that surrounds the midgut or digestive chamber appears to have muscle bands that may aid in the flow of blood through the sinus. Peristaltic movement of the midgut may also aid in circulating blood in this area. Figure $6 \mathrm{~B}$ shows the position of the heart in the pereion where a lateral artery joins the heart.

Blood enters the heart through the venous ostia and then is forced by contractions into the anterior, posterior and lateral aortae. Videotapes show the heart beating at a rate of 7 beats $/ \mathrm{s}$ (at $25^{\circ} \mathrm{C}$ ) while Phronima is at rest. Blood flows through the various sinuses and is directed, to some extent, into other parts of the body through a "canal system" (as defined by Claus), 
formed by the septa of the sinuses (Fig. 6D). According to Claus (1879) blood in the posterior aorta appears to flow into the abdomen, descend and flow through loops of vessels into the pleopods through the ventral canal, ascend to the pericardial sinus and dorsal canal and then back to the heart. Blood in the anterior aorta circulates through the head and returns directly to the pericardial sinus. Finally, blood in the lateral arteries flows through the two sinuses surrounding the digestive system, then moves ventrally through a vessel paralleling the nerve cord to the fourth-sixth thoracic segments and ascends back to the heart. 
Demarsupiation

Demarsupiation, or deposition of progeny on the host, has been described for Vibilia armata (Laval, 1963, 1980), and Lestrigonus schizogeneios, Hyperoche mediterranea, and Bougisia ornata (Laval, 1980). I observed demarsupiation only once in a female Phronima $(18 \mathrm{~mm}$ in length). This observation was made with a stereomicroscope and incident room light. The female was in the barrel and swimming in a $250-\mathrm{ml}$ container. Approximately 50 immature forms were already on the barrel and it took approximately $50 \mathrm{~min}$ for the female to remove the remaining 50 from her marsupium.

With the body bent into a " $\mathrm{V}$ " shape, rapid beating of the first pair of pleopods forced water into the brood pouch causing it to pulsate and spread the oostegites slightly apart. While pereiopods $3,4,6$, and 7 were used to maintain the position of the animal in the barrel, pereiopods 1 and 2 moved synchronously over the marsupium in a lateral to midventral motion, gently squeezing the immature forms out between the oostegites. Pereiopod 5 was not utilized in this procedure and hung loosely out the barrel. The immature forms fell onto the inside wall of the barrel where they secured themselves and then moved together to form a band around the inside wall. After all the young were out of the marsupium the female cleaned the oostegites using pereiopods 1 and 2.

This method of demarsupiation by Phronima sedentaria differs from that observed by Laval (1980) in the use of the pleopods by the female to pump water into the marsupium. He observed pereiopods 1 and 2 spreading the oostegites and then combing the immature forms out. Phronima 
probably uses either technique. Laval observed Phronima sedentaria in a small vial, which might have prevented it from creating a strong enough current to spread out the oostegites. In both instances, only pereiopods 1 and 2 were used to remove the young while the other pereiopods held onto the barrel.

If the young are removed from the barrel and left in an aquarium, they find their way back to the barrel, crawl along its external surface to an opening, crawl inside, and realign themselves with the other young. I have also noted that if the young are kept in the dark at night they disperse themselves over the inside and outside surface of the barrel. If they are disturbed by a strong light or by the barrel being bumped, they quickly realign themselves into a band on the interior wall of the barrel. This behavior has also been observed by divers in the field at night (G. Dietzmann, personal communication). When the female Phronima feeds (e.g., on a salp), she drags the food item back into the barrel. The young then swarm over the surface of the food and feed on it. After they have finished eating, they realign themselves into a distinct band around the barrel. 
Barrel-Making

Females of Phronima modify salps, siphonophores or pyrosomes into barrels or houses in which they live and which they use as a nursery for their young (Laval, 1978). I have observed a female ( $35 \mathrm{~mm}$ long) making a barrel out of a solitary of Salpa maxima( $105 \mathrm{~mm}$ long). The process is basically the same as described by Laval (1978) for a smaller female making a barrel out of a Thalia democratica, except that the female I observed entered the salp through one of its apertures and did not cut a new opening. The Phronima I observed was clinging to the outside of the solitary of Salpa maxima when collected by SCUBA divers and was observed to nip at the exterior wall of the salp. Both the amphipod and the salp were returned to the lab and placed in a 2-1 aquarium, where the female began the process of forming a barrel from the salp.

The female entered the salp, cut out the brain and gill bar, and consumed them, ate the stomach and its contents, and then remained relatively quiescent for approximately $5 \mathrm{~h}$. The female then resumed eating the salp, cutting off strips of tissue at both ends, and removing pieces of the internal organs, eating only the muscle bands. The salp barrel now measured only $55 \mathrm{~mm}$, and the female began to propel it through the water in the typical phronimid manner (see Minkiewicz, 1909). She then began to scrape the internal wall of the barrel with her mouthparts and pereiopods 1 and 2 . This behavior continued intermittently for several hours, alternating with grooming behavior. Grooming behavior consisted of scraping the dorsal surface of the body with the propus of pereiopods 3 and 4 and picking at the pleopods with pereiopods $1-3$. After $40 \mathrm{~h}$ the barrel was completely formed; 
at $35 \mathrm{~mm}$, it was one third the length of the living salp. The inner wall was scraped completely smooth and the salp tunic material had become quite stiff.

I have observed, along with Schaadt (1982) and Laval (personal communication), a network of tunnels or burrows penetrating the walls of some of the barrels made by Phronima. Schaadt (1982) identified these as being made by some form of bodonid flagellate. I have also found Ephelota

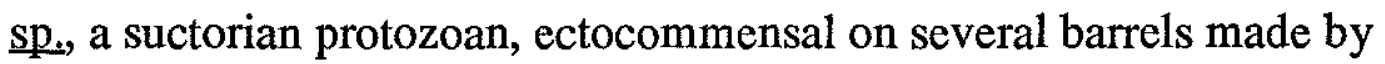
Phronima, and on the surface of Phronima itself.

Two female Phronima were observed fighting over the occupation of a barrel. This behavior occurred after I introduced a free-swimming female into an aquarium that already contained a female in a barrel with her young. The aggressive actions were similar to the movements described by Minkiewicz (1909, figs. 29-31). The introduced female attached herself to the outside end of the barrel occupied by the other female and twirled the barrel through the water in a tight circle at full swimming speed. The female inside the barrel was eventually dislodged and slipped towards the opposite end of the inside of the barrel. The female outside the barrel then quickly bent her abdomen, slipped inside the barrel through one opening and forced the other female outside through the other opening of the barrel. This aggressive behavior was repeated several times by each female until eventually the female originally in the barrel regained possession. The young stayed in a tight band on the inside of the barrel wall throughout this sequence of events. 
Feeding and Digestion

The use of the appendages and mouthparts by Phronima varies somewhat according to the consistency of the food item being ingested. In general the videotapes of Phronima feeding on salps show that pereiopods 1 and 2 handle the food, pereopods 3 and 4 position the food in front of the mouth, and the maxillipeds and maxillae manipulate the food and help to break it down into smaller pieces before passing it into the esophagus. The mandible helps to break down the food into smaller pieces.

With soft bodied prey such as salps, Phronima uses pereiopods 3 and 4 to hold onto the salp while pereopods 1 and 2 alternate picking and pulling the food towards the mouth. The mouthparts may remove smaller pieces, or, if the pieces of food are small enough, they may be pushed directly into the esophagus. If the tissue is somewhat tough, pereiopods 1-3 may stretch the food across the mouthcone where the mandibles can bite and tear off small pieces of tissue, which pass directly into the esophagus. On the other hand, if the material to be ingested is fairly fluid (e.g., salp stomach contents), Phronima uses its mandibles to bite through the tough stomach wall and create an opening that, with the help of pereiopods $1-3$, is positioned over the mouthcone. The mouthparts then flatten against the wall of the mouthcone. Using gut peristalsis and the muscles of the esophagus, Phronima sucks the fluid through the mouth and esophagus directly into the digestive chamber.

As stated previously, food particles enter the foregut where mechanical breakdown (and possibly predigestion) occurs, after which they are passed into the midgut for final breakdown and absorption. Undigested matter is moved into the anterior intestine where it is compacted into fecal 
pellets, and surrounded with a peritrophic membrane. Fecal pellets move rapidly through the hindgut and out the anus with the help of muscular contraction of the hindgut and anal uptake of water.

Phronima is a carnivorous predator feeding mainly on crustaceans, cnidarians, thaliaceans and chaetognaths (Shih, 1969; Richter, 1978; Schaadt, 1982). I have made several measurements of the gut passage time of salps consumed by Phronima sedentaria (Table I). In general there appears to be a difference in times between those fed during the day and those fed at night. The average gut passage time during the night is $4 \mathrm{~h} 46 \mathrm{~min}(\mathrm{~N}=6$; plus or minus $2 \mathrm{~h} 25 \mathrm{~min}$ ). Phronima fed more readily at night and usually consumed greater amounts of food. The increased volume of food consumed may help to account for the shorter residence times. The gut passage time during the day was $14 \mathrm{~h} 07 \mathrm{~min}(\mathrm{~N}=2)$ (see Table I). 


\section{Discussion}

Phronima is a fascinating animal that lives up to the Greek origin of its name, which means "clever." They are one of the most well known and common hyperiid amphipods in the plankton, and their relationship with gelatinous zooplankton such as salps and siphonophores has been central to their invasion of the pelagic zone. They have adapted to the pelagic realm through various morphological, physiological and behavioral specializations. If one compares Phronima with the diagram of the generalized amphipod condition in McLaughlin (1980) several differences are evident in its internal anatomy. There is a simplification of the digestive system with the foregut reduced to one chamber, which retains few masticating or triturating teeth and ridges. The midgut has fewer and smaller midgut caeca or diverticula and a shortened intestine. The optic lobes of the brain have become enlarged and winglike accomodating the increased number of optic tracts coming from the eyes. Other than these few differences the internal anatomy is similar to the generalized amphipod condition described by Mc Laughlin (1980).

The differences in the foregut deserve special mention because there appear to be morphological specializations within the Hyperiidea. The foregut of Phronima is similar to that of Hyperia (Agrawal, 1967) and Parathemisto (Themisto) (Sheader and Evans, 1975) in that it is a toothed chamber reduced in size and surrounded by an enlarged midgut. The function of the foregut is probably the mechanical breakdown of food before it is passed quickly to the midgut. Within the midgut are "foregut sheets," which may protect the midgut epithelium from the abrasive action of food 
being moved around the chamber, yet still allows for digestion and absorption to take place.

The structure and function of the foregut of Phronima differ somewhat from other hyperiid amphipods. In Lanceola the foregut is an enlarged chamber with no visible armament (Woltereck, 1927). The foregut of Lanceola may function more as a stomach where food is initially stored during bouts of feeding and then broken down by enzymes secreted into the chamber by the midgut cells. I have observed this method of feeding and digestion in Lanceola in the field on several occasions. In oxycephalid hyperiids such as Oxycephalus, Streetsia, and Rhabdosoma I have observed that the foregut is reduced to a small chamber armed with a few teeth, and functions as an esophageal chamber. Food passes quickly into the digestive caeca where it is broken down for digestion. Differences in their digestive anatomy may reflect differences in the ecology, of these other hyperiids. 


\section{ACKNOWLEDGEMENTS}

I thank Dr. L. Madin, C. Cetta, G. Dietzmann, T. Stebbins, D. Richards and all others who helped collect Phronima at sea. The Oceanography Department and Dr. G. Brusca at Humboldt State University allowed me to pick through some of their plankton tows for specimens. Dr. R. Brusca also provided additional specimens from his plankton tows. Humboldt State University provided space in their histology laboratory. Dr. L. Madin and Dr. G. R. Harbison kindly provided shiptime and space on several different cruises. I am grateful to L. Madin and G. Brusca for critically reading the manuscript and offering many constructive suggestions. This work was supported in part by the Education Office at the Woods Hole Oceanographic Institution and by the Lerner-Gray Fund for Marine Research of the American Museum of Natural History. This is Contribution No. 6604 of the Woods Hole Oceanographic Institution. 


\section{Literature Cited}

Agrawal, V. P. 1967. The feeding habit and digestive system of Hyperia galba. -Proceedings of the Symposium on Crustacea held at Ernakulam, Marine Biological Association of India, 2: 545-548.

Ball, E. E. 1977. Fine structure of the compound eyes of the midwater amphipod Phronima in relation to behaviour and habitat. -Tissue \& Cell 9: 521-536.

Bowman, T.E. 1960. The pelagic amphipod genus Parathemisto

(Hyperiidea: Hyperiidae) in the North Pacific and adjacent Arctic Ocean. -Proceedings of the United Stated National Museum, 112 (3439) : 343392.

, and H. E. Gruner. 1973. The families and genera of Hyperiidea

(Crustacea: Amphipoda). -Smithsonian Contributions to Zoology 146:164.

Brusca, G. J. 1981a. On the anatomy of Cystisoma (Amphipoda:

Hyperiidea). -Journal of Crustacean Biology 1: 358-375.

Brusca, G. J. 1981b. Annotated keys to the Hyperiidea (Crustacea:

Amphipoda) of North American coastal waters. -Technical Report of the Allan Hancock Foundation 5:1-76.

Clark, G. (ed.). 1973. Staining Procedures used by the Biological Stain Commission. Third Edition-The Williams and Wilkins Company, Baltimore, Maryland. Pp. 1-418. 
Claus, C. 1879. Der Organismus der Phronimiden. Arbeiten aus dem Zoologischen Institut der Universitat Wien und der Zoologischen Station in Triest 2:59-146.

Dall, W., and D. J. W. Moriarty. 1983. Chapter 4: Functional Aspects of Nutrition and Digestion. -In: L. Mantel (ed.): The biology of Crustacea, Vol. 5. Internal anatomy and physiological regulation. Pp. 215-251. Academic Press, New York.

Dunbar, M.J. 1946. On Themisto libellula in Baffin Land coastal waters. Journal of the Fisheries Research Board of Canada 6: 419-434.

Forskål, P. 1775. Descriptiones Animalium, Avium, Amphibiorum, Piscium, Insectorum, Vermium, quae in itinere orientali observavit $P$. Forskal. Hauniae. Pp. 1-220.

Garbowski, T. 1896. Hyperidenartige Amphipoden des Mittelmeeres. Monographisch bearbeitet auf Grund des wahrend der funf Expeditionen S. M. Schiffes "Pola" gesammelten Materiales (1890-1894). 1. Thiel. Die Sciniden. -Denkschriften der Osterreichischer Akademie der Wissenschaften, Mathematisch-Naturwissenschaftliche Classe 63: 39117.

Harbison, G. R., D. C. Biggs, and L. P. Madin. 1977. The associations of Amphipoda Hyperiidea with gelatinous zooplankton - II. Associations with Cnidaria, Ctenophora, and Radiolaria. Deep Sea Research 24: 465488.

Land, M.F. 1981. Optics of the eyes of Phronima and other deep-sea amphipods. Journal of Comparative Physiology145: 209-226. 
Laval, P. 1963. Sur la biologie et les larves de Vibilia armata Bov. et de $\underline{\text {. }}$ propinqua Stebb., Amphipodes Hyperides. -Comptes Rendus Hebdomadaires des Seances de l'Academie des Sciences 236: 1392.

. 1978. The barrel of the pelagic amphipod Phronima sedentaria

(Forsk.) (Crustacea: Hyperidea). -Journal of Experimental Marine Biology and Ecology 33: 187-211.

. 1980. Hyperiid amphipods as crustacean parasitoids associated with gelatinous zooplankton. -Oceanography and Marine Biology 18: 11-56. McLaughlin, P. A. 1980. Comparative morphology of Recent Crustacea. W. H. Freeman and Company, San Francisco, California. Pp. 1-177. Madin, L. P. and G. R. Harbison. 1977. The associations of Amphipoda Hyperiidea with gelatinous zooplankton - I. Associations with Salpidae. Deep Sea Research 24: 449-463.

Minkiewicz, R. 1909. Memoire sur la biologie du tonnelier de mer (Phronima sedentaria Forsk.). -Bulletin de l'Institut Oceanographique 152: $1-21$.

Pirlot, J.M. 1932. Introduction a l'etude des Amphipodes Hyperides.Annales de l'Institut Oceanographique12: 1-36.

Richter, G. 1978. Beobachtung zu Entwicklung und Verhalten von Phronima sedentaria (Forskal)(Amphipoda). -Senckenbergiana Maritima10: 229-242.

Schaadt, M.S. 1982. The origin of the barrel and the food of the mesopelagic, hyperiid amphipod Phronima sedentaria in the eastern north Pacific Ocean. -Masters thesis, California State University, Long Beach. Pp. 1- 55. 
Sheader, M., and F. Evans. 1975. Feeding and gut structure of Parathemisto gaudichaudi (Guerin) (Amphipoda, Hyperiidea). -Journal of the Marine Biological Association of the United Kingdom 55: 641-656.

Shih, C.T. 1969. The Systematics and Biology of the Family Phronimidae (Crustacea: Amphipoda). -Dana Report 14 (74): 1-100.

Woltereck, R. 1927. Die Lanceoliden und Mimonectiden der Deutschen Sudpolar-Expedition 1901-1903. -Deutschen Sudpolar-Expedition, 19 (Zoologie 11) : 57-84. 


\section{Figures}

Figure 1. Phronima sedentaria, female. External anatomy.

Figure 2. Phronima, generalized female. aa, anterior aorta; $b$, cerebral ganglion; de, dorsal eye; hg, hindgut; hs, head sinus; md, midgut diverticula; mdc, midgut digestive chamber; mt, midgut tube; o, ovary; pa, posterior aorta; ve, ventral eye; vnc, ventral nerve cord.

Figure 3. Digestive system of Phronima. A., lateral view of digestive system; B, midgut digestive chamber dissected to show foregut; $\mathrm{C}$, cuticular plate with different toothed structures; $D$ transverse section of midgut diverticulum; $\mathrm{E}$, transverse section of a midgut tube; $\mathrm{F}$, lateral view of midgut digestive chamber showing extension of foregut sheets (after Claus, 1879). bc, blister cell; bn, binucleate cell; cp, cuticular plate; e, esophagus; fs, foregut sheet; hg, hindgut; 1, lumen; m, mouth; md, midgut diverticulum; mdc, midgut digestive chamber; mi, microvilli; mt, midgut tube; mu, muscle that attaches to cuticular plate; $r$, ridges; $s p$, sphincter; $t$, teeth.

Figure 4. Female reproductive system of Phronima. A., lateral view of early stage of development; B., ventral view of early stage of development; C., lateral view of mature stage of development; D., ventral view of mature stage of development; E., dorsal view of mature stage of development. de, dorsal eye; gp, gonopore; hg, hindgut; m, mouth; mc, mouthcone; mdc, midgut chamber; mt, midgut tube; od, oviduct; ov, ovary; p5, pereionite 5; sp, sphincter; ve, ventral eye. 
Figure 5. Nervous system of Phronima. A., lateral view of the nervous system; B., supraesophageal ganglionic mass; C., subesophageal ganglionic mass; D., dorsal view of nervous system; E., lateral view of the cerebral ganglionic mass; F., transverse section through the cerebral ganglionic mass. cec, circumesophageal connectives; cgm, cerebral ganglionic mass; dent, dorsal eye nerve tracts; e, esophagus; fn, fused nucleus; $n A^{\prime}$, nerves to antennules; nA", nerves to antennae; nM, nerves to mouthparts; ol, optic lobe; $\mathrm{p}$, pereionite; pl, pleonite; sbg, subesophageal ganglion; spg, supraesophageal ganglion; ve, ventral eye; vent, ventral eye nerve tracts; vnc, ventral nerve cord; vncc, ventral nerve cord connectives.

Figure 6. Circulatory system of Phronima. A., lateral view of circulatory system; B., transverse section in pereionite 1; C., transverse section of the heart; D., canal system (after Claus, 1879). a, aorta; aa, anterior aorta; e, esophagus; DC, dorsal canal; dss, digestive system sinus; h, heart; hs, head sinus; Ic, interseptal sinus; la, lateral artery; mdc, midgut digestive chamber; $\mathrm{mt}$, midgut tube; mu, muscle that attaches to cuticular plate; ol, optic lobe; pa, posterior aorta; SC, segmental canal; v, one-way valve; ve, ventral eye; vc, ventral canal; vo, venous ostium. 
Figure 1. Phronima sedentaria, female. External anatomy. 


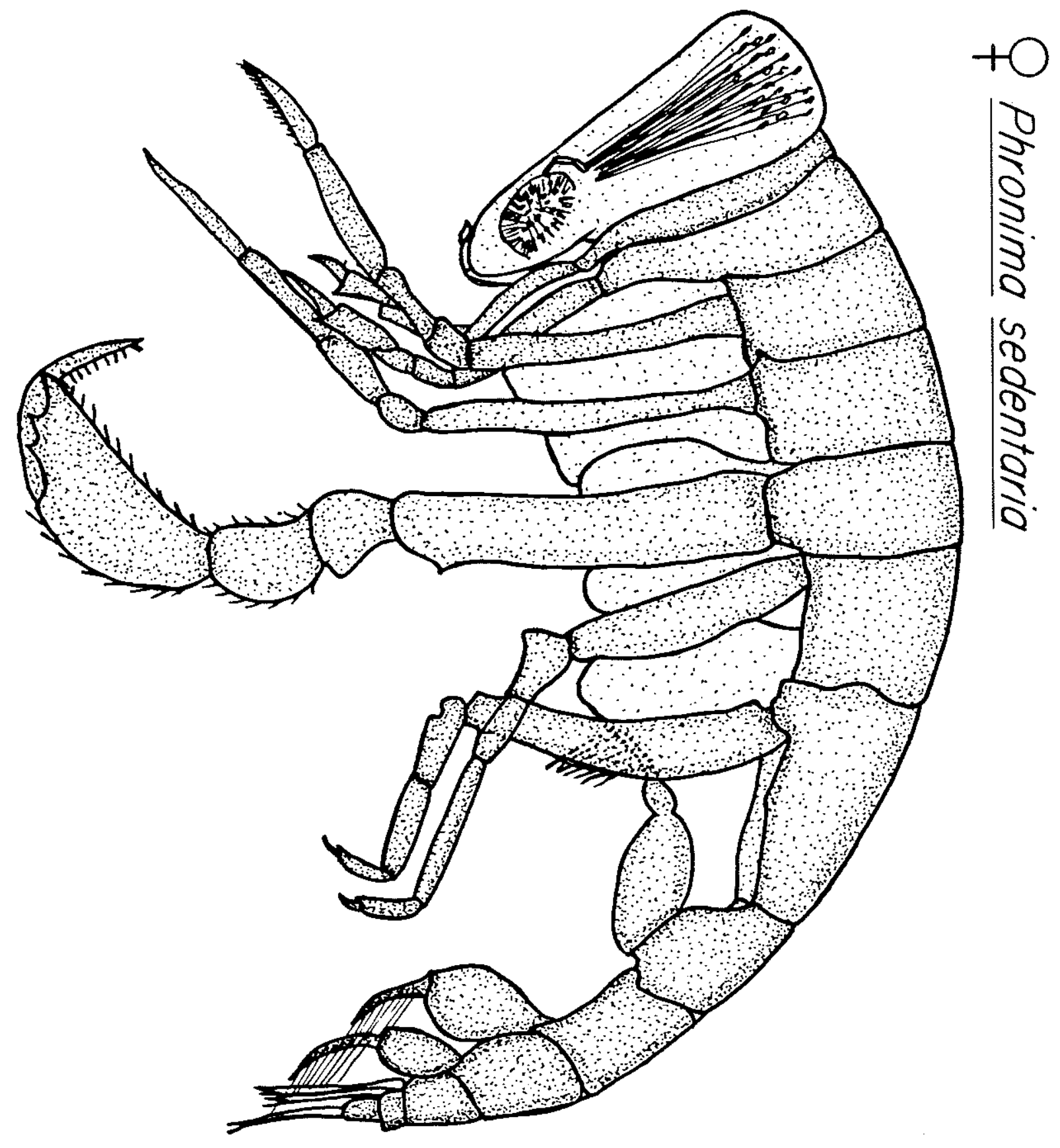


Figure 2. Phronima, generalized female. aa, anterior aorta; $b$, cerebral ganglion; de, dorsal eye; hg, hindgut; hs, head sinus; md, midgut diverticula; mdc, midgut digestive chamber; mt, midgut tube; o, ovary; pa, posterior aorta; ve, ventral eye; vnc, ventral nerve cord. 


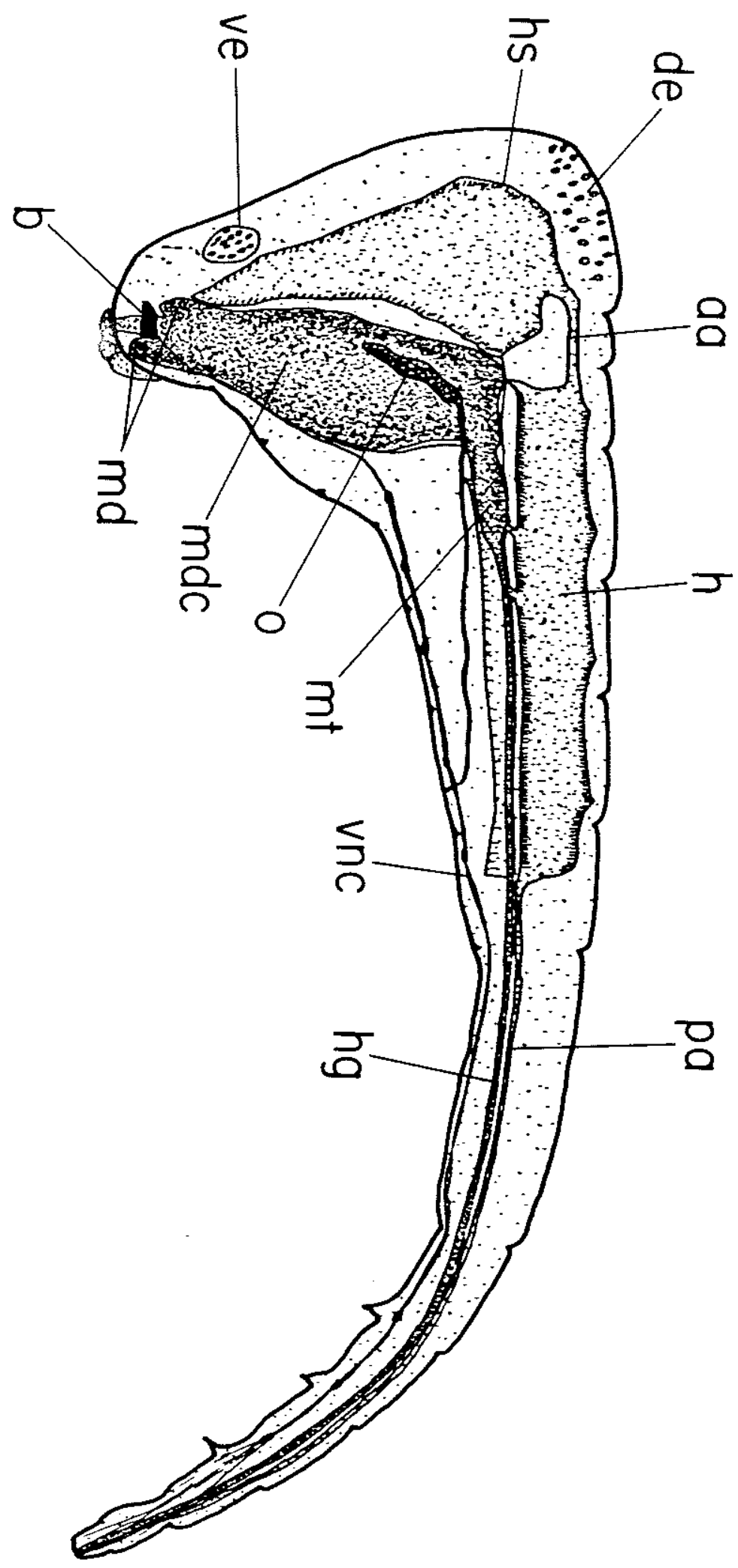


Figure 3. Digestive system of Phronima. A., lateral view of digestive system; B, midgut digestive chamber dissected to show foregut; C, cuticular plate with different toothed structures; D transverse section of midgut diverticulum; $\mathrm{E}$, transverse section of a midgut tube; F, lateral view of midgut digestive chamber showing extension of foregut sheets (after Claus, 1879). bc, blister cell; bn, binucleate cell; cp, cuticular plate; e, esophagus; fs, foregut sheet; hg, hindgut; 1, lumen; $\mathrm{m}$, mouth; $\mathrm{md}$, midgut diverticulum; mdc, midgut digestive chamber; $\mathrm{mi}$, microvilli; $\mathrm{mt}$, midgut tube; mu, muscle that attaches to cuticular plate; r, ridges; $s p$, sphincter; $t$, teeth. 

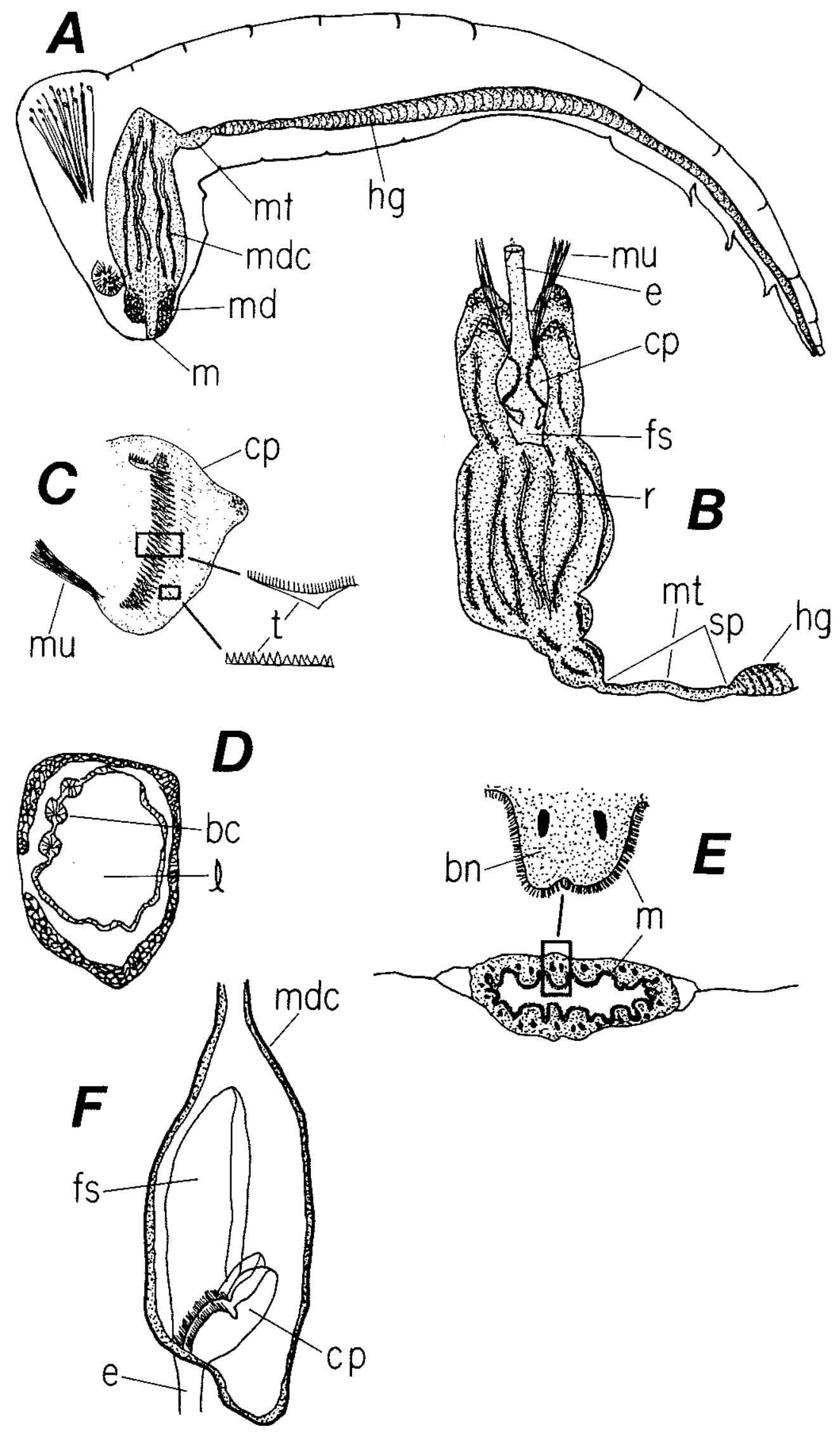
Figure 4. Female reproductive system of Phronima. A., lateral view of early stage of development; B., ventral view of early stage of development; C., lateral view of mature stage of development; D., ventral view of mature stage of development; E., dorsal view of mature stage of development. de, dorsal eye; gp, gonopore; hg, hindgut; $\mathrm{m}$, mouth; mc, mouthcone; mdc, midgut chamber; mt, midgut tube; od, oviduct; ov, ovary; p5, pereionite 5; sp, sphincter; ve, ventral eye. 


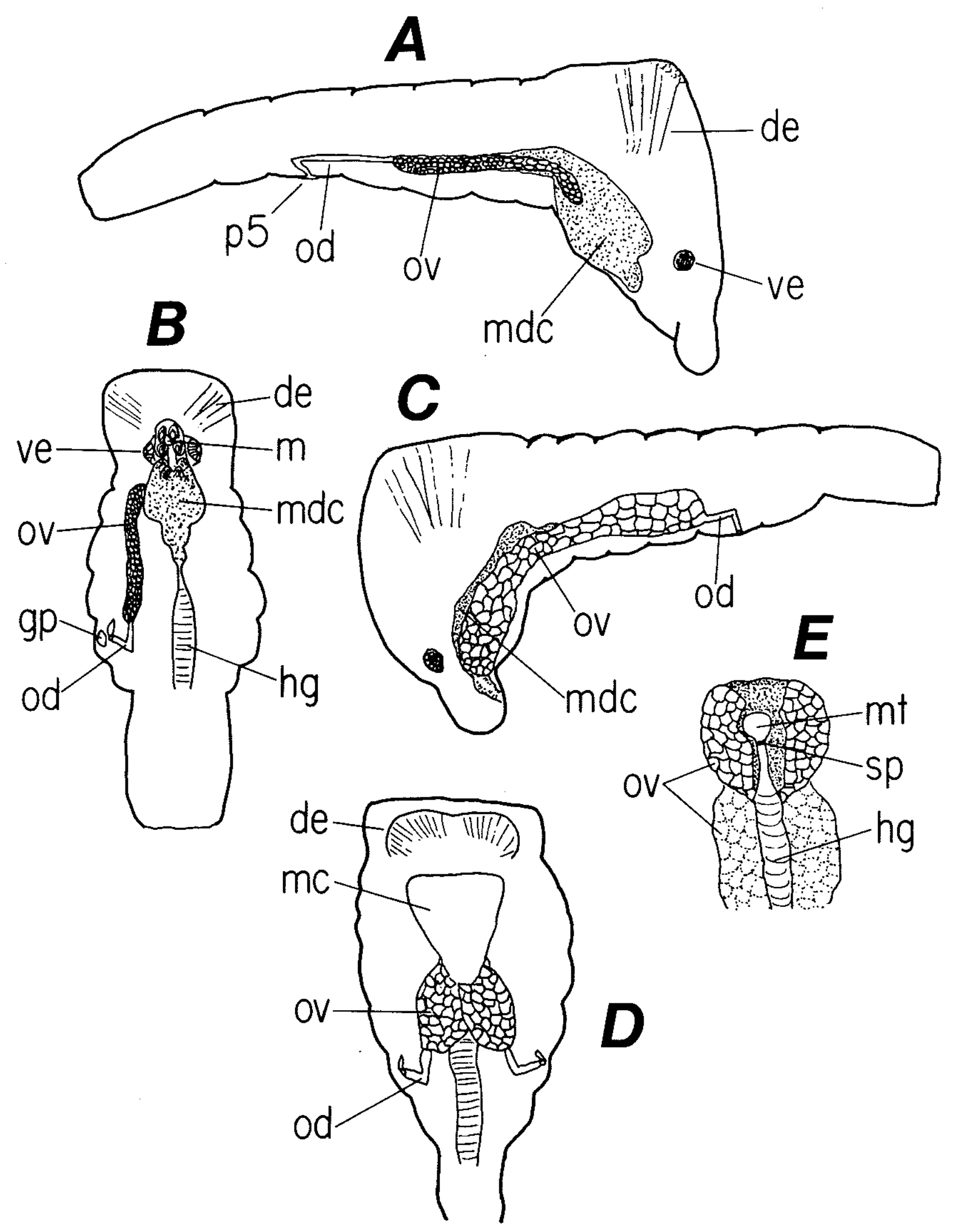


Figure 5. Nervous system of Phronima. A., lateral view of the nervous system; B., supraesophageal ganglionic mass; C., subesophageal ganglionic mass; D., dorsal view of nervous system; E., lateral view of the cerebral ganglionic mass; $F$., transverse section through the cerebral ganglionic mass. cec, circumesophageal connectives; cgm, cerebral ganglionic mass; dent, dorsal eye nerve tracts; e, esophagus; fn, fused nucleus; nA', nerves to antennules; nA", nerves to antennae; nM, nerves to mouthparts; ol, optic lobe; $p$, pereionite; pl, pleonite; sbg, subesophageal ganglion; spg, supraesophageal ganglion; ve, ventral eye; vent, ventral eye nerve tracts; vnc, ventral nerve cord; vncc, ventral nerve cord connectives. 

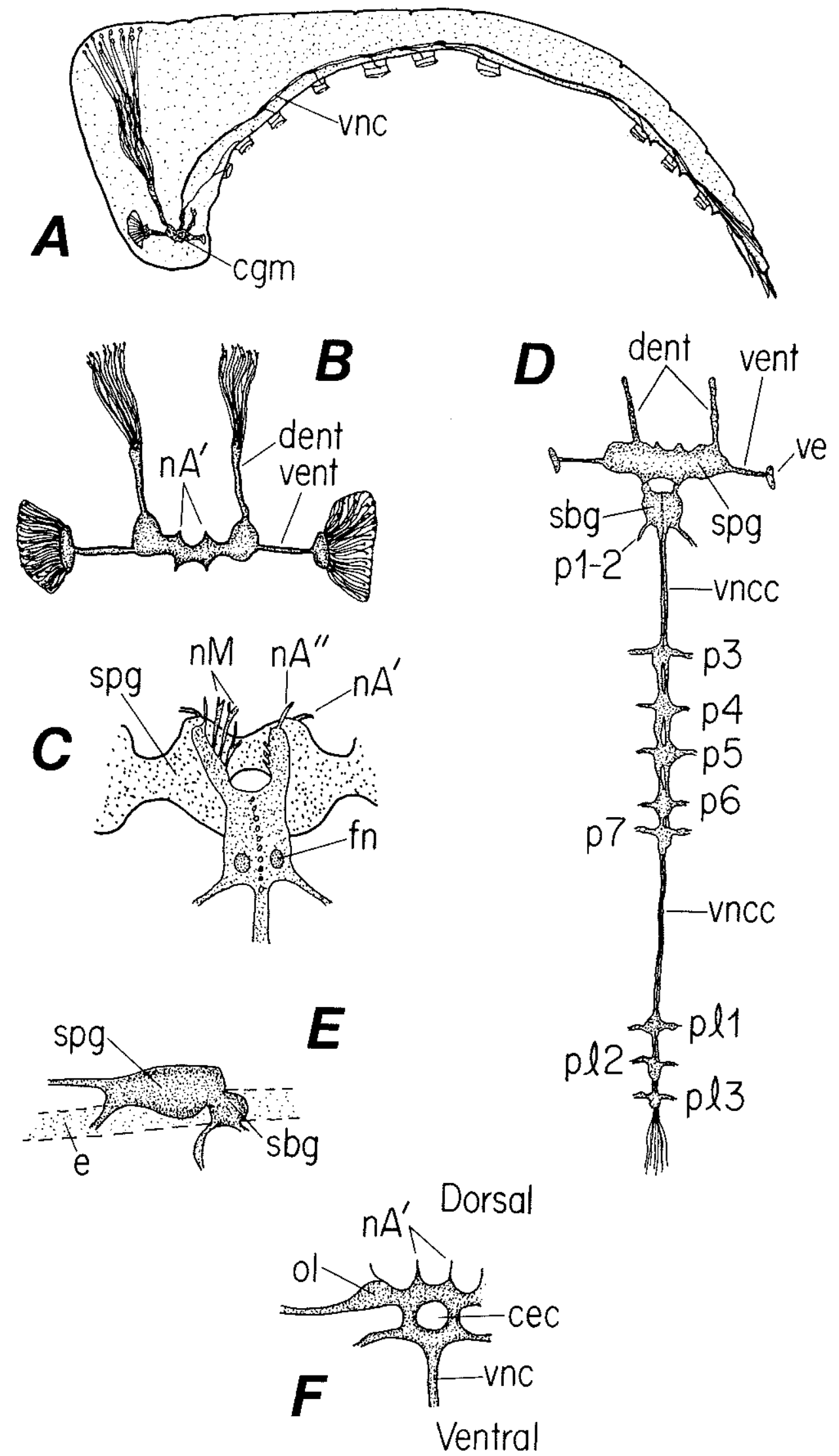
Figure 6. Circulatory system of Phronima. A., lateral view of circulatory system; B., transverse section in pereionite 1; C., transverse section of the heart; D., canal system (after Claus, 1879). a, aorta; aa, anterior aorta; e, esophagus; DC, dorsal canal; dss, digestive system sinus; h, heart; hs, head sinus; Ic, interseptal sinus; la, lateral artery; mdc, midgut digestive chamber; $\mathrm{mt}$, midgut tube; mu, muscle that attaches to cuticular plate; ol, optic lobe; pa, posterior aorta; SC, segmental canal; v, one-way valve; ve, ventral eye; vc, ventral canal; vo, venous ostium. 


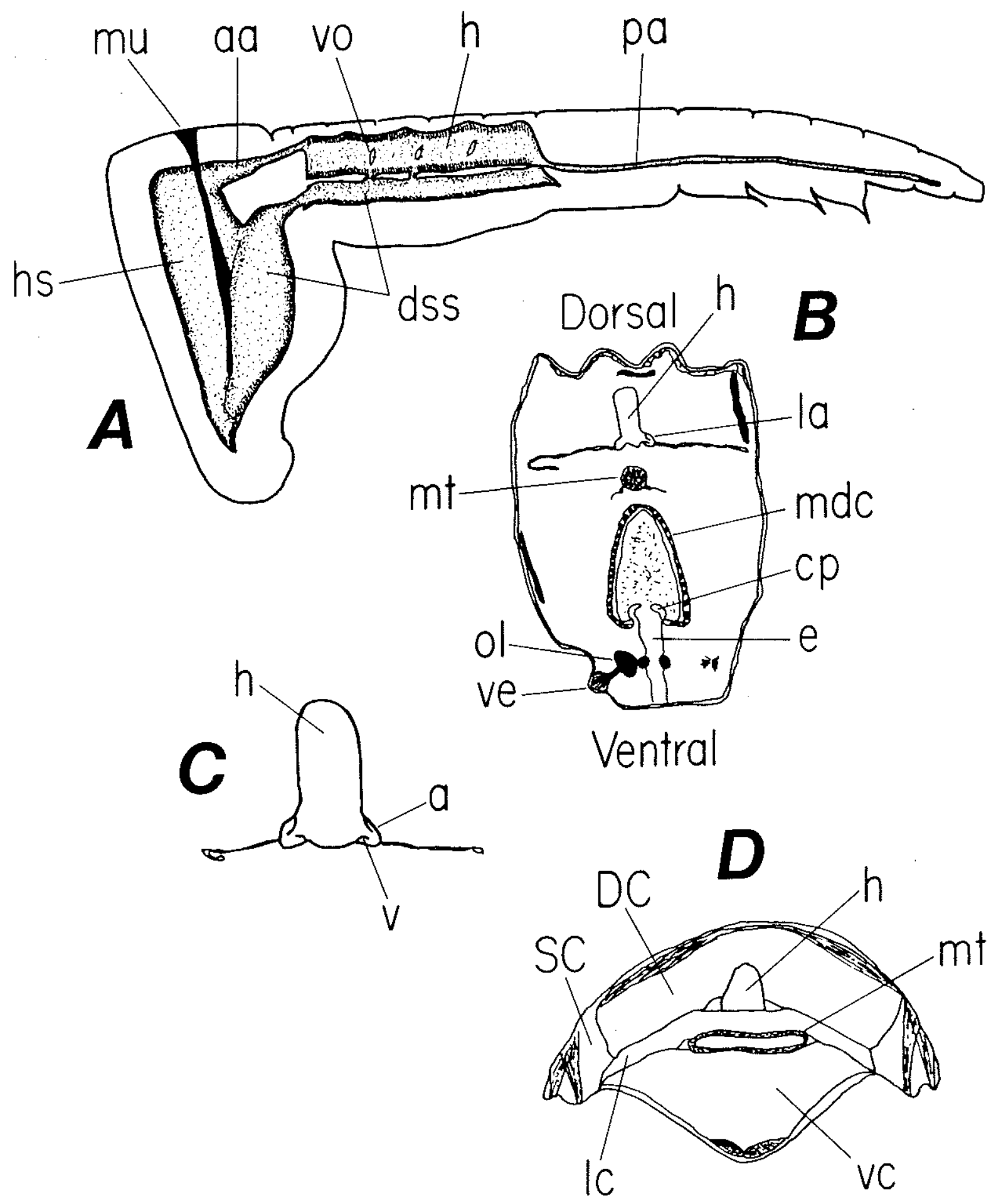


Table I. Gut passage times of salps consumed by Phronima sedentaria $\cdot \mathrm{N}=$ number of individuals.

Phronima $(\mathrm{N}=8)$

Gut passage time

1. Night

2. Night

$2 \mathrm{hrs} 36 \mathrm{~min}$

3. Night

$7 \mathrm{hrs} 45 \mathrm{~min}$

4. Night

$3 \mathrm{hrs} 58 \mathrm{~min}$

5. Night (juveniles)

$2 \mathrm{hrs} 25 \mathrm{~min}$

6. Night

7. Day

$4 \mathrm{hrs} 06 \mathrm{~min}$

8. Day

$7 \mathrm{hrs} 49 \mathrm{~min}$

$14 \mathrm{hrs} 07 \mathrm{~min}$

$14 \mathrm{hrs} 07 \mathrm{~min}$ 
184 


\section{SUMMARY}

Hyperiid amphipods are believed to be a polyphyletic group, descending from different lineages of benthic gammaridean amphipods (Pirlot, 1932). They have invaded the plankton by developing a symbiotic benthic-like existence on gelatinous zooplankton. This behavior has been described as 'parasitoid' (Laval, 1982); as almost all hyperiid species are symbionts for at least part of their lives with gelatinous zooplankton such as siphonophores, ctenophores, medusae, and salps. It is, in fact this symbiotic relationship that makes them ecologically distinct from other pelagic crustaceans and gammaridean amphipods, and that may take on added meaning when considering the ecology and evolution of the Hyperiidea. Host location is crucial to their life cycle as they utilize gelatinous zooplankton as platforms for feeding, a food source, or as a nursery for developing young.

The goal of this study was to address the overall question of how hyperiids are able to locate and thus maintain their specific symbioses with salps. Host location may be based on chemical, visual or mechanical cues. This thesis explores the potential cues presented by salps, the receptors present on hyperiids which allow them to respond to these cues, and the behavioral response of hyperiids towards the cues presented by the salps. Observations on the anatomy and behavior of one species, Phronima sedentaria , is also described. This species shows both changes in internal anatomy and behavior that may reflect its ecological place in the plankton.

To summarize the findings of this thesis:

1. Salps leave a trail that may be characterized as a pulsed jet combining a continuous column of water with periodic vortex rings. It may persist for up 
to 60 seconds in the water column. This cloud of salp water has been shown to contain ammonium and several different amino acids, but estimates of their concentration in the salp wake is low -nanomolar range. This is similar to background levels but the distinctiveness of the mixture may be more important than the concentration as in insect pheromones. Therefore, this trail may be distinct both chemically and mechanically from the background, and be a very important cue for host location by hyperiids.

2. The three genera of hyperiids all possess numerous sensory hairs (sensilla) on the surface of the exoskeleton and antennules that vary in number, pattern and morphology according to species. The morphological type and placement of four types of sensilla on the dorsal surface of the exoskeleton of the three genera were mapped. Vibilia had the greatest number of hairs and possessed all four types of sensory hairs; with one that was unique to Vibilia. Phronima had the fewest number of sensory hairs and only two morphological types. Lycaea had an intermediate number of hairs but only one sensory hair type. These sensory hairs most likely function as chemo- and/or mechanoreceptors. Aesthetascs, a distinct type of sensory hair found only on the antennules of crustaceans were also found on all three hyperiid genera. The distribution of aesthetascs on the antennules of both sexes of all three genera is shown. There was a striking difference in the number of aesthetascs present on the antennules of males and females in both Phronima and Lycaea; with greater numbers on the males. Vibilia did not show as great a difference, although there was a trend of a few more aesthetascs on the antennules of the male when compared with the female. 3. The ultrastructure of the aesthetascs on Vibilia was determined and showed that it satisfied the criteria established for other crustacean aesthetascs. They are located exclusively on the antennules, the cuticle is thin 
and poreless, they are innervated by greater than 20 sensory cells, there is the absense of a dendritic sheath, two ciliary segments arise from each cell, and the outer dendritic segments branch.

4. Behavioral experiments in a "Y" apparatus show that Vibilia and Lycaea respond significantly to the chemical stimuli of hosts on which they are most commonly found. The results of the tests on Vibilia show a significant preference towards the stimulus water of the salps Salpa and Pegea with no preference towards Cyclosalpa. These data support the observations made in the field where Vibilia is often found on Pegea or Salpa but never Cyclosalpa. The results of tests on Lycaea also show a strong preference for the stimulus water of three different salp species on which it is often found. It differed from Vibilia in that it showed an immediate response to the early incubations of stimulus water. Vibilia often required an incubation time of up to four hours while Lycaea responded at one hour. There are two possible reasons for this. The first is handling as Lycaea was removed immediately and kept separate from its host after it was collected, while Vibilia remained on the salps until just prior to testing. The survival rate of Vibilia was much higher if this done. The second is the difference in their ecology. Vibilia is an obligate symbiont that rarely leaves a salp and may thus be used to higher concentrations of stimulus as it is constantly surrounded by the salp. Lycaea on the other hand, leaves a salp more freely and as a result is normally exposed to differing concentrations of stimulus and may thus be more sensitive to chemical stimuli at a lower concentration. Lycaea did not differentiate between salp species implying that although it may be able to chemically sense a salp, it may not know which species it is solely on chemical cues. 
5. Phronima has an internal anatomy that is roughly similar to other described amphipods but differs from some hyperiids and gammarids in certain respects. There is a simplification of the digestive system. The foregut is reduced and completely enclosed by a midgut chamber, and the midgut caeca are fewer in number and reduced in size. The brain is circumesophageal and has four pairs of major nerves, which lead to the dorsal and ventral compound eyes, ventral nerve cord, and antennules. There are enlarged wing-like optic lobes which are composed of the nerve tracts or optic nerves to the eyes. These nerve tracts are easily separated into two distinct bundles, one originating from the dorsal eye and the other from the ventral eye. The circulatory and reproductive systems are similar to those of other hyperiid and gammarid amphipods.

Feeding behavior varies with the consistency of the gelatinous organisms being ingested. They may pick and pull off small pieces of tissue with their pereopods, bite off small pieces with their mandibles, or if the material is fairly fluid they may suck the fluid into the foregut using the muscles of the esophagus and gut. Demarsupiation, aggressive behavior, and barrel-making are all described.

The salp trails are indicative of the potential cues that many different animals in the plankton may be producing and leaving behind in the water column. This phenomena is potentially very important as these trails constitute signposts in an environment that has very few directional cues (especially when light is not present). Although these trails are not obvious to us and may be difficult for us to conceptualize hyperiids most likely have the ability to use them to their advantage when seeking potential hosts.

Consider this scenario: at a distance greater than their range of visual detection a hyperiid may use its chemical senses to detect the presence of salp 
trails, and in cooperation with their mechanical senses it is able to follow that trail in the direction of the salp. Once it is within visual range, the visual sense works with the other senses to determine whether or not it is the right species of salp.

The chemical and mechanical receptors on hyperiids are sensory hairs that are distributed in bilaterally symmetrical patterns on the surface of the body. The three genera of hyperiids studied here appear to have fewer and simpler sensory hairs than their gammaridean ancestors (Mauchline and Ballentyne, 1977; Cuadras, 1982). There was very little variation in the pattern between individuals of the same species. Vibilia has both the greatest diversity and density of sensilla of the three genera, and is also the closest in morphology and habitat to gammarids. It has small eyes and lives inside a salp which is physically similar to the tubes of gammarids. On the other hand, Lycaea has large eyes and also lives inside salps for a significant part of its life; but, has only one hair type distributed on every segment of the dorsal surface of the exoskeleton. Phronima has large eyes and is a free swimming predator; but, the females may live in and modify salps into barrels for deposition of their young. It is difficult to decide whether the trend towards reduction in number and morphological simplification of sensory hairs is a result of a higher evolutionary stage or a reflection of their unique ecological niche in the plankton. The morphological simplification may be due to the non-abrasive nature of their new habitat. The trend towards reduction in numbers of hairs is more difficult to assess. I might softly suggest that since these three genera share a similar habitat and host that the distribution and density of sensory hairs may be of greater taxonomic importance. Indeed, Fleminger (1973) found that the pattern and number of sensory pores was species specific. It is the age old problem of environment versus lineage and 
the two often become so intertwined that the significance of one over the other becomes obscured. In the case of hyperiids, this information should help us to determine if all hyperiids evolved from one gammaridean ancestor or whether they arose from multiple gammaridean groups.

It is also quite interesting that in the case of the specialized chemosensory hairs on the antennules -aesthetascs- there is a definite trend towards an increase in number on the male antennules of Phronima and Lycaea. This sexual dimorphism in the antennules suggests a sex (pheromone) detection function. The antennules of moths show this same trend and, a deep ocean fish (Cyclothone) shows great nose development in mature males only. The apparent ubiquitous presence of aesthetascs in crustaceans indicates that they represent a morphological type of sensillum that has been selectively retained through evolution.

\section{$\underline{\text { Literature Cited }}$}

Caudras, J. 1982. Microtrichs of amphipod Crustacea. Morphology and distribution. Mar. Beh. and Physiol. 8: 333-343.

Fleminger, A. 1973. Pattern, number, variability, and taxonomic significance of integumental organs (sensilla and glandular pores) in the genus Eucalanus (Copepoda, Calanoida). Fishery Bulletin 71: 9651010 .

Laval, P. 1980. Hyperiid amphipods as crustacean parasitoids associated with gelatinous zooplankton. Oceanogr. Mar. Biol. Ann. Rev. 18: 1156.

Mauchline, J. and A. R. S. Ballantyne. 1975. The integumental organs of amphipods. J. mar. biol. Ass. U. K. 55: 345-355.

Pirlot, J. M. 1932. Introduction a l'etude des Amphipodes Hyperides. Ann. de l'Inst. Ocean. 12: 1-36. 


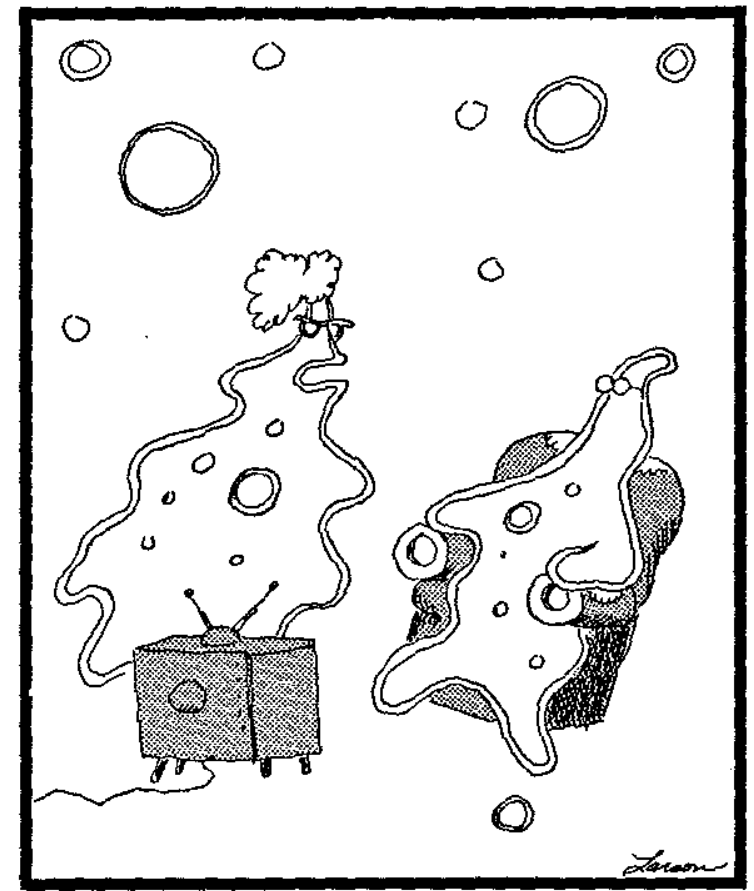

"Stimulus, response! Stimulus, response! Don't you ever think?" 
